$$
\begin{gathered}
\text { MEOFNEO } \\
\text { Wh } 30 \text { yes } \\
\text { OSTI }
\end{gathered}
$$

\title{
Transuranic and Low-Level Boxed Waste Form Nondestructive Assay Technology Overview and Assessment
}

\author{
G. Becker \\ M. Mcllwain \\ M. Connolly
}




\section{DISCLAIMER}

This report was prepared as an account of work sponsored by an agency of the United States Government. Neither the United States Government nor any agency thereof, nor any of their employees, make any warranty, express or implied, or assumes any legal liability or responsibility for the accuracy, completeness, or usefulness of any information, apparatus, product, or process disclosed, or represents that its use would not infringe privately owned rights. Reference herein to any specific commercial product, process, or service by trade name, trademark, manufacturer, or otherwise does not necessarily constitute or imply its endorsement, recommendation, or favoring by the United States Government or any agency thereof. The views and opinions of authors expressed herein do not necessarily state or reflect those of the United States Government or any agency thereof. 


\section{DISCLAIMER}

Portions of this document may be illegible in electronic image products. Images are produced from the best available original document. 


\title{
Transuranic and Low-Level Boxed Waste Form Nondestructive Assay Technology Overview and Assessment
}

\author{
G. Becker \\ M. Mcilwain \\ M. Connolly
}

Published February 1999

Idaho National Engineering and Environmental Laboratory

Department

Lockheed Martin Idaho Technologies Company

Idaho Falls, Idaho 83415

Prepared for the

U.S. Department of Energy

Under DOE Idaho Operations Office

Contract DE-AC07-94ID13223 



\section{SUMMARY}

The Mixed Waste Focus Area (MWFA) identified the need to perform an assessment of the functionality and performance of existing nondestructive assay (NDA) techniques relative to the low-level and transuranic waste inventory packaged in large volume box type containers. The primary objectives of this assessment were to: (1) determine the capability of existing boxed waste form NDA technology to comply with applicable waste radiological characterization requirements, (2) determine deficiencies associated with existing boxed waste assay technology implementation strategies, and (3) recommend a path forward for future technology development activities, if required.

The technology capability assessment consisted of an investigation of boxed waste inventory attributes in conjunction with an evaluation of existing, fabricated or in the design phase, boxed waste NDA technologies. Inventory attributes of interest are those that affect the response of nondestructive assay techniques, including matrix density, matrix elemental composition, radioactive material radionuclide/isotopic distributions, and spatial variations of these parameters. Waste form configuration information was extracted from available DOE site specific data bases to establish the prevalence of the various waste attributes. This information was used to evaluate the applicability and utility of known nondestructive boxed waste assay techniques per inventory waste form attribute. As a result, four primary boxed waste form nondestructive assay technique deficiencies were noted. In terms of per box waste form configuration parameters these include: (1) high matrix moderator/absorber concentration and matrix density, (2) heterogeneous matrix composition and spatial distribution, (3) variable radionuclidic/isotopic composition and radioactive material mass spatial distributions, and (4) variations in radioactive material physical form.

Based on this assessment, it is recommended that a box NDA development and demonstration project that expands the existing boxed waste NDA capability to accommodate the indicated deficiency set be implemented. To ensure that technology will be commercially available in a timely fashion, it is recommended this development and demonstration project be directed to the private sector. It is further recommended that the box NDA technology be of an innovative design incorporating sufficient NDA modalities, e.g., passive neutron, gamma, etc., to address the majority of the boxed waste inventory. The overall design should be modular such that subsets of the overall NDA system can be combined in optimal configurations tailored to differing waste types. Such an approach would accomplish two objectives: (1) enable radiological characterization of complex waste configurations using two or more measurement modalities, i.e., a fully integrated system, and (2) customized individual measurement modalities for less complex waste configurations. 
The development and demonstration project structure should be comprised of several elements including: (1) a detailed description of the technology

deficiencies for review by interested technology holders, (2) a technical review of contributed proposals regarding potential to address the deficiency set over the boxed waste inventory, (3) specification of a technology development strategy, and (4) objective demonstration of the completed system to accommodate waste form configurations incorporating the various deficiency elements. 


\section{ACKNOWLEDGMENTS}

Descriptions of existing boxed waste nondestructive assay technologies necessitated input and review by technology owners. Special acknowledgment is due to personnel at Canberra Industries, Inc., BNFL Instruments, Inc., and Los Alamos National Laboratory for their valuable input. The authors also want to thank the DOE site contractor personnel at Hanford, Idaho National Engineering and Environmental Laboratory, Oak Ridge, Rocky Flats Environmental Technology Site, Los Alamos National Laboratory, and Lawrence Livermore National Laboratory for providing boxed waste inventory data. This work was supported by the U.S. Department of Energy, Office of Science and Technology through the Mixed Waste Focus Area under Idaho Operations Office contract DE-AC07-94ID13223. 


\section{CONTENTS}

SUMMARY

ACRONYMS

1. INTRODUCTION

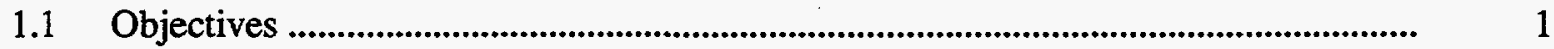

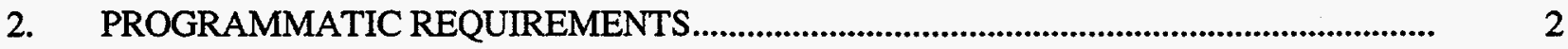

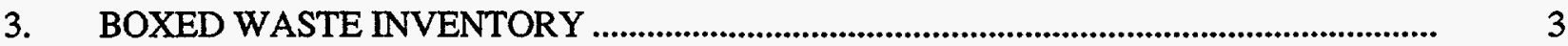

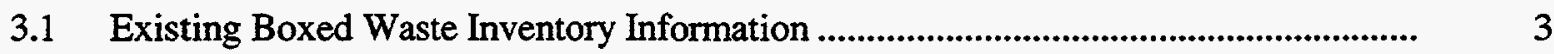

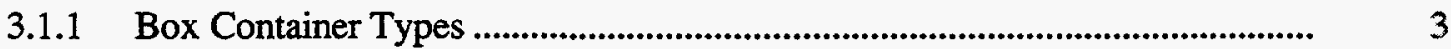

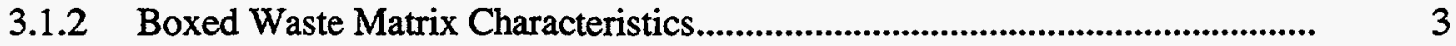

3.1.3 Boxed Waste Physical Properties ........................................................................... 4

3.1.4 Boxed Waste Radionuclide Inventory Information .......................................... 4

3.1.5 Boxed Waste Packaging Techniques .................................................................... 5

3.2 Projected Future Boxed Waste Inventory Information .......................................... 5

4. BOXED WASTE NONDESTRUCTIVE ASSAY TECHNOLOGIES ................................ 7

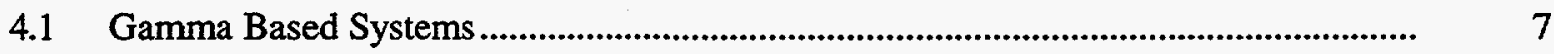

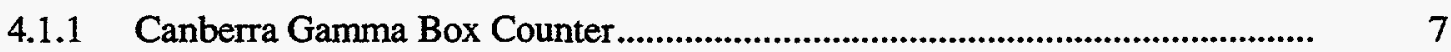

4.1.2 ORNL Y-12 Box Assay System .......................................................................... 8

4.1.3 ETTP K-25 Box Assay System............................................................................

4.1.4 ORNL WEAF B-25 Box Assay System (B-BAS) .......................................... 10

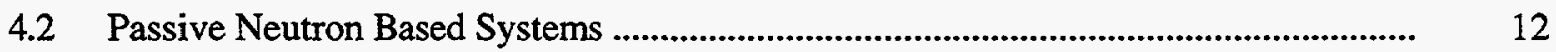

4.2.1 Super High Efficiency Neutron Counter (Super-HENC).................................. 12

4.2.2 Canberra - High Efficiency Waste Crate Assay System (HE-WCAS) ............. 14

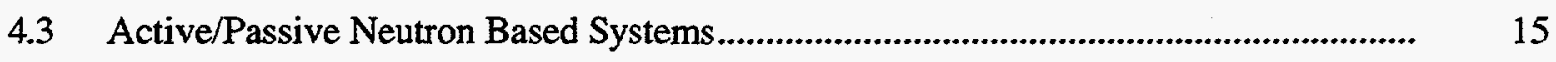

4.3.1 Boxed Waste Assay System (BWAS) ........................................................... 15

4.3.2 Variable Boxed Waste Assay System (VBWAS) ................................................ 18

4.3.3 Rocky Flats Environmental Technology Site Multi-Purpose Crate

Counter (RFETS MPCC) ........................................................................... 18

4.3.4 Waste Monitoring and Compaction (WAMAC) .............................................. 19

4.3.5 Crated Waste Assay Monitor (CWAM) ............................................................. 20

4.3.6 Rocky Flats Environmental Technology Site Passive/Active Crate Counter (PACC) .............................................................................................. 22

4.3.7 ANTECH Model 4201 Fission-Fission Neutron Correlation System............... 24 
5. BOXED WASTE ATTRIBUTES AFFECTING NDA SYSTEM PERFORMANCE ........... 26

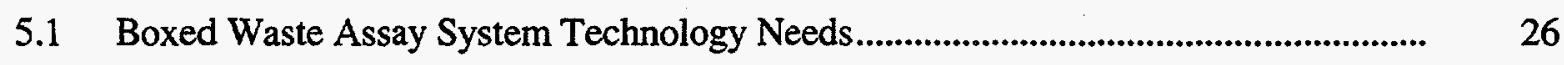

5.1.1 Homogeneous Waste Configurations.......................................................... 27

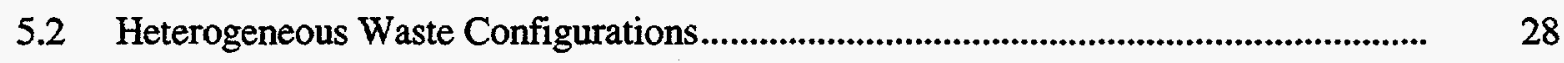

5.2.1 Nonuniform Radioactive Material Spatial Distribution (Constant Isotopic/Radionuclidic Composition) ............................................................ 28

5.2.2 Nonuniform Radioactive Material Isotopic/Radionuclidic Composition ......... 29

5.2.3 Radioactive Material Physical Form............................................................... 29

5.2.4 Nonuniform Matrix Material Density Spatial Distribution............................... 29

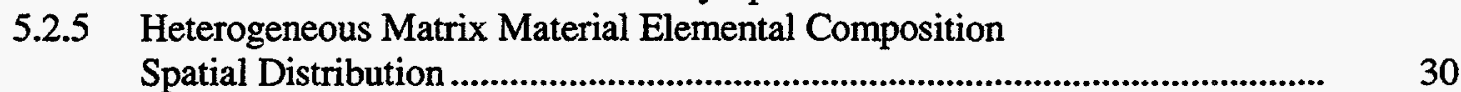

5.2.6 Combined Radioactive Material and Matrix Nonuniformities ....................... 31

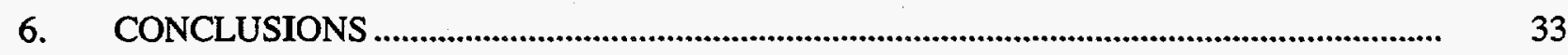

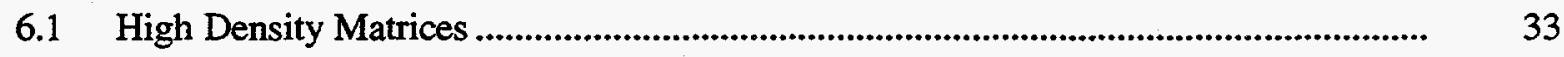

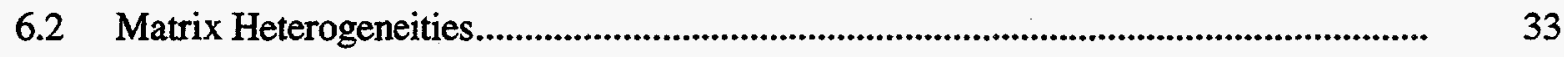

6.3 Variable Radionuclidic/Isotopic Compositions Per Box Container.............................. 33

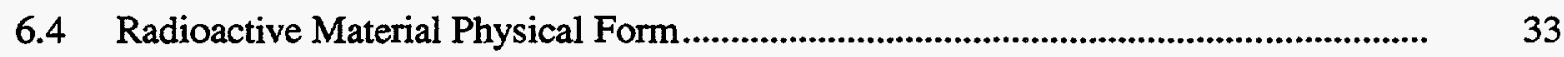

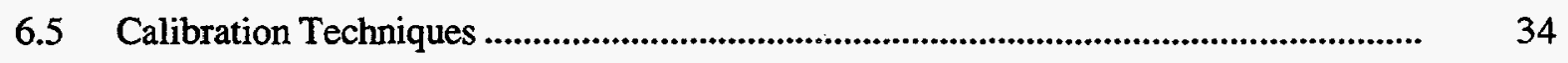

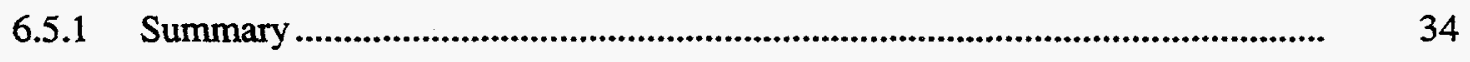

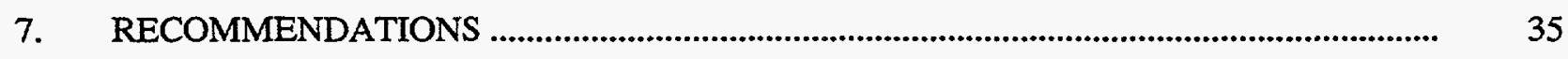

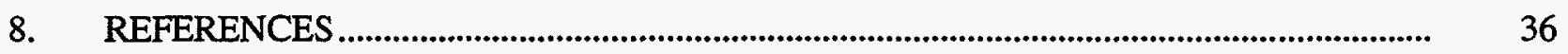

Appendix A-Waste Acceptance Criteria

Appendix B-Box Waste Distribution by Site

Appendix C-Waste Distribution by MPC

Appendix D-Matrix Properties

Appendix E-Radionuclide Inventories

Appendix F-Future Waste Generation 


\section{ACRONYMS}

\begin{tabular}{|c|c|}
\hline AAS & Add-A-Source \\
\hline $\mathrm{ACE}$ & alternating conditional expectation \\
\hline AMX & Active Matrix \\
\hline B-BAS & Box Assay System \\
\hline BWAS & Boxed Waste Assay System \\
\hline CEP & Capability Evaluation Project \\
\hline CTEN & Combined Thermal Epithermal Neutron \\
\hline CWAM & Crated Waste Assay Monitor \\
\hline $\mathrm{D} \& \mathrm{D}$ & decommissioning and deactivation \\
\hline DOE & Department of Energy \\
\hline DU & depleted uranium \\
\hline ETTP & Eastern Tennessee Technology Park \\
\hline EU & enriched uranium \\
\hline FFNCS & Fission-Fission Neutron Correlation System \\
\hline GRNN & generalized regression neural networks \\
\hline HENC & High Efficiency Neutron Counter \\
\hline HPGe & high purity germanium detector \\
\hline INEEL & Idaho National Engineering and Environmental Laboratory \\
\hline ISOCS & In Situ Object Counting Software \\
\hline JNC & Japanese Nuclear Corporation \\
\hline LBX & Layered Box Vector \\
\hline LLD & lower level of detection \\
\hline LLNL & Lawrence Livermore National Laboratory \\
\hline LLW & low-level waste \\
\hline MLLW & mixed low-level waste \\
\hline
\end{tabular}




\begin{tabular}{|c|c|}
\hline MPC & matrix parameter characteristic \\
\hline MPCC & Multi-Purpose Crate Counter \\
\hline MWFA & Mixed Waste Focus Area \\
\hline NDA & nondestructive assay \\
\hline NIST & National Institute of Science and Technology \\
\hline NUCS & Non Uniformity Correction Software \\
\hline ORNL & Oak Ridge National Laboratory \\
\hline ORS & Oak Ridge Site \\
\hline PACC & Passive/Active Crate Counter \\
\hline $\mathrm{PMCCM}$ & programmable multichannel coincidence module \\
\hline RFETS & Rocky Flats Environmental Technology Site \\
\hline RTR & real-time radiography \\
\hline RWMC & Radioactive Waste Management Complex \\
\hline SRS & Savannah River Site \\
\hline SWB & standard waste box \\
\hline TCA & time correlation analyzer \\
\hline TRU & transuranic \\
\hline VBWAS & Variable Boxed Waste Assay System \\
\hline WAMAC & Waste Monitoring and Compaction \\
\hline WEAF & Waste Examination and Assay Facility \\
\hline WIPP & Waste Isolation Pilot Plant \\
\hline WRAP & Waste Receiving and Processing \\
\hline
\end{tabular}




\section{Transuranic and Low-Level Boxed Waste Form Nondestructive Assay Technology Overview and Assessment}

\section{INTRODUCTION}

Needs have been identified by a number of Department of Energy (DOE) Site Technology Coordination Groups for cost-effective radiological characterization via nondestructive assay (NDA) techniques for large volume box sized waste containers. Radiological characterization is required for low-level and transuranic contaminated waste forms to demonstrate compliance with applicable transportation and waste repository acceptance requirements. Sites specifying boxed waste NDA need statements include: Los Alamos National Laboratory, Lawrence Livermore National Laboratory, Oak Ridge Operations, Rocky Flats Environmental Technology Site, and the West Valley Demonstration Project. Presently, the capability and performance of existing nondestructive assay technologies for application to the boxed waste form have not been demonstrated. The deployment of technologies without an initial capability and limitation evaluation as a function of waste form inventory attributes can result in ineffective technology implementation. This situation occurred in the development and deployment of NDA systems for drummed waste, where deficiencies were discovered on a piecemeal basis after implementation.

\subsection{Objectives}

The fundamental premise of the boxed waste form nondestructive assay capability assessment is to ensure the development and availability of technologies capable of complying with applicable functional and performance requirements. The assessment is a proactive measure to identify deficiencies that exist in the technology base as a function of the low-level and transuranic boxed waste inventory attributes. Objectives of the assessment include:

- Compilation and evaluation of low-level and transuranic contaminated boxed waste inventory data to support presence and prevalence of inventory waste matrix and radioactive material attributes representing potential complications to nondestructive assay technologies

- Documentation of existing boxed waste form nondestructive assay technology techniques, designs, and implementation strategies

- Assessment of the boxed waste assay system technology base limitations as a function of boxed waste inventory attributes, e.g., matrix elemental composition, matrix density, and radioactive material species distributions

- Recommendation of a technology development path forward strategy, as appropriate, to address identified deficiencies and assess performance of developed technologies. 


\section{PROGRAMMATIC REQUIREMENTS}

There are a number of requirements (i.e., 49CFR173...) governing the disposition of Department of Energy (DOE) generated waste at both federal and commercial disposal sites. Requirements for transuranic and low-level waste characterization provide specific information the waste generator must supply. In general, the waste generator is required to provide the disposal site information quantifying 95\% of the hazard associated with the entrained radioactive materials. Furthermore, the waste generator can be required to demonstrate that the information satisfies requirements and meets applicable data quality objectives. Those compliance criteria related to radiological characterization of the waste constitute the basis for nondestructive waste assay system functional and performance requirements. Descriptions of typical disposal site requirements are provided to illustrate the compliance environment nondestructive boxed waste characterization technologies must address.

Requirements for the disposition of transuranic waste types are defined in the Waste Isolation Pilot Plant (WIPP) Waste Acceptance Criteria ${ }^{1}$ and the associated Quality Assurance Program Plan. ${ }^{2}$ WIPP Waste Acceptance Criteria and requirements for contact-handled, transuranic waste are provided in Table A-1. Although the criteria contained in this table are specific to the 55-gallon drum size waste container, it is fully expected that it will apply to the box size containers. Table A-1 requires that boxed waste nondestructive assay (NDA) systems be able to quantitatively determine alpha emitting transuranic elements with a half-life greater than 20 years that comprise $95 \%$ of the hazard. It also requires that NDA systems have sufficient sensitivity to verify that the total alpha activity per gram of waste matrix exceeds $100 \mathrm{nCi} / \mathrm{g}$ of waste matrix. In addition, the NDA technique is to have a measurement range equal to or greater than a 325 fissile gram equivalent. Table A-2 contains alpha activity range specific data quality objectives for measurement bias and precision for which NDA measurement systems must demonstrate compliance.

The DOE generated boxed waste inventory includes low-level waste, in addition to transuranic wastes. The DOE Nevada Test Site low-level disposal facility Waste Acceptance Criteria ${ }^{3}$ provides requirements nominally representative for waste disposition at all DOE low-level waste disposal sites. These requirements (see Appendix A) specify the range of acceptable container sizes and that the transuranic alpha activity concentration to be less than $100 \mathrm{nCi} / \mathrm{g}$. RadWaste of Utah ${ }^{4}$ (Envirocare) provides for the acceptance criteria for waste forms. Waste container sizes accepted include B-25, B-12, standard 55-gallon drums, overpack drums, and monolithic forms having densities of $70 \mathrm{lb} / \mathrm{ft}^{3}$. Table A-3 presents the radioactive isotope maximum average concentration in the waste for disposal at Envirocare. GTS Durotech ${ }^{5}$ primarily processes low-level waste and has limits related to the transuranic and radionuclide content of the waste. GTS Durotech accepts a range of waste types as detailed in Tables A-4 through A-11. Waste material can be packed in a range of containers, however, the GTS Durotech specified box is preferred.

General requirements pertaining to nonhazardous disposal of wastes in landfills are dictated by state and local agencies. In terms of requirements pertinent to NDA system performance, most landfill sites require that the waste have a radionuclide content of less than the natural background. Depending on site, the natural background ranges from 15 to $100 \mathrm{pCi} / \mathrm{g}$ of soil. 


\section{BOXED WASTE INVENTORY}

Information regarding boxed waste form characteristics is essential to the assessment of the existing waste NDA radiological characterization capability. For this reason, data have been compiled, to the extent available, on the inventory attributes of boxed waste, e.g., matrix compositions, radioactive material constituents, and box size. It is important to note that the compiled data were supplied by a limited number of sites and are not all inclusive of the total DOE inventory. The data are, however, sufficiently complete to provide a representation of the major DOE site inventories and characteristics of boxed waste.

\subsection{Existing Boxed Waste Inventory Information}

An overview of general boxed waste distributions and characteristics is provided to define general tasks and roles of NDA systems. Boxed waste inventory distributions by site and waste category are tabulated in Appendix B. ${ }^{6-12}$ Tables B-1 and B-2 provide a tally of box containers by site and waste category in terms of the number of boxes and volume in units of cubic meters, respectively. With the exception of the Idaho National Engineering and Environmental Laboratory (INEEL) and the Savannah River Site (SRS), the majority of boxed waste is not classified as transuranic per the databases examined.

\subsubsection{Box Container Types}

Information concerning the range of box container types used at major DOE sites to package waste is provided in Table B-3. It is evident from Table B-3 that a diverse range of box sizes and volumes are employed. Box container volumes vary from as small as $0.06 \mathrm{~m}^{3}$ to as large as $42.5 \mathrm{~m}^{3}$. Tables B-4 through B-9 provide information related to box size prevalence by site. The Rocky Flats Environmental Technology Site (RFETS) primarily uses seven different boxes having four distinct volumes $(1.6,1.0$, 2.7 , and $3.4 \mathrm{~m}^{3}$ ). Lawrence Livermore National Laboratory (LLNL) uses a range of boxes with volumes ranging from 4.5 to $7.5 \mathrm{~m}^{3}$. Most of LLNL's box waste is contained in $4.5 \mathrm{~m}^{3}$ or 54 in. $\times 52$ in. $\times 87$ in. sized boxes. The Oak Ridge Site (ORS) uses 14 different boxes with a major portion of its waste packaged in two container types: B-25 $\left(1.7 \mathrm{~m}^{3}\right)$ and M96 $\left(2.7 \mathrm{~m}^{3}\right)$. Hanford uses 19 different boxes types ranging in volume from $0.8 \mathrm{~m}^{3}$ to $14.1 \mathrm{~m}^{3}$. Grouping these boxes into the categories, small $\left(<2 \mathrm{~m}^{3}\right)$, medium $\left(2<<7 \mathrm{~m}^{3}\right)$, large $\left(>7 \mathrm{~m}^{3}\right)$, and casks, results in most of the inventory residing in medium and large boxes. The SRS uses three boxes for non-TRU waste: B-6, B-12, and B-25. TRU waste is stored in polyethylene, black, and miscellaneous boxes. Of the 36 box sizes used across the complex, there are five types of boxes that are predominantly used (see Table B-3).

\subsubsection{Boxed Waste Matrix Characteristics}

The waste matrix characteristics of the boxed waste inventory are addressed in terms of matrix parameter characteristics (MPCs). A brief description of MPC codes used to describe the principal constituents comprising a particular waste form or waste stream is provided in Appendix C. The MPC classification scheme provides information related to the major material types comprising the waste. MPC is used to provide information related to the physical properties of waste known to represent various fractions of the DOE inventory. This information is in turn used to consider the existing NDA characterization capability.

The waste form distribution for INEEL's box inventory in provided in Table C-1. A major fraction of the INEEL inventory is classified into four MPCs: S5100 (inorganic debris), S5110 (metal debris), S5300 (organic debris), and S5410 (heterogeneous debris). Approximately $75 \%$ of LLNL box waste (Table C-2) is either S5110 (metal debris) or S5440 (predominantly organic debris). The ORS waste (Table C-3) is classified into numerous MPCs. A significant portion of ORS waste inventory is classified 
as $\$ 5110$ (metal debris), S5120 (inorganic debris), S5390 (organic debris), and S5490 (heterogeneous debris). Over $80 \%$ of Hanford's boxed waste (Table C-4) is categorized as S5110 (metal debris), S5120 (inorganic debris), S5420 (predominantly inorganic debris), and S5440 (predominantly organic debris). The RFETS inventory is similar to that of INEEL, consisting of S5110 (metals debris), S5300 (organic debris), S5420 (predominantly inorganic debris), S5440 (predominantly organic debris), and U9999 (unknown). Finally, the majority of the SRS box waste (Table C-5) is classified as S4100 (soils), S4200 (soils and debris), and S5410 (predominantly inorganic debris).

This survey of box waste MPC classifications reveals that debris waste represents the majority of waste stored in boxes. The debris waste falls primarily within two waste categories: S5100 and S5400. Category S5100 is defined as waste estimated to be $80 \%$ by volume, or more, inorganic debris materials, e.g., scrap metal, concrete, brick, and glass. Category S5400, heterogeneous debris includes waste that is at least $50 \%$ by volume debris materials that do not meet the criteria for assignment as either Inorganic Debris (S5100) or Organic Debris (S5300). An example of this category is waste that is at least 50\% by volume debris materials, with the balance being soil or homogeneous solids.

\subsubsection{Boxed Waste Physical Properties}

Information on basic physical properties of the boxed waste inventory, e.g., density and material type are provided in Table D-1. Table D-2 is provided to give estimated densities for each of the MPCs detailed in Appendix C. Volume averaged matrix density information in terms of MPC on a site basis is provided in Tables D-3 through D-9. The average, minimum, and maximum matrix density for each MPC is presented. The matrix density data are determined using the net waste weight and the total container volume. Matrix density data derived from this assessment contains some uncertainty determined by the quality of the information contained in the various databases and unknowns associated with the volume percent of the box occupied by the waste form. Because the density is computed assuming the matrix occupies the entire box volume, and it is known that voids and partially filled boxes exist, the reported densities should be biased low. This low bias expectation is countered by the fact that the majority of the average densities are higher than that associated with drum container densities for similar MPCs. Regardless, the average densities listed in Tables D-3 through D-9 are reasonable and can be considered representative of the inventory provided it is recognized there is an overall uncertainty on the order of $40 \%$.

\subsubsection{Boxed Waste Radionuclide Inventory Information}

Radionuclides entrained in waste materials are important to the determination of waste NDA capabilities with respect to the range of elements and their relative amounts. Site radionuclidic/isotopic composition inventories are presented in Appendix E. Tables E-1 and E-2 provide information related to the radionuclides found in materials associated with the major MPC categories of INEEL TRU and mixed low-level waste (MLLW). A survey of all INEEL MPC categories indicates that the waste can contain isotopes of Plutonium (Pu), Uranium (U), Americium (Am), Neptunium (Np), Californium (Cf), and Thorium (Th). The data supplied by Table E-2 show that only Pu, U, Am, and Np isotopes are identified for the MPCs comprising the largest fraction of the INEEL TRU inventory. Table E-3 provides the mass of radionuclides of various waste types being generated at RFETS where isotopes of $\mathrm{Pu}, \mathrm{U}, \mathrm{Am}, \mathrm{K}$, and Th are reported. LLNL TRU waste radionuclide content is provided in Table E-4. Isotopes of $\mathrm{Pu}, \mathrm{U}$, and Am are reported. It should be noted that LLNL wastes contain a significant range of differing radionuclide species produced as a result of research and development activities. Specific elements expected to be present are not known, however, a variety of radioisotopes similar to those reported for ORS can be expected. The ORS waste is generated from activities associated with Eastern Tennessee Technology Park (ETTP), Y-12 Plant, and ORNL. Waste from these sites is expected to contain considerable amounts of $U$ and associated daughter radionuclides. Table E-5 provides information related 
to the overall spectrum of radionuclides present in ORNL waste. Because of radioisotope production activities conducted at ORNL, nearly every radioisotope is identified. The ORNL TRU inventory contains a more limited number of radionuclides including Silver (Ag), Cadmium (Cd), Cesium (Cs), Europium (Eu), Strontium (Sr), Am, Pu, and U. The radionuclides found in the Hanford inventory (Table E-6) waste are typical of fuel irradiation activities and include Manganese (Mn), Cobalt (Co), Sr, Yttrium (Y), Technetium (Tc), Cs, and Barium (Ba). SRS reports (Table E-7) contain a larger inventory of radionuclides, although similar to Hanford. Additional elements reported include Cerium (Ce), Curium $(\mathrm{Cm})$, tritium, Nickel (Ni), Antimony (Sb), Selenium (Se), and Zirconium ( $\mathrm{Zr}$ ).

\subsubsection{Boxed Waste Packaging Techniques}

Packaging techniques influence NDA system response through the mixture of waste material types and their spatial dependent elemental compositions and densities. Additionally, most sites have packaging practices that result in as-packaged void volumes. Although specific details for individual site packaging practices are not addressed in this assessment, certain general packaging observations at RFETS, ORS, and LLNL can be made. RFETS waste packaging practices typically result in a good degree of segregation on a matrix basis. Oak Ridge Site personnel indicate that most D\&D operations are conducted such that material is randomly added to boxes. No attempt is currently being made to achieve waste organization to obtain optimum packaging densities. Only in the case of soils, or soils and debris, do waste apparent densities approach anticipated density values. LLNL provided specific information concerning TRU waste box packing. In most cases, materials were placed in the box and foamed into place. Foaming appeared to be practiced even in the case of combustible type materials. Based on apparent densities of the LLNL waste, it was not densely packed. Large components with large void fractions were placed whole into the boxes. Based on the above, boxed waste is expected to be nonuniform in waste matrix density distribution for most MPC waste forms.

\subsection{Projected Future Boxed Waste Inventory Information}

Future generation of boxed waste forms will result from operational activities with a significant fraction resulting from decommissioning and deactivation (D\&D) projects. ${ }^{13,14}$ Known D\&D activities at select sites are presented to aid the determination of future volume estimates for TRU, MLLW, and LLW. D\&D activities at the INEEL are planned to support site remediation efforts, particularly for waste pits and trenches. Future generation of MLLW and LLW boxed waste at the INEEL is associated with the D\&D of facilities at the Central Facilities Area, Test Area North, Radioactive Waste Management Complex (RWMC), and Idaho Nuclear Technology Center (formally ICPP). INEEL transuranic inventories will be increased through activities associated with remediation of various subsurface disposal areas, including RWMC, Pit 9. Cleanup activities at the Hanford site will produce significant volumes in all waste categories. These activities include D\&D of the 100,200 , and 300 areas at Hanford. A significant source of the future LLW and TRU waste inventories involve actions taken to D\&D the highlevel waste tanks and plutonium handling facilities. The primary sources of waste generation at LANL will be associated with environmental restoration and D\&D activities associated with surplus plutonium and weapons fabrication facilities. Continued LANL weapons and space reactor fuel missions will also result in TRU waste generation. LLNL environmental restoration and D\&D of surplus facilities have been identified as potential sources of MLLW and LLW. Closure and transition of the Oak Ridge ETTP site and remediation and D\&D of facilities at $Y-12$ will continue to produce sizable amounts of TRU, MLLW, and LLW. Continued operations associated with ORNL will produce primarily MLLW and LLW. D\&D of waste tanks at ORNL will generate TRU waste. Closure of RFETS will generate a sizeable amount of all types of waste. The closure and D\&D of various buildings at RFETS site will generate both MLLW and LLW. Environmental restoration and D\&D activities at SRS are expected to continue and will produce various types of waste. Significant projects include deactivation of site reactors, deactivation of the $\mathrm{F}$ and $\mathrm{H}$ canyons, and $\mathrm{D} \& \mathrm{D}$ of the $\mathrm{FB}$ and $\mathrm{FH}$ processing lines. 
Projected waste generation and distribution estimates are provided in Tables F-1, F-2, and F-3 for TRU, MLLW, and LLW, respectively. Significant contributors to mixed and nonmixed TRU inventories include Hanford, LLNL, Rocky Flats, and SRS. Data shown in Table F-3 correlate with the planned D\&D activities at most sites.

Data specific to waste matrix characteristics were not reviewed for TRU and LLW types; such data related to MLLW is provided in Table F-4. Projected additions to the inventory are expected to occur in MPC categories $\mathrm{S} 3100$ (inorganic homogeneous solids), S4000 (soil, debris, and rock), S5000 (debris waste), S5100 (metals debris), and S5400 (heterogeneous debris). Environmental restoration actions associated with evaporation and holding ponds and D\&D of old sewers and tanks will generate most of the $\mathrm{S} 3100$ waste. Environmental restoration of areas associated with $D \& D$ facilities will produce most of the $\$ 4000$ waste. D\&D activities associated with old facilities will be responsible for $S 5000$ and $\$ 5400$ waste. D\&D of reactors, processing lines, and canyon processing equipment will produce S5100 waste. LLW will have similar characteristics, except there will be less $\$ 3100$ waste associated with sludges. The projected future waste matrix attributes are anticipated to be similar to the present inventory. 


\section{BOXED WASTE NONDESTRUCTIVE ASSAY TECHNOLOGIES}

General descriptions of known box waste nondestructive assay systems are provided to identify technologies constituting the boxed waste NDA capability baseline. Consideration of the NDA baseline is necessary to support the determination of capability deficiencies to be addressed through development projects. The systems are in various implementation stages ranging from design concepts to fabricated, installed, and preliminary testing. The detail associated with system hardware and software configuration description is dependent on the development state of the system. Additionally, certain aspects of a number of the systems contain proprietary information and cannot be detailed in the discussion. The descriptions are organized to the extent practicable, by technology type, i.e., gamma based systems are separated from neutron, and strictly passive type systems are separated from active passive combination systems.

\subsection{Gamma Based Systems}

\subsubsection{Canberra Gamma Box Counter}

4.1.1.1 Background. The Canberra Gamma Box Counter is designed to be flexibly configured to accommodate a variety of box container sizes up to the large sea-land shipping container. The system is typically configured with either two to eight high purity germanium detectors (HPGe). The detectors can be placed close to the container to optimize sensitivity or at a distance for a far field measurement of higher dose rate containers. The system is intended to characterize fission and activation product waste, as well as waste generated from plutonium, uranium, radium, and thorium processing applications. These waste forms are typically generated in decommissioning or environmental restoration applications. A Canberra Gamma Box Counter has been installed at Envirocare of Utah for the primary purpose of confirming waste generator shipping manifest data.

4.1.1.2 System Description. The Envirocare system uses four HP Ge detectors mounted in fixed positions (horizontally), which have been optimized for the B-25 box configuration. The system is used to assay B-12 boxes, pallets of four 55-gallon drums, and individual 55-gallon drums. Standard germanium spectroscopy techniques are used to determine the container assay. Mathematical calibrations are generated using Canberra' In Situ Object Counting Software (ISOCS). ${ }^{15}$ Matrix corrections are performed using an average density matrix correction technique based on the sum of spectral data from all detectors. Corrections for nonuniform source spatial distributions can be accomplished through the calibration methodology and via differential peak absorption analysis techniques. Qualitative evaluations of nonuniformity can also be made by evaluating the response of the individual detectors.

4.1.1.3 Calibration. Calibration is accomplished through the ISOCS routine comprised of three steps. First, the response function for each detector in the system is determined using MCNP modeling. Detection radiation response profiles are determined for a 50-meter sphere centered on the detector over the energy range $50 \mathrm{KeV}$ to $7 \mathrm{MeV}$. Next, software shield/collimation and box specific geometry templates are defined. Finally, waste box matrix and source-detector distance parameters are defined. A number of such calibrations can be determined in this manner, each pertaining to a different matrix configuration. These data are then combined with MCNP detector characterizations to generate an efficiency calibration curve for each matrix configuration. This approach is inherently flexible in that it allows the operator to reanalyze the measurement data for a given waste box using different parameters if the initial parameters are considered suspect. 


\subsubsection{ORNL Y-12 Box Assay System}

4.1.2.1 Background. The Y-12 B-25 box nondestructive assay system is used to sort "nonradioactive waste" from low-level waste at the $35 \mathrm{pCi} / \mathrm{g}$ total uranium activity fiducial. The system was designed and built at the Y-12 plant and commenced operation in early 1996 . The waste form characterized by the system is produced as a by-product of $\mathrm{Y}-12$ plant operations, decontamination and decommissioning activities, and is routinely packaged in the B-25 type box. The waste streams are typically well segregated by uranium enrichment. Under normal circumstances, a given box will contain either depleted uranium or $93 \%$ enriched uranium. There are infrequent occasions in which waste streams are commingled within a single box.

The primary function of the Y-12 box system is to qualify as much waste as possible for disposal at the Y-12 Industrial Landfill. The landfill acceptance criterion is that solid waste must be less than $35 \mathrm{pCi} / \mathrm{g}$ total uranium activity concentration. Two measurement conditions will direct the box to waste storage rather than the landfill: (1) if the waste package assayed is greater than $35 \mathrm{pCi} / \mathrm{g}$ total uranium activity; or (2) if the effective density is greater than approximately $0.2 \mathrm{~g} / \mathrm{cm}^{3}$ where the gamma-ray attenuation is less than the allowable transmission requirement of $1 \%$.

4.1.2.2 System Description. The Y-12 box assay system is composed of two arrays of uncollimated 5-in. diameter $\times$ 5-in. thick NaI(Tl) detectors. ${ }^{16}$ Each array consists of six detectors placed on the long sides of the box. Detector spacing is determined per the Nyquist critical spatial frequency, i.e., the distance between adjacent detectors is the sum of the distances corresponding to that point where the detector response is one-half the maximum for a point source response at $31.75 \mathrm{~cm}$ from the detector face. Each detector is also positioned $31.75 \mathrm{~cm}$ from the surface of the waste box. The output of each detector is routed to a multichannel analyzer for display and analysis. Regions of interest are set for peak area quantification at the $185.7 \mathrm{KeV}$ gamma ray of ${ }^{235} \mathrm{U}$ and the ${ }^{238} \mathrm{U} /{ }^{234 m} \mathrm{~Pa}$ daughter $1,001 \mathrm{KeV}$ gammaray line. Analysis is performed using a point-source efficiency response followed by a transmission correction for attenuation, thus quantifying the radioactivity of ${ }^{235} \mathrm{U}$ and ${ }^{238} \mathrm{U}$. Four HP Ge detectors, two on each side, screen the box for the presence of nonuranium isotopes such as ${ }^{232} \mathrm{Th}$. This provides a limited enrichment determination capability using the low energy, photopeak deconvolution code MGA-U. A $5 \mathrm{~cm}$ thick iron wall on each side of the detector arrays provides background radiation shielding.

In a separate measurement station, a three-position gamma-ray transmission measurement is made through the short, horizontal axis of the box. This measurement allows for the correction of the uncollided flux for matrix attenuation. The transmission measurement is acquired via three collimated $\mathrm{NaI}$ detectors ( $3 \mathrm{in}$. diameter $\mathrm{x} 3 \mathrm{in}$. thick) located on one side of the box, opposite three depleted uranium (DU) and three enriched uranium (EU) transmission sources on the other side.

Data from the two measurement systems are fused in an algorithm that yields measurement results for ${ }^{235} \mathrm{U}$ and ${ }^{238} \mathrm{U}$. Data from either the MGA-U measurements or process knowledge are used to arrive at the total uranium activity value.

4.1.2.3 Calibration. Detector response functions are determined by measuring uranium standards, placed in an empty box on a horizontal plane in front of each detector at a distance of $62.5 \mathrm{~cm}$, corresponding to the center of that detector's voxel within the B-25 box. The average spatial dependent response function for each $\mathrm{NaI}(\mathrm{Tl})$ detector in the array is determined as the total collective response for the source in each of the 12 measurement positions. This technique purposely produces conservative detector efficiencies that yield overestimates of the true-activity, particularly in cases where the uranium is closer to the container edge versus the center. The known spatial dependent efficiency is used in conjunction with the measured uncollided transmission flux to determine the ${ }^{235} \mathrm{U}$ and ${ }^{238} \mathrm{U}$ isotope 
activity/mass for each detector. The sum of mass values over all detectors is used to arrive at the total mass estimate.

Matrix attenuation data are acquired through the use of three depleted uranium sources and three enriched uranium sources. The box is positioned between the six sources and three NaI(Tl) detectors. A functional form for the $95 \%$ lower confidence bound for the three point average transmission of the data set was determined from a set of actual waste boxes filled with waste. The matrix attenuation correction factor for the emitted uncollided flux is then expressed as a function of the lower confidence bound by a fitted model. If the average transmission value is less than $1 \%$, the box is set aside as not within assay capability for determining disposition at the landfill limit. Once the transmission corrected measurements are completed for ${ }^{235} \mathrm{U}$ and ${ }^{238} \mathrm{U}$, total uranium activity is computed from a combination of direct measurements and process knowledge. The activity of ${ }^{234} \mathrm{U}$ and ${ }^{236} \mathrm{U}$ is determined from a relationship developed as a function of ${ }^{235} \mathrm{U}$ enrichment.

\subsubsection{ETTP K-25 Box Assay System}

4.1.3.1 Background. The East Tennessee Technology Park, formerly the K-25 Site, is a shutdown uranium enrichment facility that processes and stores a large variety of radioactive wastes. These waste forms are generated primarily as a result of maintenance and decontamination and decommissioning operations in the five gaseous diffusion plants. The B-25 type box is the predominant container type used for waste packaging. Matrix types are segregated into two broad categories: combustibles and metallic waste forms. The waste is primarily contaminated with uranium at variable enrichments that historically have averaged at approximately 3\%. Characterization of this waste is performed at an NDA facility established in FY 1993. ${ }^{17}$ Techniques used include NaI(Tl) gamma, HP Ge gamma, and passive neutron. The measurement protocol commences with an assay at the $\mathrm{NaI}(\mathrm{Tl})$ detector station, followed by a passive neutron measurement for metallic type matrices only and a final measurement via an $\mathrm{HP} \mathrm{Ge}$ gamma spectroscopy system.

4.1.3.2 System Description. The $\mathrm{NaI}(\mathrm{Tl})$ measurement station is comprised of four 5-in. diameter $x$ 3-in. thick lead collimated NaI(T1) detectors interfaced to a PC-based analyzer equipped with four $1 \mathrm{~K}$ multichannel analyzers. Two detectors are centered (heightwise) on each long side of the B-25 box, 18 in. from the edge at a 36 -in. box surface offset. The system independently processes signals from each of the four detectors. Regions of interest are set on the MCA for the $185.7 \mathrm{KeV}^{235} \mathrm{U}$ and 1,001 $\mathrm{KeV}{ }^{238} \mathrm{U} /{ }^{239 m} \mathrm{~Pa}$ gamma lines. The sum response of the four detectors, corrected for efficiency, attenuation, and background is the basis for mass determination on either ${ }^{235} \mathrm{U}$ or ${ }^{238} \mathrm{U}$.

The radioactive source spatial and matrix attenuation dependent detector response is modeled for each $\mathrm{NaI}(\mathrm{Tl})$ detector via the program GAMMAEFF. Corrections for matrix attenuation are based on net box weight to determine matrix density and knowledge of the matrix type to arrive at appropriate gamma attenuation coefficients. The matrix density is determined from the net box weight with the assumption that the matrix fills the box homogeneously. The program GAMMAEFF uses the matrix type, density, and associated attenuation coefficients for determination of matrix attenuation correction factors over a range of matrix types and densities. The matrix correction factor is applied to each of the $\mathrm{NaI}(\mathrm{Tl})$ responses and the sum of the four detectors is used to arrive at the isotope mass. A 3\% uranium enrichment is assumed for the $\mathrm{NaI}(\mathrm{Tl})$ measurement when the ${ }^{235} \mathrm{U}$ and ${ }^{238} \mathrm{U}$ masses are less than 0.2 and 30 grams, respectively. Mass values less than these do not allow use of the HP Ge system for enrichment measurements due to sensitivity considerations. Under such conditions, the $\mathrm{NaI}(\mathrm{Tl})$ system is effectively a stand-alone measure.

The passive neutron measurement station is primarily used to verify that large masses of highly enriched ${ }^{235} \mathrm{U}$ have not been missed in the heterogeneous steel matrix. An approximate quantification of 
uranium in the assumed form of $\mathrm{UO}_{2} \mathrm{~F}_{2}$ or uranium metal can be determined for dense metals type waste matrices. The method is based on measurement of neutrons from the ${ }^{19} \mathrm{~F}(\alpha, n)^{22} \mathrm{Na}$ reaction originating from ${ }^{234} \mathrm{U}$ bonded to fluorine atoms. All uranium is assumed to be in the form of $\mathrm{UO}_{2} \mathrm{~F}_{2}$. The neutron measurement system consists of two polyethylene slabs, each containing five 1 -in. diameter $\times 20$-in. long 4 atmosphere ${ }^{3} \mathrm{He}$ detectors. The measurement is acquired by positioning the long side of the $\mathrm{B}-25$ box 12-in. equidistant from the two slab surfaces. Quantification occurs through the known efficiency of the neutron detector slabs, the background, and the measured neutron totals rate.

The HP Ge high resolution gamma spectroscopy measurement is primarily used to estimate the ${ }^{235} \mathrm{U}$ enrichment and identify the presence of other gamma-ray emitting radionuclides. Other radionuclides found in the waste include ${ }^{137} \mathrm{Cs},{ }^{230} \mathrm{Th},{ }^{232} \mathrm{Th}$, and ${ }^{237} \mathrm{~Np}$. The $\mathrm{NaI}(\mathrm{Tl})$ based mass of ${ }^{235} \mathrm{U}$ or ${ }^{238} \mathrm{U}$ is used as the reference value for determination of enrichment and mass of other radionuclides through HP Ge measured relative ratios. The system consists of one collimated HP Ge detector positioned to view the long side center of the box. The HP Ge detector is interfaced to a PC data acquisition and analysis system. The results of radionuclide identification and peak fit routines per commercially available programs, e.g., SAMPO 90, Genie $2 \mathrm{~K}$, etc., are input to Program ISOTOPIC. ${ }^{18}$ The ISOTOPIC program uses this information with measurement configuration data to compute geometry and matrix attenuation corrections. Matrix and container material types are adjusted to ensure applicable mass attenuation coefficients are employed for the gamma-ray energies of interest. The HP Ge results are normalized to the ${ }^{235} \mathrm{U}$, and occasionally ${ }^{238} \mathrm{U}$, mass derived from the $\mathrm{NaI}(\mathrm{Tl})$ measurement station. The $\mathrm{NaI}(\mathrm{Tl})$ based ${ }^{235} \mathrm{U}$ mass value is used as this measure has a smaller geometry dependent correction versus the HP Ge system.

4.1.3.3 Calibration. Response modeling of the individual NaI(Tl) detectors is performed via the use of traceable point sources incrementally positioned at specific locations in an empty B-25 box. The program GAMMAEFF spatial dependent detector response model is benchmarked to the known source intensity and position. Representative matrix surrogates are not used to determine matrix dependent corrections. Rather GAMMAEFF computations using the net box weight, matrix type, and assumption of a homogeneously filled box to determine a matrix correction factor for the $\mathrm{NaI}(\mathrm{Tl})$ mass estimate.

The passive neutron system total neutron count response is calibrated with traceable point sources to establish an average detection efficiency. Matrix corrections are not applied to the response of the passive neutron system.

The HP Ge gamma spectroscopy system is calibrated with point source traceable gamma sources at various positions in an empty container. The HP Ge geometry correction assumes the container is evenly divided into many activity locations. The distance to the detector, plus the angular efficiency, are computed for each location. An average efficiency is then computed for the configuration. Corrections for matrix attenuation are performed using Program ISOTOPIC with knowledge of the matrix type and calculated matrix density. Fine tuning of the matrix corrections is manually performed through the mechanisms of Program ISOTOPIC by aligning gamma-ray intensities as a function of attenuation.

\subsubsection{ORNL WEAF B-25 Box Assay System (B-BAS)}

4.1.4.1 Background. The specification and preliminary design of a waste assay system for the identification and quantification of gamma-ray emitting radionuclides in the B-25 waste box container has been performed at the Oak Ridge National Laboratory Waste Examination and Assay Facility (WEAF). The system is tentatively called the B-25 Box Assay System (B-BAS). The B-BAS is designed to address the need to measure the radionuclide content of a B-25 waste box at its site of residence. This is specifically intended to reduce costs by minimizing transportation of the box to a facility specifically for nondestructive assay or physical sampling of its contents. 
The B-BAS construction is such that it can be transported and installed at the waste generator site. For the ultrahigh sensitivity, No Rad Added type of measurement, the array can be placed within the existing real-time radiography (RTR) shielded vault located at the WEAF. The $x$-ray chamber is a leadlined enclosure that makes it suitable for low-level radiation counting applications. Once measured, if the box is below the required activity limits, it can be treated as nonradioactive or sanitary waste. The measurement enables the early segregation of waste between radioactive and nonradioactive (sanitary) yielding a significant potential for cost savings. Cost savings are also realized in the cost difference between transport of nonradioactive waste and radioactive waste within the site. Cost savings are realized in eliminating the paperwork required for rad shipments.

4.1.4.2 System Description. The B-BAS is based on an array of eight low-resolution/highefficiency 7.6-cm x 7.6-cm NaI(Tl) detectors for identification and quantification of waste entrained, gamma emitting radionuclides. Four detectors are positioned on one long side of the B- 25 box with a symmetrical arrangement of the remaining four on the opposite side. The eight detectors are mounted to a moveable support structure with large wheels, allowing the B-BAS assembly to be moved by hand down the long axis of a B-25 waste container. This moveable structure is designed to be easily transportable between measurement sites. The wheels are removed to insert the B-BAS in the WEAF RTR system for the ultrahigh sensitivity "No Rad Added" type measurements.

The moveable detector assembly positions the detectors at a distance of $30 \mathrm{~cm}$ from the surface of the B-25 box. The detector spatial configuration is designed to allow a maximum field of view for the middle two detectors and a minimum field of view for the uppermost and lowermost detectors. The two middle detectors have the same collimator design, i.e., a 34.2-degree angle from the centerline of the collimator. The uppermost collimator has a smaller field of view with only a 9.5-degree angle of the collimation with respect to the centerline. The smallest field of view implemented in the lowest detector (4.4 degree angle w.r.t. centerline). Each collimator has at least $2.5 \mathrm{~cm}$ of $\mathrm{Pb}$ to shield background gamma rays.

The measurement protocol for the B-BAS is to acquire data in a scanning fashion by movement of the $\mathrm{NaI}(\mathrm{Tl})$ detector array across the B-25 box. This scanning data acquisition mode is performed manually by operating personnel. When the B-BAS is inserted into the WERF RTR chamber, the wheels of the B-BAS are removed and the detectors are fixed. Scanning is achieved within the RTR chamber via a B-25 box transport system, which moves the box past the fixed detector array at a constant speed.

Signals from the NaI(Tl) detectors are routed into two mixer/routers. Each of the two mixer/routers allow simultaneous acquisition of up to four signals. These mixer/routers have a preamplifier and an amplifier on each channel. The preamp/amp combination allows the user the ability to gain match the detectors. The purpose of gain matching is to allow spectra summing for the detector arrays by adding channel to channel. The summed spectra are processed through a PC based, multichannel analyzer card. The PC based software can communicate with other programs using Dynamic Data Exchange allowing communication between data acquisition software, hardware, and the Microsoft Windows environment. For example, a Word document can be programmed to start Microsoft Excel, load a worksheet or write values to the worksheet, execute the calculation, and retrieve the result. A macro may be programmed that will present a special interface to the user. Through such a configuration, the user can take data, analyze data, and put the data into an Excel spreadsheet by clicking on a button.

4.1.4.3 Calibration. The B-BAS has not been fabricated at this time. It is expected that a volume averaged response for the detector array will be constructed through the acquisition of point source response data. 


\subsection{Passive Neutron Based Systems}

Passive neutron assay is based on neutron coincidence counting of neutrons resulting from the decay of spontaneously fissioning isotopes, e.g., ${ }^{240} \mathrm{Pu},{ }^{252} \mathrm{Cf}$. Each spontaneous fission event produces two or more neutrons simultaneously in time. As the neutrons are produced in a time correlated manner, they are also detected in that fashion through implementation of various coincidence counting techniques. Mass quantification is performed by relating the spontaneous fission neutron event rate to the mass of the isotope appropriately corrected for losses.

\subsubsection{Super High Efficiency Neutron Counter (Super-HENC)}

4.2.1.1 Background. The Rocky Flats Environmental Technology Site awarded the LANL NIS-5 group a contract to supply a trailer mounted box NDA system to quantify plutonium activity contained in waste forms packaged in the standard waste box (SWB) in early 1998. The system is currently in the design and initial fabrication phase. Performance requirements are based in RFETS safeguards and accountability criteria and for certification with respect to the Waste Acceptance Criteria for disposal at WIPP. The system is to accommodate SWBs weighing up to 5,000 pounds. The as delivered system is to include all hardware, software, documentation, calibration, and most importantly, demonstrated performance per WIPP requirements.

4.2.1.2 System Description. The Super-HENC box assay system uses passive neutron measurement principles to determine the mass of waste entrained, radioactive materials. A primary consideration in the use of the passive neutron technique is to minimize or eliminate some of the matrix and radioactive material induced bias effects associated with the active neutron and gamma techniques. This is feasible if the sensitivity of the passive neutron detection system approaches that achievable by active neutron and gamma techniques. The Super-HENC system detection efficiency and background reduction techniques are designed to yield a detection limit sufficient to segregate at the $100 \mathrm{nCi} / \mathrm{g}$ lowlevel/TRU fiducial. The passive neutron technique is also extremely desirable for those instances where the radioactive material is in dense accumulations or clumps. There is minimal radioactive material clump induced bias associated with a passive neutron measurement as compared to active neutron and gamma measures.

The Super-HENC detection system consists of approximately 25010 atmosphere ${ }^{3} \mathrm{He}$ proportional counters located in the top, bottom, and four side walls. The ${ }^{3} \mathrm{He}$ detectors are arranged in a dual row fashion embedded in a polyethylene matrix of optimized spacing and thickness. The design neutron detection efficiency is $40 \%$. The system is operated in the passive neutron coincidence or time-correlated mode to measure the ${ }^{240} \mathrm{Pu}_{\text {eff }}$ spontaneous fission rate. The system also has the potential to determine ${ }^{235} \mathrm{U}$ at masses above a few grams by measuring delayed neutrons from the induced fission reaction via a ${ }^{252} \mathrm{Cf}$ source. However, for this active assay mode, the ${ }^{252} \mathrm{Cf}$ source must be larger and the software modified for active/passive assay. The Super-HENC does not incorporate a high resolution gamma detection system for determination of radionuclidic/isotopic species identification and relative ratios of such. These data must be acquired from either acceptable knowledge or direct measurement with an appropriate gamma system.

Corrections for waste matrix effects on the observed coincidence measure are addressed through the Add-A-Source (AAS) technique. The basis of the AAS method is to measure the matrix perturbation to the counting rate from a small ${ }^{252} \mathrm{Cf}$ source, which is extracted from a shield and positioned adjacent to the waste container wall at a select number of locations. The source is then retracted into the shield for the duration of the passive measurement. The observed ${ }^{252} \mathrm{Cf}$ AAS perturbation is related to a matrix correction factor through an empirical relationship. This relationship is established through measurements of a set of simulated waste matrices spanning the properties expected in actual waste. A 
volume averaged perturbation for each matrix type is obtained by counting a plutonium source at multiple positions within an empty waste container and for the set of simulated waste matrices. This volume averaged coincident neutron event ratio for the empty waste container over the matrix filled container gives the volume averaged perturbation over the matrix set. For each waste matrix configuration, the ${ }^{252} \mathrm{Cf}$ source empty to matrix filled container coincident neutron event ratio is also measured. These are plotted against each other to obtain an AAS perturbation correction factor curve that addresses a variety of matrices. The actual waste container specific AAS perturbation can then be used to compute a corresponding matrix correction.

It is important to note the AAS correction assumes that the plutonium is not all concentrated at the center or edges of the box container. Where possible, a multiplicity based efficiency correction is used to consider source distribution significantly departing from the capability envelope of the AAS technique. The neutron multiplicity analysis uses the singles, doubles and triples rates to solve for the ${ }^{240} \mathrm{Pu}_{\text {eff }}$ mass and efficiency (matrix correction). This analysis gives the true matrix correction independent of plutonium distribution, however it is only achievable for containers with sufficient plutonium mass loadings and the statistical precision is not as good as for the AAS method.

The detection of milligram quantities of ${ }^{240} \mathrm{Pu}$ requires the use of background reduction techniques. A primary design goal of the Super-HENC is to optimize the detectability limit to ensure waste segregation at the $100 \mathrm{nCi} / \mathrm{g}$ alpha activity fiducial can be accommodated. To obtain a low detectability limit, a high counting efficiency, small active detector volume, a large coincidence gate fraction, and a low neutron background rate are necessary. High detection efficiency and small active detector volume are opposed to each other requiring a compromise and the implementation of background reduction techniques. The cosmic ray spallation neutron background can be treated by taking advantage of the differences in the multiplicity distribution between fission and cosmic ray events. This can be accomplished through truncated multiplicity techniques, as well as using the multiplicity events that are greater than one to correct for the low multiplicity background. These analyses can also be performed as a function of matrix type and bulk mass. Several new background reduction techniques are either in the design of the Super-HENC or are under consideration for implementation.

The fissile content, e.g., ${ }^{235} \mathrm{U},{ }^{239} \mathrm{Pu}$, and ${ }^{241} \mathrm{Pu}$, can be measured using active neutron interrogation with the ${ }^{252} \mathrm{Cf}$ source. The active mode uses the shuffler principle, where the source is inserted next to the waste container for a brief period of time, is withdrawn, and delayed neutrons from the ${ }^{252} \mathrm{Cf}$ induced fission reactions are measured. This cycle is repeated until reasonable statistics are obtained. It is estimated that a minimum detectable ${ }^{235} \mathrm{U}$ mass using this method is somewhat in excess of 1 gram.

4.2.1.3 Calibration. Calibration of the Super-HENC is accomplished using plutonium samples of known mass and composition. Calibration is performed in an empty container where the calibration is in terms of coincident neutron event counts per second versus ${ }^{240} \mathrm{Pu}_{\text {eff }}$ mass. The corrected coincident neutron event rate in an actual waste drum is simply the measured coincident neutron event multiplied by the ASS derived correction factor.

In parallel with the AAS result, the Super-HENC gives the Pu mass derived from the multiplicity analysis. This result is independent of the AAS correction factor. The software for Super-HENC will make the decision as to the best result (AAS vs. multiplicity) based on the counting rates and the magnitude of the AAS correction. If the AAS matrix correction is small, the AAS calibration result is preferred because of the good precision obtained using the doubles rates. The standards and the calibration measurements are the same for the multiplicity analysis and the AAS doubles analysis. 


\subsubsection{Canberra - High Efficiency Waste Crate Assay System (HE-WCAS)}

4.2.2.1 Background. The HE-WCAS design was prepared in response to a Rocky Flats Environmental Technology Site procurement specification. The box assay system design combines passive neutron counting with high resolution gamma spectroscopy. A prototype WCAS has been built and tested for use at the Japanese Nuclear Corporation (JNC) facilities in Japan. The JNC WCAS prototype passive neutron detection efficiency is $18 \%$, which is approximately half that of the HE-WCAS. The WCAS development and test effort provided the basis for matrix type performance analyses and background reduction techniques for large samples incorporated into the HE-WCAS design. Additional developments included minimization of high- $Z$ structural components to reduce cosmic ray interactions in the counter. The HE-WCAS design is modular such that it can be disassembled and transported.

4.2.2.2 System Description. The HE-WCAS assay technique is based on passive neutron counting of spontaneous fission neutrons to determine the ${ }^{240} \mathrm{Pu}_{\mathrm{eff}}$. This measure is combined with a high resolution HP Ge gamma isotopic measurement to determine the quantity of the associated plutonium isotopes and other radionuclides such as ${ }^{235} \mathrm{U},{ }^{238} \mathrm{U},{ }^{241} \mathrm{Am}$, and ${ }^{244} \mathrm{Cm}$. The passive neutron system design is similar to the Super-HENC, using a high neutron detection efficiency approach in conjunction with several background reduction techniques. This design is intended to yield a detection limit sufficient to segregate low-level from TRU waste categories. Similar to the Super-HENC, the passive neutron counting technique was selected to avoid some of the bias sources associated with active neutron and gamma techniques. Corrections for matrix induced bias elements are determined through the AAS technique in a manner similar to that described for the Super-HENC.

The passive neutron detection system design incorporates in excess of $3006-\mathrm{ft}{ }^{3} \mathrm{He}$ proportional counters (7.5 atmosphere) embedded in polyethylene. The number of tubes, their placement, and polyethylene moderator configuration are based on MCNP modeling of system parameters and expected waste matrix properties. ${ }^{19}$ The assay chamber design and tube placement provide for an effective $4 \pi$ coverage to minimize the coincident neutron spatial dependent response. The cavity is shielded by $12 \mathrm{in}$. of high density polyethylene to reduce the neutron background from external sources. The as designed neutron detection efficiency is $34 \%$.

Several cosmic ray background reduction techniques are incorporated into the HE-WCAS design. An AAS derived background correction using matrix moderation indices is used to refine the cosmic ray background estimate. This technique is intended to remove a positive bias that results from reductions in the cosmic ray background associated with the increase in matrix moderator content. Known matrix and multiplicity difference methods are used to separate the cosmic ray induced neutron signal from that due to the entrained fissile material. To enhance measurement precision at low fissile material mass loadings, the truncated multiplicity technique is applied. Variable endpoint truncation of the measured multiplicity histogram is used to remove cosmic ray effects on background and matrix interference corrections. The most appropriate background reduction analysis technique is automatically selected based on the acquired data.

Neutron source spatial dependent corrections are based on the response of the separate neutron detector packages in conjunction with a source localization algorithm. The source localization algorithm assumes there exists a limited number of point sources distributed throughout the sample along with a homogeneous source. The positions of the point source activities are treated as free parameters. Using the response of the detector set, it is possible to identify four point sources in a uniform background.

The neutron detection cavity incorporates eight HP Ge detectors mounted through the HDPE shielding, four per long side. The HP Ge detectors acquire a plutonium isotopic ratio measure, in addition to quantification of other entrained radionuclides. The HP Ge detectors are designed to allow detection 
and quantification at low radioactive material mass loadings consistent with the low-level/TRU segregation fiducial. Gamma spectroscopy data are analyzed by either the TRIFID or the MGA plutonium isotopics codes. The HP Ge detector array response is also used to provide source localization and correction capability using the Canberra Non Uniformity Correction Software (NUCS). ${ }^{20}$

4.2.2.3 Calibration. Calibration of the neutron system is performed through the use of a traceable radioactive standard. Spatial dependent mapping of the neutron cavity is performed by incrementing the source through known positions of the neutron detection cavity. Matrix corrections are derived per the AAS technique, where perturbation data are acquired over the range of waste matrix attributes expected. Detector efficiency as a function of gamma-ray energy for the source geometry of interest is determined through the ISOCS calibration method. An MCNP model of the detector is developed. The model is then independently validated using measurements with a traceable radioactive source. Given the validated model, the response characteristics of the detector are created to address any location inside a sphere of radius 50 meters, centered on the detector, and over a photon energy range of $50 \mathrm{KeV}$ through $7 \mathrm{MeV}$. The end result is a series of mathematical equation describing the absolute detector efficiency as a function of energy, angle, and distance from the detector. These models can simulate a wide variety of common waste package shapes, including boxes. Attenuation due to absorbers within the source and in the intervening space between the source and detector is also taken into account via the ISOCS technique.

\subsection{Active/Passive Neutron Based Systems}

Active neutron measurements are acquired through the stimulation of fission reactions in fissile materials, (i.e., ${ }^{241} \mathrm{Pu},{ }^{239} \mathrm{Pu},{ }^{235} \mathrm{U}$, and ${ }^{233} \mathrm{U}$ ) via a source of interrogating neutrons. The source of interrogating neutrons are either from pulsed Zetatron neutron generators or ${ }^{252} \mathrm{Cf}$ sources such as used in the shuffler. Interrogation neutrons are injected into a waste assay chamber, which subsequently thermalized in the waste matrix and detection chamber walls and have a probability of inducing a fission reaction in the entrained fissile materials. The interrogation regime is typically separated into a number of time intervals depending on the system design and data reduction routine. There are typically a number of internal cavity flux monitors. These flux monitors are used to provide information regarding the absorption and moderating properties of the waste matrix for corrections to the assay. Systems based on the active neutron interrogation technique can also acquire passive neutron count data, although the system designs are typically optimized to support the active mode measurement. Hence, there are specific data acquisition protocols used to decide when the active or passive mode is most appropriate for mass quantification based on the attributes, e.g., plutonium mass of the specific container.

\subsubsection{Boxed Waste Assay System (BWAS)}

4.3.1.1 Background. A Boxed Waste Assay System (BWAS), designed and manufactured by Pajarito Scientific Corporation, (now BNFL Instruments, Inc.) was installed in the Waste Receiving And Processing (WRAP) facility at the DOE Hanford site in early 1997. The system is designed to classify the contents of waste boxes as LLW of Category A, C, or greater than C or as TRU waste. Waste forms to be processed cover a number of different box sizes containing waste contaminated with plutonium and other transuranics, uranium, and an array of fission products. Hanford waste matrix types are generally heterogeneous mixtures of equipment, concrete, dirt, glass, paper, plastics, steel, wood, and lead, etc. The system detection cavity can accommodate box sizes up to $5 \mathrm{ft} \times 5 \mathrm{ft} \times 8 \mathrm{ft}$ with gross weights up to 15,000 pounds. The different dimensions of common box types, SWB, B-25, etc., are accounted for in the calibration process. The operator can also enter box dimensions for nonstandard boxes required for the measurement process. It is to be noted that although the BWAS is functional and has gone through preliminary performance testing, certain acquisition protocols and data integration/reduction processes need refinement before preparing for the $\mathrm{CAO}$ audit process. 
4.3.1.2 System Description. The BWAS incorporates active neutron, passive neutron, and gamma measurement techniques. The active neutron mode uses the differential dieaway technique to acquire information on the quantity of fissile isotopes such as ${ }^{239} \mathrm{Pu}$ and ${ }^{235} \mathrm{U}$. The passive neutron mode uses a coincidence counting technique to acquire information on the mass of spontaneously fissioning isotopes such as ${ }^{240} \mathrm{Pu}$. The neutron detection system consists of $142{ }^{3} \mathrm{He}$ proportional counting tubes $\left(183 \mathrm{~cm} \mathrm{x} 5 \mathrm{~cm}\right.$, two atmosphere) installed in the top, bottom, and two side walls. The ${ }^{3} \mathrm{He}$ detectors are embedded in polyethylene modules, which are subsequently encapsulated in a layer of cadmium followed by an external layer of boroflex. This shielded detector configuration yields a neutron detection efficiency of $\sim 10 \%$ for a fission source placed in the cavity center. The system also includes a neutron generator/moderating assembly (MA) centered in one of the side walls for active neutron measurements. Three ${ }^{3} \mathrm{He}$ detector flux monitors (122 cm long $\mathrm{x} 2.54 \mathrm{~cm}$ diameter, two atmosphere) are mounted horizontally on the internal detector chamber cavity wall directly across from the neutron generator. Each of the three flux monitors is shielded with cadmium such that the bare section of the tube views the waste box. These flux monitors are used to acquire data on the neutron absorption properties of the waste matrix for use in the derivation of matrix dependent correction factors. The response of the horizontally mounted shielded fast neutron detectors across from the MA during the active mode measurement yields information regarding the neutron moderating properties of the waste matrix.

The BWAS gamma detection subsystem consists of sixteen $12 \mathrm{~cm}$ diameter by $5 \mathrm{~cm}$ thick NaI(Tl) detectors mounted four each in the top, bottom, and side walls. Additionally, a single $40 \%$ efficient high purity Germanium gamma detector is located on one wall for the acquisition of high resolution gamma spectra used in radionuclide identification and relative ratio determinations. The system also includes eight ${ }^{60} \mathrm{Co}$ and eight ${ }^{137} \mathrm{Cs}$ gamma sources for acquiring gamma transmission data through the waste matrix on a spatial basis.

The BWAS measurement protocol is to first move the box past the array of $\mathrm{NaI}$ detectors for gamma-ray assay and source localization analysis. All detectors are centered on the same plane perpendicular to the long axis of the box. Source localization gamma-ray measurements are accomplished by recording individual spectra from each $\mathrm{NaI}(\mathrm{Tl})$ detector at incremental positions of the box through the detector plane. The gamma-ray transmission sources are located on the top and along one side of the system, also in the plane of the $\mathrm{NaI}(\mathrm{Tl})$ detector array. The $\mathrm{NaI}(\mathrm{Tl})$ detector collimation is designed so that each bank of four detectors view substantially nonintersecting cone shaped segments of the largest box size. The combined spatial response of all 16 detectors covers all volume elements in the vertical plane of the box. Detector collimation used in conjunction with the two gamma-ray transmission peaks (from ${ }^{137} \mathrm{Cs}$ and ${ }^{60} \mathrm{Co}$ ) allows determination of gamma-ray attenuation transmission on a volume element basis.

Once a pass through the $\mathrm{NaI}(\mathrm{Tl})$ array has been completed, the box proceeds into the neutron detection portion of the system. The BWAS passive neutron analysis is based on the detection of spontaneous fission neutrons in a time correlated manner through the use of a programmable multichannel coincidence module (PMCCM). The PMCCM does a pulse-by-pulse time correlation determination of all detected events, gross coincidence rates, as well as singles, doubles, and when possible, triples. Total neutron count data from the separate detector packages are grouped into a count rate vector. The count rate vector used in conjunction with an appropriately selected passive reconstruction matrix and a background vector are used to solve for the source vector. The source vector is used to weight the total measured coincidence rate per predetermined coincidence efficiencies as a function of source spatial distribution and waste matrix properties. This weighted coincident value is used to determine the mass of the spontaneously fission isotope, i.e., ${ }^{240} \mathrm{Pu}_{\mathrm{eff}}$. The passive reconstruction matrix is built from calibration measurements on known waste matrices. A number of such matrices have been constructed spanning waste matrix type and container geometry. Selection of a given reconstruction matrix to solve for the source vector is based on a the actual waste box neutron system response measures. The reconstruction 
response parameter set that most closely approximates the measured waste box set is used to calculate the source vector.

BWAS active neutron measurements use interrogating neutrons produced from a pulsed Zetatron neutron generator housed within a polyethylene/graphite/lead moderating assembly. The BWAS interrogation regime is separated into three time intervals: (1) epithermal, (2) early, and (3) late. The matrix moderator properties are determined by using the epithermal time regime for the shielded detectors across from the MA. Data acquired from the cavity mounted flux monitors and a small flux monitor internal to the neutron generator/moderating assembly during the epithermal and early time intervals provide information with respect to the neutron absorption properties of the waste. The absorption index derived from the response of the flux monitors in combination with the moderator index from the response of the shielded packages in the wall behind the flux monitors is used to select the appropriate active reconstruction matrix. The source vector is determined using a measured count vector comprised of the net induced fission signal, an active background vector, and the active reconstruction matrix. The source vector is used to weight the net induced fission response per predetermined active efficiencies as a function of source spatial distribution and waste matrix properties. The weighted induced fission signal is used to compute the mass of the fissile isotope.

After a single pass through the active and passive neutron detection system is completed, the box is removed from the detection chamber, rotated 180 degrees, and the neutron measurement process is repeated. This is required as the neutron detection package arrangement in the walls is not symmetric due to the neutron generator moderating assembly located in the one side wall. The rotation also allows for a more complete interrogation of the waste matrix volume via the active interrogating neutrons.

The detection limit of the active mode neutron measurement can be improved by measuring the coincidence neutron response in the active mode, rather than the traditionally used singles response. Because of the reduced background signal for coincident neutrons, the lower limit of detection is reduced. Another improvement arises from the use of an active neutron multiplicity sorter. The sorter is used in both active and passive measurement modes to determine neutron detection efficiencies on a box basis. The option of using active coincidence data is appropriate when unusually small lower limits of detection (LLDs) are required.

The final measurement station of the BWAS is the $40 \%$ efficient HP Ge detector mounted on one side wall. The purpose of the HP Ge detector is to obtain high resolution, gamma spectra of the four highest "hot spots" identified during the $\mathrm{NaI}(\mathrm{Tl})$ measurement. Acquired gamma-ray spectra are used to identify and quantify individual radionuclides emitting gamma energies through the range of $40 \mathrm{KeV}$ to $1.6 \mathrm{MeV}$. The system is currently configured to identify ${ }^{60} \mathrm{Co},{ }^{125} \mathrm{Sb},{ }^{134} \mathrm{Cs},{ }^{137} \mathrm{Cs},{ }^{144} \mathrm{Ce},{ }^{152} \mathrm{Eu},{ }^{154} \mathrm{Eu},{ }^{233} \mathrm{U}$, and ${ }^{239} \mathrm{Pu}$. Hot spot localization in front of the HP Ge detector is accomplished through the combined effects of 180-degree box rotation conveyor transport along the long axis of the box and the up/down positioning of the HP Ge detector. The detector is positioned as close as possible to the "hot spot" for the acquisition of the radionuclidic/isotopic information. This information is used in conjunction with the "absolute" mass value determined via either the passive or active neutron measurement modes to compute the mass of other isotopes and radionuclides entrained in the waste matrix. This allows computation of required parameters such as TRU alpha activity, thermal power, etc.

4.3.1.3 Calibration Technique. The BWAS neutron calibration technique fundamentally relies on the production of reconstruction matrices for the active and passive neutron measures. The reconstruction matrices are developed using NIST traceable depleted uranium and ${ }^{252} \mathrm{Cf}$ sources to measure detector response for each element of the source vector for a range of matrix types for each possible detector position. The waste matrix types are specified with respect to their bulk neutron 
absorption and moderation characteristics. This may be supplemented with MCNP simulations of system response per matrix configuration.

\subsubsection{Variable Boxed Waste Assay System (VBWAS)}

4.3.2.1 Background. The VBWAS was designed and fabricated by BNFL Instruments, Inc., in 1996, for use in the Pit 9 remediation project at the INEEL. The primary application and design basis for the VBWAS was to perform radioactive material characterization of $2.5-\mathrm{ft} . \times 4.0-\mathrm{ft} . \times 8.0-\mathrm{ft}$. soil boxes and 4.0-ft. $\times 4.0-\mathrm{ft} . \times 8.0-\mathrm{ft}$. waste boxes with gross weights up to 10,000 pounds. Because of programmatic changes, the VBWAS was not implemented at the INEEL site and inactively resides at the BNFL Instruments, Inc., Los Alamos facility. The VBWAS has gone through preliminary performance testing at the BNFL facility.

4.3.2.2 System Description. The VBWAS incorporates the same design and operational principles as the BWAS, with a couple of differences. The first difference is that the top chamber wall containing the neutron detection assemblies can be varied via a hydraulic actuated top detector package to adjust to waste box height. This variable top chamber wall is positioned as close as possible to the top of a waste box to maximize the neutron detection efficiency. The second difference concerns the neutron detection system. The BWAS has a double row arrangement ${ }^{3} \mathrm{He}$ detectors, whereas the VBWAS has a single row. This single row configuration has $47{ }^{3} \mathrm{He}$ proportional counting tubes $(183 \mathrm{~cm} \times 5 \mathrm{~cm}$, two atmosphere) installed in the top, bottom, and two side walls. There are also three $71-\mathrm{cm}$ long $\times 5-\mathrm{cm}$ diameter, two atmosphere ${ }^{3} \mathrm{He}$ proportional counting tubes mounted horizontally in the counting chamber directly across from the neutron generator similar to the BWAS. The VBWAS, unlike the BWAS, does not have any gamma detection capabilities in its current state. Otherwise, the operating principles and data reduction process is nearly identical to the BWAS.

4.3.2.3 Calibration. VBWAS calibration has been performed for soil acquired from the INEEL facility where the system was to be implemented. Neutron absorption effects were expected to vary minimally for soil during actual operation. The major moderator effects expected are related to soil moisture content. For these reasons, only one calibration was performed and all moderation effects are calculated based on the one calibration and variable moisture content. Calibrations for the debris waste type cover a range of waste matrix types, including: (1) low density, lightly moderating and lightly absorbing waste forms, (2) medium to high density, highly moderating and moderately absorbing waste types, and (3) medium to high density, lightly moderating and highly absorbing matrix configurations. A low density mixture of vermiculite and peat moss is used to simulate the lightly moderating and lightly absorbing matrices. A high density concrete rubble matrix is used to simulate the highly moderating and moderately absorbing wastes. A medium density scrap metals matrix is used to simulate the lightly moderating and highly absorbing waste forms.

\subsubsection{Rocky Flats Environmental Technology Site Multi-Purpose Crate Counter (RFETS MPCC)}

4.3.3.1 Background. The RFETS MPCC is currently in the design and preliminary fabrication phase at the BNFL Instruments, Inc., Los Alamos facility. The production of this NDA box counter is a result of a successful bid on the RFETS DynaCorp procurement, where a contract for production installation was awarded in mid-1998. Per procurement specifications, the system is to serve as a multipurpose assay device accommodating $\mathrm{Pu}, \mathrm{U}$, and $\mathrm{Am}$ radionuclides over four waste forms, dry combustibles, wet combustibles, light metal, and plastics. The system will not function for highly absorbing matrices such as borated glass at low fissile material mass loadings. The system does have to be designed such that it can be readily disassembled and moved to another facility if and when required. 
4.3.3.2 System Design. The RFETS MPCC design is similar to the BWAS. The neutron detection component of the system consists of a single row of shielded ${ }^{3} \mathrm{He}$ detectors versus the double row arrangement of the BWAS. Additionally, the RFETS MPCC system employs two planar HP Ge detectors: one mounted on each side at different box heights. The operational mode therefore is based on the active and passive neutron measurements processed similar to the BWAS method and a gamma energy analysis routine using the high resolution gamma spectra obtained via the HP Ge detectors. There is no "hot spot" gamma localization routine as implemented in the BWAS. The RFETS MPCC gamma analysis routine does include a method to address gamma energy specific efficiency and attenuation effects. This technique is designed to correct all actual measured gamma line intensities for their in situ efficiency and attenuation factors before use in isotopic determinations.

The measurement protocol is similar to the BWAS. The waste box is centered in the chamber and screened to determine the optimum measurement protocol for the box. The crate is then moved such that the 1-foot incremental measures can be taken starting at one end of the box. At each increment, an active measure is acquired followed by a simultaneous passive neutron and high resolution gamma measurement. This procedure is repeated through all 1-foot increments.

4.3.3.3 Calibration. Similar as per BWAS.

\subsubsection{Waste Monitoring and Compaction (WAMAC)}

4.3.4.1 Background. The WAMAC system was installed at the Sellafield facility in the United Kingdom in 1995. The WAMAC is a combined 200 liter and $1.1 \mathrm{~m}^{3}$ box assay system for plutonium and uranium.

4.3.4.2 System Description. The WAMAC neutron detection system configuration consists of $80^{3} \mathrm{He}$ proportional counting tubes ( $114 \mathrm{~cm} \times 5 \mathrm{~cm}$, two atmosphere) installed in the top, bottom, and four side walls. The detectors are in a single row arrangement, embedded in polyethylene, subsequently shielded with a layer of cadmium. There are eight $(30.5-\mathrm{cm}$ long $\times 2.54-\mathrm{cm}$ diameter, two atmosphere) ${ }^{3} \mathrm{He}$ proportional counting tube installed horizontally internal to the cavity opposite the neutron generator/moderation assembly. There are also six ${ }^{3} \mathrm{He}$ proportional counterbarrel flux monitors located close to the waste package, which are shielded on the side facing away from the box with cadmium. All internal cavity flux monitors are shielded with cadmium such that the bare portion of the detector views the waste package. The time gated response of the flux monitors provides an indication of the thermal neutron flux transmission through the matrix. The internal cavity flux monitor set is used for determining waste matrix properties that provide a basis for bias corrections. The WAMAC is calibrated for the active mode measure only and does not have any gamma detection capabilities. An aspect of the WAMAC system worthy of note is that active calibrations were performed to address the heterogeneity of the waste matrix. This was accomplished by acquiring data on layered and partially filled boxes.

The measurement protocol consists of performing an active assay of the drum or box at four increments, 90 degrees apart. The WAMAC data analysis routine commences with the determination of a Layered Box Vector (LBX) for each waste package. The LBX vector is comprised of the epithermal and thermal neutron cavity response of the eight horizontally mounted monitors indicating epithermal flux transmission as a function of box height and the six barrel flux monitors yielding thermal flux transmission information. This response set is then compared to a library of LBX vectors previously measured from a variety of homogeneous and heterogeneous matrix configurations. To determine the matrix type associated with the waste box under consideration, the measured LBX vector is compared against the library vectors through a least squares technique to find a closest match. Once the appropriate $\mathrm{LBX}$ vector has been selected, an appropriate Active Matrix (AMX) value is determined. The AMX matrix is used in an image reconstruction algorithm to convert measured fissile signals in the wall 
detection packages to a fissile material distribution. Selection of the AMX matrix is performed in two ways depending on whether the waste matrix is homogeneous or heterogeneous. If the LBX vector contains a token indicating a homogeneous matrix distribution, the AMX matrix with the closest absorber index is selected. If the LBX vector selection identifies a heterogeneous matrix, the AMX matrix that should be used will be embedded in the LBX vector name. Once the appropriate AMX matrix is selected, the image reconstruction is performed to obtain a final ${ }^{239} \mathrm{Pu}$ mass value. That is, the equation $\mathrm{d}=\mathrm{As}$ is solved for $s$, where $\mathrm{d}$ is the detector response, $\mathrm{A}$ is the AMX matrix selected, and $\mathrm{s}$ is the fissile signal in units of $\mathrm{mg}{ }^{239} \mathrm{Pu}$. This procedure provides a mechanism to account for both matrix effects and source distribution effects on the system response.

4.3.4.3 Calibration. WAMAC calibration requires the construction of matrices to identify the waste matrix characteristics and to solve for the combined matrix/source distribution corrected fissile material mass. This necessitates the preparation of matrix surrogates that span the neutronic characteristics associated with the waste form of interest. Once prepared, numerous measurements of a characterized radioactive source must be made as a function of spatial location within the surrogate matrix.

\subsubsection{Crated Waste Assay Monitor (CWAM)}

4.3.5.1 Background. The Crated Waste Assay Monitor (CWAM) project was initiated in 1995 at the Oak Ridge $\mathrm{Y}-12$ Plant to design a differential dieaway system capable of measuring ${ }^{235} \mathrm{U}$ in contaminated waste streams contained in B-25 type boxes. The active neutron technique was specified for this particular application as passive gamma techniques suffer from uranium and/or plutonium gamma-ray attenuation in dense matrices. Since uranium has no passive neutron signal, active neutron methods are especially suited to the dense matrix uranium waste configuration. Fabrication of the CWAM system was finished in August 1997, and assembly of the structural components was completed by October of that year. Mechanical and electronic systems were installed and tested during the first half of fiscal 1998. Calibration efforts are currently on standby due to funding uncertainties.

The CWAM design and development effort has benefited from and incorporates many of the technology aspects arising from the ongoing LANL Combined Thermal Epithermal Neutron (CTEN) project. The CTEN system is a drum-sized active/passive neutron DDT instrument. The structural design of CWAM was patterned after the CTEN instrument, allowing both thermal and epithermal neutron interrogation with the intent of incorporating a mechanism to account for active neutron fission material self-shielding effects. Methods of data acquisition and analysis developed for CTEN have improved assay accuracy and sensitivity for drum-sized containers. It is the intent to adapt these developments to the larger volume CWAM box assay system. The systems are therefore inherently alike and it is intended that one basic software package will service both systems.

4.3.5.2 System Description. The CWAM system is optimized as an active neutron system employing the differential dieaway technique. Prompt neutrons from interrogating neutron induced fissions are detected providing a measure of the fissile content of the container, i.e., ${ }^{239} \mathrm{Pu},{ }^{241} \mathrm{Pu}$, or ${ }^{235} \mathrm{U}$. While the measurement technique is very sensitive to the presence of fissile material, its accuracy depends on significant corrections to compensate for response effects induced by the matrix material. The CWAM can also operate in the passive neutron mode with a detection efficiency of approximately $14 \%$.

The CWAM design consists of 15 aluminum stand-alone modules that are fastened together to form an assay system with an overall footprint of $180 \mathrm{ft}^{2}$. As in the design of the CTEN drum instrument, the inner assay chamber walls contain graphite in lieu of polyethylene. This graphite wall design extends the neutron slowing-down time allowing detectors to recover from the initial neutron generator burst and 
detect induced fissions created by higher energy epithermal neutrons. This feature was originally incorporated in the CTEN drum system to account for fissile material lumps or dense accumulations of such to provide a basis for self- shielding corrections as epithermal neutrons have a larger mean free path.

The CWAM contains $96{ }^{3} \mathrm{He}$ proportional counters, each $5 \mathrm{ft}$ in length by 2 in. in diameter at 4 atmospheres pressure. The detectors in the four side walls are positioned vertically with the top and bottom detectors oriented to run from the front to back of the chamber. The detectors are packaged into groups of four, each wrapped in a 60 -mil cadmium sheet, for a total of 24 shielded detector packages. The detector packages are installed behind a 6-in. graphite layer and are symmetrically positioned in their respective walls. In addition to the ${ }^{3} \mathrm{He}$ detector packages, there are four ${ }^{4} \mathrm{He}$ detectors mounted on the interior walls of the chamber cavity. These detectors are used to acquire information on the degree of interrogating neutron self-shielding in fissile material such as ${ }^{235} \mathrm{U}$. There are also approximately 10 smaller gas proportional and recoil monitors, some cadmium shielded and some bare, mounted to the interior wall of the chamber cavity. Additionally, there are 12 cadmium collimated flux monitors installed in the floor. This flux monitor set is installed to acquire information to produce corrections for waste matrix bias effects on the assay. The exact number and configuration of this cavity flux monitor set to optimize the quantity and nature of information about the matrix is to be determined.

The neutron generator is mounted on a motorized track to allow generator movement to three different positions during the assay. This is performed to account for nonuniform interrogating flux profiles expected to occur in the large assay chamber. Three cadmium and borated rubber covered detectors are mounted outside the assay chamber for neutron generator output normalization. The CWAM, as currently configured, has no gamma detection component to acquire radionuclidic/isotopic composition. The system will either have to operate in conjunction with such a system or use valid process knowledge.

A signal from each wall installed detector package is routed to a PADEM (preamplifieramplifier-discriminator-ECL-OR module) channel. The ganging of signals from the cavity flux monitors is to be determined during the CWAM response characterization phase. It is expected that the 12 floor mounted flux monitors will be ganged with some segregation among the shielded and bare interior cavity mounted flux monitors. The present plan for ganging the four ${ }^{4} \mathrm{He}$ detectors is to combine them together and route through one PADEM input. Logic signals from the PADEMS are then transmitted to two independent data collection paths, a series of time gated scalers, and LANL-designed PATRMs (pulse arrival time recording module). The scalers provide independent counts for each detector package with limited timing, while the PATRM has superior timing information, but does not distinguish between detector packages.

During the active measurement mode, the scaler mode uses time gated scalers to collect data from detector signals in five separate time regions. The active measurement uses the signals from the 24 shielded ${ }^{3} \mathrm{He}$ detector packages, the internal cavity mounted flux monitors, and the ${ }^{4} \mathrm{He}$ detectors. List mode acquisition is accomplished by routing signals into one of two PATRMs. Neutron arrival times are recorded with increasing time values with a time zero referenced to the neutron generator burst. Timing data are recorded independently for the sum of the 24 shielded wall packages, the floor mounted flux monitors, and cavity wall mounted monitors. The list mode data from the shielded detectors are also used to extract correlations in the neutron signals using the Feynman reduced-variance method.

The approach for determining matrix corrections to be implemented in the CWAM differs from the traditional means of establishing absorber and moderator indices. The CWAM technique focuses on determining a correction for the interrogating flux distribution with a separate correction for the transmission of neutrons from the matrix to the detectors. Hence, all calibration, data acquisition, and reduction methods are oriented to the determination of parameters that result in corrections expressed in 
terms of transmission and interrogating flux profiles. These corrections address matrix effects, as well as source position effects.

4.3.5.3 Calibration. The CWAM calibration procedure uses a technique that incorporates some nontraditional processing steps and does not rely solely on absorber and moderator indices. Part of the impetus of this technique is to attempt to use all acquired data to derive response corrections as a function of matrix and source spatial effects. The first component of this procedure is to acquire response data as a function of chamber cavity source position, thus producing a three-dimensional response map for all detectors. This is performed by incrementing known radioactive sources through an empty B-25 box and B- 25 boxes with various matrix materials spanning as many attributes as possible. This procedure is repeated for three different neutron generator positions. An MCNP model of the CWAM has been constructed to perform this same response characterization process and is benchmarked against actual measurements.

Calibration is based on the acquisition of radioactive material spatial response data over a number of different matrices. The standard matrices were specified to span the expected range of moderator and absorber densities using combinations of hydrogen and boron. Data collected for each calibration configuration include raw data, i.e., net counts from the shielded detector packages in five time windows and timing data for the flux monitors and ${ }^{4} \mathrm{He}$ detectors. Several related quantities are also calculated. These include ratios of detector signals from various positions and from different time windows, Feynman distributions, correlated ratios, and dieaway times. A calibration factor is calculated for each matrix type/source position, relative to the empty waste container. The measured passive transmission is used to separate the transmission and flux related correction factors. A reduced list of variables that have the greatest contribution to the correction factors is determined using the alternating conditional expectation (ACE) algorithm. The main indicators of interest are flux generation and decay, fissile signal transmission, and position of the source material in the waste container. Two parameters most effectively determining flux and transmission correction factors resulted, i.e., the ratio of shielded flux monitors from the epithermal time regions to the bare flux monitor from the thermal region and the normalized drum monitor response from the thermal region. For determining source position, the best indication of source height within the container is the ratio of the shielded detectors in the ceiling to those in the floor.

The determination of the overall matrix effects on the interrogating thermal flux is accomplished through the use of two generalized regression neural networks (GRNN). One neural network takes flux monitor data for determining corrections related to interrogating flux neutrons. The second neural network determines corrections for the transmission of neutrons from the matrix to the system detectors. The first neural network determines position averaged correction factors. The average flux correction factor, position averaged values for the two parameters, and the known flux correction factor are used to train the neural network. The same indicators were used to train the second neural network for the average transmission correction factor using the known transmission correction factor. Thus, for each correction factor, two neural networks were trained independently. The total correction factor is the product of the flux and transmission correction factors applied to the fissile signal to compute the mass of the fissile isotope.

\subsubsection{Rocky Flats Environmental Technology Site Passive/Active Crate Counter (PACC)}

4.3.6.1 Background. The PACC was fabricated by Pajarito Scientific Corporation and installed in Building 569 at the Rocky Flats Plant in 1983. Recently the system has been commissioned to determine whether boxed waste meets Nevada Test Site low-level waste criteria. The system is not used to classify or quantify TRU waste forms, although it is used as a nuclear material accountability system per RFETS safeguards criteria. The system has recently been recalibrated in mid-1998 in preparation to be used to 
assay plywood waste box containers, as well as metal RF80 type and S type TRUPACT II containers for a variety of transuranic contaminated waste streams. The calibration procedure and system performance had to be acceptable to both the Nuclear Materials Safeguards Organization and Waste Operations Organization directives and guidelines at RFETS.

4.3.6.2 System Description. The Building 569 PACC is a standard second-generation differential dieaway NDA system. It contains a combination of graphite and polyethylene moderator in the chamber walls. The detector configuration within the PACC system consists of six banks of polyethylene encased ${ }^{3} \mathrm{He}$ detectors wrapped with cadmium, shielded detectors. Each shielded detector bank contains three $6 \mathrm{ft}$ x 2 -in. diameter detectors for a total of 18 , with a total detection efficiency of $1.2 \%$. The PACC also contains six banks of unshielded, no cadmium wrap, ${ }^{3} \mathrm{He}$ detectors at six detectors per bank totaling 36 detectors with a detection efficiency of $12.8 \%$. The detector tubes run horizontally in all walls except the door where they are mounted vertically. All detector banks are located behind a 4-in. graphite layer with respect to the cavity.

The PACC system contains a $14 \mathrm{MeV}$ pulsed neutron generator mounted in the center of the ceiling of the crate counter cavity for active neutron measurements. A 6 -in. long $\times 1$-in. diameter, 10 atmosphere ${ }^{3} \mathrm{He}$ cavity flux monitor is mounted at the back wall center interface with the top wall. An $18 \mathrm{in}$. $\times 2$-in. diameter cadmium collimated ${ }^{3} \mathrm{He}$ box flux monitor is mounted horizontally at the center of the back wall at the interface with the bottom wall. The collimation is such that the box flux monitor effectively views the center of the waste box. These internal cavity flux monitors are used to acquire matrix absorption values important to the data reduction process. System operation and assay data output is performed using a standard industrial grade Microsoft Windows 95 based computer system in combination with a custom National Instruments Labview-based software package.

The RFETS PACC does not use gamma measurements to determine radionuclidic/isotopic compositions. Such distributions are applied per process knowledge, i.e., weapons grade plutonium.

4.3.6.3 Calibration. Calibration of the RFETS PACC system was accomplished through the use of a set of National Institute of Science and Technology (NIST) traceable distributed plutonium oxide/RTV matrix standards for plutonium loadings ranging up to 305 grams. These radioactive standards were used in conjunction with five different waste matrix surrogate crates to acquire the calibration data. Data from the calibration measurements were used to develop matrix specific active and passive neutron mass calibration curves for IDCs 330 (dry combustibles, IDC 337H (heavy plastics), IDC 374 (blacktop, concrete, soil and sand), IDC 442 (Raschig rings), and IDC 480 (mixed metals).

The calibration procedure is based on a randomized sequence placement of radioactive standards throughout the surrogate waste matrix. Calibration data were acquired by placing the radioactive standards in a total of 20 out of 40 possible locations within the surrogate box. These randomized sequence calibrations were performed using 14 different plutonium mass loadings ranging form 0.102 to 305.2 grams. The randomized sequence location method works by randomizing box tube position, vertical box tube position, and $\mathrm{Pu}$ standard sequence for each $\mathrm{Pu}$ gram loading of the 20 randomized sequence calibration runs. This same nonrepeatable randomized sequence location method was done for each of the $14 \mathrm{Pu}$ gram loadings. Matrix specific calibration curves derived from these data include the overall variability of plutonium spatial position across the calibration range for each matrix specific IDC.

The matrix specific calibration curves are based in the randomized radioactive standard/box surrogate matrix configurations. Observation of historical box assay data indicates that a certain fraction of the absorber and moderator indices range outside those associated with the surrogate matrices. Therefore, the calibration method is further modified such that the calibration functions are more wide ranging in their ability to accommodate matrix attribute variations. This is performed by correlating each 
set of matrix specific average absorber and moderator values with their corresponding average active and passive mass calibration curve slopes. Through this correlation the measured absorber or moderator index can be used to determine an appropriate active or passive mass average slope. Using the selected active or passive slope and either the active shielded totals to flux monitor ratio net rate ratio or passive system net coincidence rate, the plutonium gram loading is then determined. In this manner the active mode absorber index or the passive moderator index forms the basis of the wide ranging mass calibration function. This calibration function covers matrix IDCs from an empty box to the highly absorbing glass IDC. The active mode is preferred for use in determining the plutonium mass as it is a more dynamic function than the passive. In those instances where the absorber index is outside acceptable values, the passive mode of the system is used.

\subsubsection{ANTECH Model 4201 Fission-Fission Neutron Correlation System}

4.3.7.1 Background. The Fission-Fission Neutron Correlation System (FFnCS) was developed for the absolute nondestructive assay of uranium and plutonium. The system provides sufficient sensitivity to segregate alpha contaminated low-level waste from transuranic waste. The technique is in the design phase and is primarily intended for application to drum sized containers, but is expected to be of utility for the smaller sized box. The technique combines both active neutron interrogation with the measurement of total and pair correlated neutrons, as well as conventional passive neutron multiplicity counting. A particularly useful feature of this technique is the minimization of extensive matrix calibration procedures in that the waste matrix configuration is characterized from the measured detection efficiency. Calculated detection limits for the system in a 200 -liter drum at a $100 \mathrm{Kg}$ matrix weight are, 100 micrograms fissile $\mathrm{U}$ and 60 micrograms fissile $\mathrm{Pu}$ for the active mode and $10 \mathrm{mg}^{240} \mathrm{Pu}_{\mathrm{eff}}$ using pair correlation and $300 \mathrm{mg}^{240} \mathrm{Pu}_{\text {eff }}$ using triples correlation in the passive mode.

4.3.7.2 System Description. The system uses both passive and active neutron measurements. The passive mode employs the passive neutron multiplicity counting technique, measuring totals, pairs, and triplets. In the active mode of operation, the FFnCS uses a theoretical model, developed by Dr. W. Hage, to perform active neutron pair correlation analysis. The model is a generalization of the model for the passive neutron assay of plutonium. ${ }^{1-5}$ Using neutron totals and correlated neutron doublets, one is able to perform an absolute assay of fissile plutonium and uranium by determining the induced fission rate.

The system hardware is comprised of a neutron generator and a measurement chamber lined with a neutron moderator to thermalize the interrogating neutron flux. A number of detector banks, consisting of shielded ${ }^{3} \mathrm{He}$ neutron proportional counters, are used to measure the neutrons arising from active mode induced fission reactions. There are several detector modules, each consisting of four 1 -in. ${ }^{3} \mathrm{He}$ detectors ganged into a single charge sensitive amplifier. Each module is cadmium lined and made of high density polyethylene. The ANTECH neutron time correlation analyzer (TCA), using both signal trigger and periodic trigger methods and 16 simultaneous observation intervals (gates), is used to determine both active and passive neutron multiplicity distributions. Active neutron data are also acquired through the use of a multichannel scaler.

4.3.7.3 Calibration. The FFnCS is designed to function as an absolute method for determining both the induced fission rate from plutonium and uranium and the detection probability (detection efficiency) of the detector/waste drum configuration. As the detection probability characterizes the matrix, the method does not require matrix corrections or matrix specific calibration factors under many conditions. It is however to be noted that waste matrix properties that significantly influence the active neutron interrogating flux profile must be accounted for during initial system characterization. Acquisition of interrogating flux profile data is accomplished through the use of flux monitors positioned in the measurement chamber adjacent to the sample. These flux monitors measure the neutron buckling, 
thereby providing an indication of the degree of interrogating flux penetration into the waste matrix. It is required that the response of these flux monitors be normalized as a function of waste matrix

hydrogen/absorber concentration during system commissioning. 


\section{BOXED WASTE ATTRIBUTES AFFECTING NDA SYSTEM PERFORMANCE}

The response and subsequent accuracy of an NDA system is strongly dependent on the aspackaged waste matrix and radioactive material configuration. Furthermore, the waste configuration produces NDA system response perturbations particular to the NDA technique, gamma or neutron, and the configuration of a given system. Waste matrix attributes include the elemental composition, density, the density and elemental composition spatial distribution, and the overall mass and physical dimensions of the waste matrix/container. Radioactive material attributes include the radioactive material isotopic/radionuclidic composition, chemical compound, physical form, e.g., diffuse, clumps, etc., relative ratios of differing radioactive material species, radioactive material mass, and spatial distribution of these parameters. Background sources due to cosmic ray events and radioactive materials in the vicinity of an assay system also affect the sensitivity of certain types of NDA systems.

The boxed waste NDA systems previously discussed all have, to one degree or another, techniques to account for bias and precision elements manifested in the system response by waste and radioactive material attributes. The degree of success of a given response correction is dependent on the NDA system operating principle, the nature of the bias and/or precision variable, and bases for correction techniques. Correction techniques are predicated on certain assumptions concerning the response perturbation variable and are functional through a certain range. To the extent assumptions regarding the variable are applicable, the technique can produce reasonable and defensible response corrections. In the case where the assumptions are not necessarily applicable or the waste configuration contains other variables interfering with the correction technique, an inadequate accounting of bias elements can result.

To ensure the necessary box assay technology capabilities are available for radiological waste characterization, it is desirable to have objective data on system performance over those waste types and associated attributes of interest. Such objective data are difficult to obtain without a comprehensive test and demonstration program that encompasses waste configurations representative of the inventory. An evaluation of this nature is impeded by the fact that many box assay systems are still in the design and fabrication phase and there are limited actual waste measurement data available for analysis. Despite this, there is sufficient knowledge regarding the operating principles of the various NDA techniques, in addition to the availability of measurement data acquired from similar NDA technologies on 55-gallon drum sized containers. In particular, an objective evaluation program for drum sized containers has been conducted yielding information on system performance as a function of waste matrix attributes. A primary source of such data is the MWFA Capability Evaluation Project (CEP) conducted in FY $1998 .^{21}$ Consideration of existing box assay systems, designs, and boxed waste form attributes, in conjunction with CEP data provide a basis for a general determination of box assay capabilities and limitations.

General descriptions of boxed waste assay technology development needs determined from knowledge of waste form characteristics, box assay system design and operating principles, and information derived from the CEP project are provided. The needs are purposely stated in general terms to maintain separation between need and technology holder specific system design.

\subsection{Boxed Waste Assay System Technology Needs}

A review of existing box assay technologies reveals that the same detection fundamentals and analysis techniques commonly applied for NDA of waste forms in the smaller drum sized container are applied to the larger volume box container. Gamma techniques are used to determine the radionuclidic/isotopic composition and in some systems constitutes the basis for the mass estimate. 
Active and passive neutron techniques are used to quantify induced fission signals and spontaneous fission time correlated events.

Although detection techniques being applied to the boxed waste form are the same as for smaller waste containers, the matrix mass and dimensions are not. For most boxed waste MPCs, the primary distinguishing waste form feature relative to drummed waste is indeed the box matrix mass and associated dimensions. The matrix material types resulting from TRU production process are also similar, i.e., combustibles in the drum size container will for the most part have the same elemental composition and density as combustibles packaged in the box type container. There are, however, some boxed waste MPC codes that exhibit matrix compositions and density distributions that are not as likely to be found in the drummed waste inventory. In particular, the S5400 heterogeneous debris MPC, a significant fraction of the inventory, can present a nonuniform mixture of material types that would not be typical of drummed waste codes. The S5400 MPC includes waste that is at least $50 \%$ by volume debris materials that do not meet the criteria for assignment as either inorganic debris S5100 or organic debris S5300. Such a matrix configuration could readily be generated in decommissioning operations where organic debris materials including plastics, paper, and wood at least $50 \%$ by volume would be mixed with metals and soil, e.g., S5440.

The TRU radionuclide distribution characteristics are similar for the majority of waste streams at the INEEL, RFETS, and LLNL sites (see Tables E-1 through E-3). There is a noted departure of the radionuclide inventory distributions from the typical production related TRU composition at ORNL, SRS, and Hanford (see Tables E-4 through E-6). The radionuclide inventory distribution at the ORNL includes a spectrum of radionuclides, in addition to the typical transuranics. SRS also exhibits a number of radionuclides not typically associated with TRU production processes, but rather research and development activities. Hanford possesses typical transuranics, but also includes a number of fission and activation products.

The capability and performance of a given waste NDA technology is a direct function of the waste form attributes. With respect to boxed waste NDA capabilities and limitations, it is instructive to address the impact of the larger boxed waste form mass and dimensions on NDA techniques. For convenience, this discussion is divided into homogeneous and heterogeneous waste form attributes.

\subsubsection{Homogeneous Waste Configurations}

Existing box NDA system designs have reasonable potential to accommodate uniform distributions of radioactive material of constant isotopic/radionuclidic composition in a matrix of uniform density and elemental composition. Measurement techniques and associated calibration methods rely, to one degree or another, on the assumption of uniformity. This uniformity assumption ranges in application from, the entire box, to a given box spatial segment or voxel. In either case, if the radioactive material and matrix is uniform through the region of interest, data acquisition, reduction, and calibration routines are adequate under many circumstances. This statement is applicable only if it is known that the matrix and radioactive material parameters are indeed uniform.

There are of course system limitations even when the radioactive material source and matrix possess uniform characteristics. These are related to matrix properties being outside the certain operational boundaries of the NDA technique. For example, techniques relying on gamma transmission measures to determine matrix corrections will not get statistically significant data if the matrix density exceeds a certain value. Review of the drum CEP project performance data on gamma techniques indicates performance degradation related to matrix densities begins to manifest around $0.6 \mathrm{~g} / \mathrm{cm}^{3}$. Progressive performance degradation continued up to a density of approximately $1.0 \mathrm{~g} / \mathrm{cm}^{3}$ above which system capability was effectively unacceptable for most techniques. Likewise, neutron based systems can 
be limited in acquisition of matrix dependent information if the neutron moderation and/or absorptive properties of the waste exceed a certain values. Hydrogen densities in excess of $0.05 \mathrm{~g} / \mathrm{cm}^{3}(\sim 50 \%$ water by weight) tend to exceed the operational limits of neutron based techniques due to the heavy degree of moderation leading to high neutron attenuation in the matrix. A similar situation occurs when the absorber concentration exceeds a value equivalent to $0.001 \mathrm{~g} / \mathrm{cm}^{3}$ of boron.

There are several MPC categories that exhibit average matrix densities in excess of the previously indicated functional limits. These categories include $\$ 5120$ (inorganic nonmetal debris, $>1,200$ boxes) and $S 4000$ (soil, soil/debris and rock gravel, $>1,700$ boxes). This number of boxes will increase significantly during future decommissioning and deactivation projects. Hence, there is a basis to invest in techniques for radiological characterization of high density matrix boxes.

\subsection{Heterogeneous Waste Configurations}

Although there are some limiting considerations associated with the uniform waste form configurations, heterogeneous or nonuniform configurations present a greater array of capability issues. The MPC categories that represent the majority of the nonuniform waste configurations are $\$ 5100$, S5300, and S5400. Boxed waste matrix and radioactive material configurations, by nature of packaging of routines, infrequently result in uniform radioactive material and matrix configurations. These nonuniformities can result in unacceptable waste NDA system bias. Hence, a primary requirement on boxed waste assay techniques is implementation of a viable means to account for nonuniformities, matrix, and/or radioactive material.

The term nonuniformity applies to all waste matrix and radioactive material parameters. For the waste matrix, nonuniformity concerns the density and elemental composition spatial distributions. For radioactive materials, this includes the spatial distribution of the mass, chemical form, physical form, and isotopic/radionuclidic composition. The term most importantly applies to the convolution of radioactive material with waste matrix nonuniformities. NDA system capabilities with regard to the management of nonuniform configurations is best discussed by considering the various parameters in parts. System response as a function of nonuniform radioactive material distributions, nonuniform isotopic/ radionuclidic composition, and nonuniform matrix density and elemental composition is first bounded. This information is then considered in combination.

\subsubsection{Nonuniform Radioactive Material Spatial Distribution (Constant Isotopic/Radionuclidic Composition)}

Holding the matrix composition, matrix density, and radioactive material isotopic/radionuclidic composition constant and allowing the radioactive material spatial distribution to vary, can result in bias for boxed waste NDA technologies. The indicated boxed waste NDA systems all implement some technique to generate a radioactive material spatial dependent correction factor. In some cases, the base calibration of the system incorporates an averaged spatial response correction. In others, the radioactive material distribution correction is derived from the variable response of multiple detectors. For NDA systems with essentially $4 \pi$ detector coverage, the percent recovery for a point source purposely located in a low detection efficiency zone is on the order of $70 \%$ relative to the response of a uniform distribution in an empty chamber. For systems that do not have a $4 \pi$ type of detector coverage, the percent recovery under like conditions could range several hundred percent. Hence, for $4 \pi$ coverage type systems, the bias due to spatial response dependencies is not necessarily significant under the condition of uniform matrix attributes and could possibly be factored into the total uncertainty determination. For systems with other configurations, a clear means of correcting for spatial dependent bias is necessary. The importance of nonuniform radioactive material spatial distributions will become more apparent when considered in combination with nonuniform matrix distributions. 


\subsubsection{Nonuniform Radioactive Material Isotopic/Radionuclidic Composition}

An unavoidable fact of packaging in large box volumes is that materials from separate processes can be placed in the same box. Even though the matrix material type may be the same, e.g., metals, it is not valid to assume that metals from two different glove boxes, placed in the same box, will have the same radioactive material composition. Because of the widely variable specific activity of the various radionuclides known to be entrained in the waste, significant bias in the final total activity value can occur when variable compositions are neglected. For the box assay systems discussed, there is no definitive technique used to account for varying radionuclidic/isotopic compositions as a function of space in the same box. Some of the techniques homogenize the radionuclidic composition over the box volume or apply the composition measured at spatial locations of high radionuclide concentration. Other systems rely on process knowledge assumptions. Volume averaging of composite gamma spectra can lead to bias if an accounting of the spatial dependent efficiencies is not properly addressed. Additionally, there are relatively few cases where process knowledge can be justified. Presently, none of the systems appear to implement routines to determine the relative contribution of differing radionuclidic/isotopic compositions to the total activity of a given waste box. In light of this, proven techniques to account for this effect are needed.

\subsubsection{Radioactive Material Physical Form}

The physical form of transuranic type radioactive material can range from diffuse atomic distributions to dense accumulations of fine particles to relatively large lumps. Without appropriate techniques to account for the NDA system response dependency as a function of these distributions, bias can occur. The degree of bias is dependent on the NDA technique employed. Passive neutron techniques result in minimal response perturbations due to the physical form of the radioactive material below that level where self-multiplication begins to occur. Gamma based techniques are affected by self-attenuation of signature radiations in the radioactive material. The degree of the bias can span a large range depending on the degree of the accumulation or size of the lump(s). Active neutron techniques are most affected by dense accumulations or lumps as the mean free path of a thermal neutron in $\mathrm{PuO}_{2}$ is on the order of 200 microns. For these reasons, a viable NDA technique must incorporate provisions to detect the presence of radioactive material self-attenuation or self-shielding and apply an appropriate correction. This detection and quantification must accommodate the spatial distribution of the dense accumulations and/or lump(s).

The above discussion applies primarily to radioactive material types and compositions associated with transuranic radionuclides and their production processes. Activation and fission product radionuclides and the spectrum of radionuclides resulting from research and development activities at sites such as Oak Ridge and SRS are typically in a diffuse distribution. Additionally, MLLW and LLW categories, by virtue of their low activities, have a low probability of the presence of dense accumulations or lumps of radioactive material. Hence, it is a general attribute of the non-TRU and low-level waste types that self-shielding and self-attenuation are not relevant sources of bias for NDA systems.

\subsubsection{Nonuniform Matrix Material Density Spatial Distribution}

Holding all the other parameters constant and allowing the matrix density to vary as a function of space can result in unaccounted for bias. Note in the system description section, that most matrix corrections are volume averaged over coarse segments on the order of three to at most seven voxels over the entire box volume. To the degree this is sufficient to account for the bias induced by the spatial effect as a function of the NDA technique needs to be demonstrated. 
For a matrix of a given elemental composition, there is an impact on NDA system response as a function of the matrix spatial density distribution. The density can range from zero (void space) to the theoretical density of the material. For a uniform distribution of radioactive material entrained in a nonuniform distribution of matrix media, a volume averaged matrix correction will lead to a reasonable correction for matrix attenuation of the emitted radiation. For nonuniform radioactive material distributions in a nonuniform matrix density distribution, a volume averaged matrix correction can lead to unacceptable bias. Therefore, it is necessary to implement a method to account for spatial density distributions of matrix media to account for differential radiation attenuation, emitted or interrogating.

The box NDA systems described implement a range of matrix attenuation techniques. Some average the correction over the entire box, whereas others determine spatial dependent matrix corrections on a volume element basis no greater than seven voxels. At this point there does not appear to have been a definitive investigation to determine the optimum voxel size necessary to adequately account for the spatial dependent matrix density bias. Therefore, there is a need to develop techniques to demonstrate that account for bias induced by matrix density nonuniformities.

\subsubsection{Heterogeneous Matrix Material Elemental Composition Spatial Distribution}

Matrix elemental composition spatial nonuniformity represents a source of box assay system bias. As with other interfering parameters, the magnitude of the bias is driven by the nature of the matrix composition and the NDA technique. In general, materials with high hydrogen/absorber concentrations affect neutron based techniques and materials of high atomic number affect gamma based techniques. Accounting of bias introduced by the elemental composition parameter is typically performed through active techniques. Neutron techniques use external neutron sources to assess the perturbation of the matrix composition on macroscopic neutron transport in the media. Most gamma based techniques use external gamma transmission sources to estimate emitted uncollided gamma flux transmission. Data derived from these measures are averaged over voxels ranging in size from the total box volume to smaller voxels with spatial resolution no greater than one-seventh of the box volume. Thus, there is averaging of the elemental composition bias source as a function of space.

Averaging the elemental composition matrix effect will introduce a bias proportional to the heterogeneous nature of the matrix composition. Clearly, the more homogeneous the matrix is, the more realistic the derived matrix correction provided proper initial calibration. As the matrix composition becomes more heterogeneous, there will be a greater deviation from the average matrix perturbation to that of the localized spatial perturbation. One can readily postulate realistic boxed waste elemental composition heterogeneities that would yield a large bias based on volume averaged corrections. For example, MPC 5300 consists of waste that is $80 \%$ by volume, or more, organic debris material, e.g., paper, cloth, plastic, etc. It is therefore acceptable to have a contaminated metal pump housing occupying say, $2 \%$ of the volume. Furthermore, it is plausible that the majority of the activity in the box lines the interior of the metal housing. A gamma based correction factor derived from transmission data acquired over a $33 \%$ volume fraction of the box will predominantly reflect the influence of the low density organic debris. Hence, the gamma attenuation correction applied will be in error for the metal housing.

The above example is specific to a gamma based technique. A similar scenario can be stated, which impacts neutron based techniques where spatial variations in hydrogen and absorber compositions exist. Because significant unaccounted for spatial dependent composition variations can lead to unaccounted for bias, the need for development is indicated. A possible solution is to characterize NDA dependent correction technique sensitivity as a function of variable composition spatial distribution on a voxel size basis. This method would use known matrix spatial composition variations realized through the use of matrix surrogates to establish bias correction over a realistic range of composition variations. These data would form a basis for development of techniques to properly address this bias source. The 
goal would be to essentially map the matrix composition bias distribution on an appropriately determined spatial or voxel size basis. The matrix surrogates could also be used to demonstrate the viability of the resulting technique.

\subsubsection{Combined Radioactive Material and Matrix Nonuniformities}

A given actual waste container configuration consists of radioactive materials entrained in a waste matrix. Most configurations in the boxed waste inventory will be heterogeneous in these parameters. There is no basis for an assumption of a uniform spatial distribution of the radioactive material attributes, mass, and/or radionuclidic/isotopic composition. For most of the MPC categories, there is likewise no basis for an assumption of uniform matrix attributes, i.e., density and elemental composition. In fact, based on a survey of the boxed waste inventory MPC categories and associated physical properties, nonuniformities in terms of radioactive material and waste matrix parameter distributions are the norm. This is noted in Tables C-1 through C-6, where the majority of boxes fall into MPC categories, S5110 (metal debris), S5300 (organic debris), and S5400 (heterogeneous debris). In terms of nondestructive waste assay systems and techniques, the nonuniform characteristics of the inventory waste forms constitute the primary concern when considering the capability of such systems.

As previously discussed, uniform distributions of the various matrix and radioactive material parameters are under many conditions within the capability of existing box assay designs/systems. This is provided it is known that the condition of uniformity exists and that adequate calibrations and data acquisition/reduction routines have been implemented. It has not been conclusively demonstrated that this is the case for unknown heterogeneous spatial distributions of the radioactive material and matrix parameters. In particular, a nonuniform matrix spatial distribution in terms of density and elemental composition, combined with a nonuniform radioactive material mass distribution can complicate NDA system measurement interpretation. There must be appropriate NDA system measures of sufficient dynamic range to account for the nonuniformity based bias sources manifested in the system response. For most of the NDA systems discussed there are techniques intended to address radioactive material nonuniform spatial distributions. These range from volume averaged calibrations to spatial dependent efficiency corrections on a voxel basis. For the majority of the box assay systems, these techniques yield reasonable corrections for the spatial dependent response in a uniform, relatively noninterfering matrix. When the matrix is also spatially nonuniform with respect to density and elemental composition, a matrix correction on a spatial basis must be determined and applied to the spatially dependent radioactive material distribution. As has been indicated, the box NDA techniques provide matrix spatial corrections on coarse voxels ranging from the entire box volume to at most seven voxels. Even at seven voxels, this is not of sufficient resolution to properly account for the bias that can result from nonuniform waste configurations.

As noted, a significant fraction of the boxed waste inventory is comprised of MPCs S5100, S5300, and S5400 debris wastes, metal, organic and heterogeneous debris, respectively. These MPCs are heterogeneous in terms of the elemental composition and density distribution within a single box container. With respect to NDA techniques, the metal debris will represent more of a complication to gamma systems and the organic debris will represent more of a problem to neutron techniques. These waste configurations will, in general, have nonuniform spatial distributions of radioactive material that necessitates spatial dependent matrix and radioactive material corrections. For example, it can readily be postulated that a metal debris box would contain a variety of scrap metals that are relatively noncontaminated and a dense metal component such as an electric motor that is highly contaminated. Relative to a volume average matrix correction, the highly contaminated electric motor would present a localized highly attenuating item containing the majority of the radioactive material. Without an accounting of this localized radiation signal loss, the volume averaged matrix correction would underestimate the actual radioactive material mass. Techniques must be implemented to account for this 
type of bias source. Such techniques must necessarily be founded in a study of the optimum voxel size for spatial localization of matrix properties and radioactive material mass. This effort would be readily supported through the use of box matrix surrogates. The matrix surrogate designs allow matrix type volume element resolution on the order of $1 \mathrm{ft}^{3}$. Smaller resolutions can be realized through relative inexpensive production of additional smaller matrix modules used to configure a given surrogate. 


\section{CONCLUSIONS}

The following is a tabulation of general deficiencies concluded from the discussion of box NDA system designs for low-level and alpha contaminated waste forms. In all cases, techniques to resolve identified issues must be technically defensible and sufficiently accurate to ensure compliance with applicable CAO Program and Low-Level disposal site quality assurance objectives and requirements.

\subsection{High Density Matrices}

The uniform matrix/radioactive material configuration is for the most part the ideal configuration relative to minimal NDA system response complications. Nonetheless, there are NDA system limitations associated with the uniform configuration. High densities of virtually any material can exceed the operational limits of NDA techniques. For neutron systems, this primarily concerns high hydrogen and absorber concentrations. High concentrations of these materials can lead to situations where the emitted neutron rate from certain voxels goes to zero. Likewise, the active mode interrogating neutron flux profile may have many locations where it is statistically invalid. For gamma techniques, the high atomic weight elements can reach packaging densities well in excess of $1.0 \mathrm{~g} / \mathrm{cm}^{3}$, Tables D-3 through D-9, where matrix corrections become statistically invalid and emitted signature radiation uncollided flux escape fraction approaches zero for one or more box voxels. Techniques are required to address NDA of such high density matrices.

\subsection{Matrix Heterogeneities}

It is not apparent that sufficient technology development has been directed at the accommodation of matrix heterogeneities in terms of elemental composition, density, and spatial distribution within a given boxed waste package. Demonstration of techniques is needed to validate the ability to accurately account for bias elements introduced via matrix heterogeneities when convoluted with the distribution and mass loading of radioactive constituents. Of particular importance is high hydrogen/moderator and absorber density spatial distribution for neutron technologies and high density matrix distributions for gamma based techniques.

\subsection{Variable Radionuclidic/lsotopic Compositions Per Box Container}

The determination of radionuclidic/isotopic composition information on a spatial basis for lowlevel and alpha contaminated waste forms does not appear to be sufficiently developed. In many instances there is no means to validate the assumption that the relative magnitudes of radionuclides common to the DOE inventory, i.e., $\mathrm{U}, \mathrm{Pu}, \mathrm{Am}, \mathrm{Np}, \mathrm{Cm}, \mathrm{Cs}, \mathrm{Co}$, etc., are known on a box basis. Techniques are needed to account for variable radionuclidic/isotopic compositions within a given box. The technique must be viable over the spectrum of waste form configurations the indicated radionuclides are entrained in.

\subsection{Radioactive Material Physical Form}

Techniques are required to accurately account for bias induced by the physical form and geometrical distribution of radioactive materials entrained in box sized containers. It is of particular interest that the technique accommodate bias introduced by large accumulations or clumps of radioactive material. 


\subsection{Calibration Techniques}

The majority of viable NDA techniques rely heavily on resource intensive matrix dependent calibrations. Methods are needed to reduce this dependence on the use of direct calibration or standards compensated approaches. Techniques yielding direct measurement of matrix/radioactive material induced NDA system response parameters on a per container configuration are desired versus indirect correlations with known standards.

\subsubsection{Summary}

The indicated deficiencies arise from the differing waste type attributes and configurations in inventory and the capability/limitations of the various NDA techniques. Hence, the utility of an NDA technique and development efforts to address the deficiency set, are a function of the waste type and configuration. This in turn requires NDA techniques to be matched in terms of prevalent attributes and configurations of the waste type of interest. For example, techniques to enhance the capability of the passive neutron modality to effectively manage matrix variabilities would be applicable to waste forms containing known spontaneous fissioning species. Conversely, such a system would be of little value for waste streams containing radionuclides that have no passive neutron emission, e.g., Oak Ridge Y-12 uranium wastes. Likewise, gamma based techniques developed to accommodate transuranic quantification in low density matrices will not necessarily be able to accommodate waste streams with high densities and multiple radionuclides such as those known to exist at SRS and Hanford. The issue therefore appears to one of how to effectively allocate resources on a waste form/NDA system type basis to address the set of deficiencies.

Considering the issue of the appropriate means to manage the deficiencies, which are waste form and NDA technique dependent, two approaches are apparent. The first approach would be to match the appropriate NDA system design on a target waste type basis. This would make for a multifaceted development project involving a number of different NDA systems specified to maximize their utility per specified waste type(s). Alternatively, it is possible to specify a single system that incorporates all fundamental NDA modalities, gamma, active and passive neutron, such that it has the potential to characterize the majority of waste configurations. 


\section{RECOMMENDATIONS}

Based on the review of the box waste inventory characteristics and existing boxed waste NDA technologies, a number of deficiencies have been noted. These deficiencies are quoted in terms of waste configuration parameters, e.g., nonuniform matrix spatial distribution, with the exception of the calibration technique need. The deficiencies are itemized in the conclusions section.

In consideration of the two primary approaches for addressing the deficiency set over the spectrum of waste forms and NDA techniques, it is recommended that an innovative box assay system design that accommodates the majority of the waste inventory be pursued. A system of this nature would be most versatile and generally applicable in a modular configuration with respect to the NDA modalities. This modular approach would be implemented as a function of the waste form and its attributes. An integrated system configuration would also promote the development of technique/data fusion yielding an enhanced ability to detect and accommodate bias sources. Furthermore, this approach is deemed more economically feasible as compared to the implementation of multiple separate development projects at different facilities, each addressing only those deficiencies related to specific NDA techniques.

To produce a broadly applicable box assay system capable of resolving the listed deficiencies, it is recommended that a technology development and demonstration project be implemented. This project is to include several phases as itemized below:

- Describe and bound the technology deficiency set for consideration by technology holders and solicit proposals.

- Perform a technical review of contributed proposals regarding development of techniques to address the deficiency set within the context of an integrated multimodality system.

- The proposal with the greatest potential for accommodating the various deficiency items over the indicated waste types should be selected and a development strategy identified. Included in the strategy is an analysis of the waste form dependent limits of the NDA technology. This allows consideration of alternate methods to accommodate those waste configurations outside the realm of NDA methods.

- $\quad$ Provide technical oversight on development activities to ensure needs are addressed in an orderly fashion.

- Implement a demonstration phase using realistic waste configurations to evaluate the utility of the developed techniques to accommodate indicated deficiencies.

It is to be noted that of the two major waste form properties, waste matrix configuration and radioactive material attributes, that over half of the deficiencies are related to the waste matrix properties. Development and demonstration activities will therefore require the availability of known, welldocumented boxed waste matrix standards or surrogates. The boxed waste matrix configurations representing complications associated with the deficiency items must be reproducible in these surrogates. The developer can then devise and develop techniques relying on data derived from the known matrix configurations. The same box matrix surrogates, appropriately configured, can then be used in the demonstration phase of the project to assess the utility of developed technology. Radioactive standards must also be available to the development and demonstration process to replicate those complicating configurations of interest. These standards will be used in conjunction with the box matrix surrogates to produce desired waste form configurations. It is therefore also recommended that boxed waste surrogate specification, design, and fabrication activities be maintained at a level commensurate with the needs of the box assay development program. 


\section{REFERENCES}

1. Waste Acceptance Criteria for the Waste Isolation Pilot Plant, Revision 5, DOE/WIPP-069, April 1996.

2. National Transuranic Program Quality Assurance Program Plan, Section 9.0, Revision Interim Change, November 11, 1996.

3. Nevada Test Site, Waste Acceptance Criteria, NTDWAC, September 1996.

4. Utah Department of Environmental Quality Division of Radiation Control, Radioactive Material License, DCR-03-8/89, August 1989.

5. Waste Acceptance Criteria, Scientific Ecology Groups, Inc., OP-4.35, April 1994.

6. Radioactive Waste Management Complex Transuranic Waste Inventory, Engineering Design File, RWMC-EDF-837, INEL-95/194, August 1995.

7. Radiological, Physical, and Chemical Characteristics of Low-Level Alpha Contaminated Wastes Stored at the Idaho National Engineering Laboratory, Appendix A and B, INEL-95/0412, December 1995.

8. Unpublished data related to Hanford Site boxed waste inventory provided by F. Cooney of Waste Management Hanford.

9. Unpublished data related to Lawrence Livermore National Laboratory Transuranic and MLLW box inventory provided by Kem Hainebach.

10. Unpublished data related to Oak Ridge Site boxed waste inventory provided by Jeff Gilpin.

11. E-14 Waste Inventory Database, Savannah River Site, unpublished data provided by Stephen Gould.

12. Unpublished data related to Rocky Flats Environmental Remediation Site provided by K. Ricks of Wastren, Inc, Westminster, CO.

13. Integrated Data Base Report - 1996: U. S. Spent Nuclear Fuel and Radioactive Waste Inventories, Projections and Characteristics, Revision 13, December 1997.

14. Solid Waste Integrated Forecast Technical Report FY 1998 to FY 2046, Hanford Environmental Remediation Site (98.1), May 19. 1998.

15. ISOCS Efficiency Calibration, Validation and Internal Consistency Document, ISOX-VIC 4/98, 9231205A V1.2b., Canberra Industries, Inc., Meriden, CT.

16. Nondestructive Assay of Uranium-Contaminated Wastes Packaged in B25 Boxes, T.L. Tucker (Lockheed Martin Energy Systems) and J.A. Chapman (Lockheed Martin Energy Research), American Nuclear Society Transactions, Volume 78, TANSAO 78 1-194 (1998), ISSN: 0003-018X. 
17. The Building K-1423 Nondestructive Assay Facility for Measurement of Waste Stored at the Oak Ridge K-25 Site, R.L. Mayer II, R.C. Hagenauer, J.F. Harris, Technical Division, Martin Marietta Energy Systems, Inc., NDA93-118, September 1993.

18. Nondestructive Assay Quantification of Poorly Characterized Radioactive Isotopes, R.C. Hagenauer, Lockheed Martin Energy Systems, Inc., Oak Ridge K-25 Site, Oak Ridge, TN and R.L. Mayer II Lockheed Martin Utility Services, Inc. Portsmouth Gaseous Diffusion Plant, Piketon, $\mathrm{OH}$, Proceedings of the 4th Nondestructive Assay and Nondestructive Examination Waste Characterization Conference, October 24-26, 1995, CONF-951091, Lockheed Martin Idaho Technologies Company.

19. Personal communication with R.D. McElroy, Canberra Industries, Inc., Meriden, CT.

20 NUCS--A Nonuniformity Correction Algorithm for SGS/IQ3 Gamma-Ray Drum Scanners, B.M. Young, T.D. Anderson, et. al., Canberra Industries, Inc., Meriden, CT, Proceedings of the $6^{\text {th }}$ Nondestructive Assay Waste Characterization Conference, November 17-19, 1998, CONF-981105, Lockheed Martin Idaho Technologies Company.

21. Mixed Waste Focus Area/Characterization Monitoring Sensor Technology Nondestructive Waste Assay Capability Evaluation Project - End-User Summary Report, G.K. Becker, M.E. Mcllwain and M.J. Connolly, Lockheed Martin Idaho Technologies Company, INEEL/EXT-98-01108, November 1998. 
Appendix A

Waste Acceptance Criteria 
Table A-1. WIPP CH-TRU waste acceptance criteria.

\begin{tabular}{|c|c|}
\hline Criteria & Requirement/Limit \\
\hline Container Description & $\begin{array}{l}\text { DOT type 55-gallon drums } \\
\text { standard waste box (SWB) }\end{array}$ \\
\hline Container/Assembly Weight & $\begin{array}{l}\leq 1,000 \mathrm{lb} / 55 \text {-gallon drum } \\
\leq 4,000 \mathrm{lb} / \mathrm{SWB} \\
\leq \text { TRUPACT-II Weight Limits }\end{array}$ \\
\hline Removable Surface Contamination & $\begin{array}{l}\leq 20 \mathrm{dpm} / 100 \mathrm{~cm}^{2} \text { alpha } \\
\leq 200 \mathrm{dpm} / 100 \mathrm{~cm}^{2} \text { beta-gamma }\end{array}$ \\
\hline Container Marking & $\begin{array}{l}\text { Bar code } \\
\text { Shipping category }\end{array}$ \\
\hline Dunnage & Empty 55-gallon drums or empty SWB \\
\hline Filter Vents & Payload containers vented \\
\hline Liquids & $\begin{array}{l}\text { No liquid wastes } \\
<2 \text { liters total residual liquid per 55-gallon } \\
\text { drum } \\
<8 \text { liters per SWB } \\
<1 \text { in. in bottom of any container }\end{array}$ \\
\hline \multicolumn{2}{|l|}{ NUCLEAR PROPERTIES } \\
\hline $\begin{array}{l}\text { Nuclear Critically } \\
\text { (Pu-239 FGE) }\end{array}$ & $\begin{array}{l}<200 \mathrm{~g} / 55 \text {-gallon drum } \\
<325 \mathrm{~g} / \mathrm{SWB} \\
\text { TRUPACT-II Limits }\end{array}$ \\
\hline $\begin{array}{l}\text { Pu-239 Equivalent Activity } \\
\text { PE-Ci }\end{array}$ & $\begin{array}{l}\leq 80 \mathrm{PE}-\mathrm{Ci} / 55 \text {-gallon drum } \\
\leq 130 \mathrm{PE}-\mathrm{Ci} / \mathrm{SWB} \\
\leq 1,800 \mathrm{PE}-\mathrm{Ci} / 55 \text {-gallon drum overpacked in } \\
\text { SWB or TDOP } \\
\frac{\text { Treated Waste }}{\leq 1,800 \mathrm{PE}-\mathrm{Ci} / 55 \text {-gallon drum }}\end{array}$ \\
\hline Contact Dose Rate & $\leq 200 \mathrm{mrem} / \mathrm{hr}$ \\
\hline Thermal Power & $\begin{array}{l}\text { Reported if }>0.1 \text { watts } / \mathrm{ft}^{3} \\
<40 \text { watts per TRUPACT-II }\end{array}$ \\
\hline TRU Alpha Activity & $>\_100 \mathrm{nCi} / \mathrm{g}$ of waste matrix \\
\hline \multicolumn{2}{|l|}{ Chemical Properties } \\
\hline Pyrophoric Materials & $\begin{array}{l}<1 \% \text { radionuclide pyrophorics } \\
\text { No nonradionuclide pyrophorics }\end{array}$ \\
\hline Mixed Waste & $\begin{array}{l}\text { Characterization per QAPP } \\
\text { Limited to EPA Waste Codes }\end{array}$ \\
\hline
\end{tabular}


Table A-1. (continued)

\begin{tabular}{|c|c|}
\hline Criteria & Requirement/Limit \\
\hline Chemical Compatibility & $\begin{array}{l}\text { All chemicals must be allowable per the } \mathrm{CH}- \\
\text { TRAMPAC }\end{array}$ \\
\hline Hazardous Constituents & $\begin{array}{l}\text { Target analytes and TICs to be reported per the } \\
\text { QAPP }\end{array}$ \\
\hline Explosives, Corrosives and Compressed Gases & $\begin{array}{l}\text { No compressed gases } \\
\text { No ignitable, reactive or corrosive wastes }\end{array}$ \\
\hline PCB Concentration & $<50$ ppm \\
\hline \multicolumn{2}{|l|}{ Gas Generation } \\
\hline Decay Heat & $\leq$ Wattages listed in $\mathrm{CH}-\mathrm{TRUCON}$ \\
\hline Flammable VOCs & $\leq 500 \mathrm{ppm}$ in container headspace \\
\hline VOC Concentration & $\leq$ Limits shown in table \\
\hline Aspiration & $\geq$ Times shown in CH-TRUCON tables \\
\hline Shipping Category & $\begin{array}{l}\text { Content codes listed in CH-TRUCON tables; } \\
\text { and one category per TRUPACT-II }\end{array}$ \\
\hline Confinement Layers & $\begin{array}{l}\text { Liner punctured/vented } \\
\text { Number of layers known } \\
\text { Bags closed by approved methods } \\
\text { Sealed containers }>4 \text { liters prohibited (except } \\
\text { for waste material Type II. } 2\end{array}$ \\
\hline \multicolumn{2}{|l|}{ Data } \\
\hline Acceptance Data & $\begin{array}{l}\text { Auditable package of data with signed } \\
\text { Certification Statement on file } \\
\text { WWIS data transmitted }\end{array}$ \\
\hline RCRA Data & $\begin{array}{l}\text { Waste Stream Profile Form } \\
\text { Uniform Hazardous Waste Manifest } \\
\text { Land Disposal Restriction notification }\end{array}$ \\
\hline Shipping Data & $\begin{array}{l}\text { TRUPACT-II Payload Container } \\
\text { Transportation Certification Documents } \\
\text { Bill of Lading }\end{array}$ \\
\hline
\end{tabular}


Table A-2. WIPP transuranic waste quality assurance objectives for nondestructive assay.

\begin{tabular}{|c|c|c|c|c|}
\hline $\begin{array}{c}\text { Waste Activity } \\
\text { alpha-Ci range }\end{array}$ & $\begin{array}{c}\text { Nominal } \\
\text { Compliance Point, } \\
\text { alpha-Ci (g WG Pu) }\end{array}$ & $\begin{array}{c}\text { Precision } \\
(\% \mathrm{RSD})\end{array}$ & $\begin{array}{c}\text { Accuracy } \\
(\% \mathrm{R})\end{array}$ & $\begin{array}{c}\text { Total Bias } \\
(\%)\end{array}$ \\
\hline$>0.002-0.02$ & $0.008(0.1)$ & $<20$ & $75-125$ & $\begin{array}{c}\text { low } 25 \\
\text { high } 400\end{array}$ \\
\hline$>0.02-0.2$ & $0.08(1.0)$ & $<15$ & $50-150$ & $\begin{array}{c}\text { low } 35 \\
\text { high } 300\end{array}$ \\
\hline$>0.2-2.0$ & $0.8(10)$ & $<10$ & $75-125$ & $\begin{array}{c}\text { low } 67 \\
\text { high } 150\end{array}$ \\
\hline$>2.0$ & $12.5(160)$ & $<5$ & $75-125$ & $\begin{array}{c}\text { low } 67 \\
\text { high } 150\end{array}$ \\
\hline
\end{tabular}

Nevada Test Site Low-Level Waste Acceptance Criteria

Transuranics

The concentration of alpha-emitting transuranic nuclides with half-lives greater than 20 years must not exceed $100 \mathrm{nCi} / \mathrm{g}$. The net weight of the waste (excluding the weight of the container and shielding) must be used to calculate the specific activity of the waste in each container. The following isotopes shall be considered when making the TRU waste determination: ${ }^{236} \mathrm{~Np},{ }^{237} \mathrm{~Np},{ }^{238} \mathrm{Pu},{ }^{239} \mathrm{Pu},{ }^{240} \mathrm{Pu},{ }^{241} \mathrm{Pu},{ }^{242} \mathrm{Pu}$, ${ }^{244} \mathrm{Pu},{ }^{241} \mathrm{Am},{ }^{242} \mathrm{Am},{ }^{243} \mathrm{Am},{ }^{243} \mathrm{Cm},{ }^{245} \mathrm{Cm},{ }^{246} \mathrm{Cm},{ }^{247} \mathrm{Cm},{ }^{248} \mathrm{Cm},{ }^{250} \mathrm{Cm},{ }^{247} \mathrm{Bk},{ }^{249} \mathrm{Cf}$, and ${ }^{251} \mathrm{Cf}$.

Waste Types

Waste form criteria are based on current DOE LLW management policies and practices.

Container Types

$1.2 \times 1.2 \times 2.1-\mathrm{m}(4 \times 4 \times 7-\mathrm{ft})$ or $1.2 \times 0.6 \times 2.1-\mathrm{m}(4 \times 2 \times 7-\mathrm{ft})$ boxes or 208 liter (55-gallon) drums should be used. Sealand containers are accepted on a case-by-case basis.

Bulk waste generally exists in a form not suited to the conventional packaging requirement. Bulk LLW must meet the requirements of Title 49 CFR. Large items of bulk waste, such as machinery, may be considered for disposal unpackaged.

In addition to the weight limits for specific packaging designs, packages shall not exceed $4,082 \mathrm{~kg}$ $(9,000 \mathrm{lb})$ per box and $544 \mathrm{~kg}(1,200 \mathrm{lb})$ per drum.

\section{Characterization}

Generators shall characterize waste with sufficient accuracy to permit proper segregation, treatment, storage, and disposal. The characterization methods and procedures employed by the generator shall ensure that the physical, chemical, and radiological characteristics of the waste are recorded and known during all stages of the waste management process. Characterization methods should undergo a peer review by appropriate expertise. 
Table A-3. Envirocare maximum radioactive isotope concentrations.

\begin{tabular}{ll} 
Radioactive Material & Maximum Concentration \\
\hline Americium-241 & $2.3 \mathrm{E} 03 \mathrm{pCi} / \mathrm{g}$ \\
Americium-243 & $1.7 \mathrm{E} 03 \mathrm{pCi} / \mathrm{g}$ \\
Antimony-124 & $7.9 \mathrm{E} 02 \mathrm{pCi} / \mathrm{g}$ \\
Antimony-125 & $5.3 \mathrm{E} 03 \mathrm{pCi} / \mathrm{g}$ \\
Barium-133 & $4.0 \mathrm{E} 03 \mathrm{pCi} / \mathrm{g}$ \\
Beryllium-7 & $3.8 \mathrm{E} 04 \mathrm{pCi} / \mathrm{g}$ \\
Cadmium-109 & $4.6 \mathrm{E} 04 \mathrm{pCi} / \mathrm{g}$ \\
Calcium-45 & $4.0 \mathrm{E} 04 \mathrm{pCi} / \mathrm{g}$ \\
Carbon-14 & $2.0 \mathrm{E} 05 \mathrm{pCi} / \mathrm{g}$ \\
Cerium-139 & $2.0 \mathrm{E} 03 \mathrm{pC} / \mathrm{g}$ \\
Cerium-141 & $4.0 \mathrm{E} 03 \mathrm{pCi} / \mathrm{g}$ \\
Cerium-144 & $4.0 \mathrm{E} 03 \mathrm{pCi} / \mathrm{g}$ \\
Cesium-134 & $1.2 \mathrm{E} 03 \mathrm{pCi} / \mathrm{g}$ \\
Cesium-135 & $5.0 \mathrm{E} 02 \mathrm{pCi} / \mathrm{g}$ \\
Cesium-137 & $5.6 \mathrm{E} 02 \mathrm{pCi} / \mathrm{g}$ \\
Chromium-51 & $6.8 \mathrm{E} 04 \mathrm{pCi} / \mathrm{g}$ \\
Cobalt-56 & $3.6 \mathrm{E} 02 \mathrm{pCi} / \mathrm{g}$ \\
Cobalt-57 & $1.9 \mathrm{E} 04 \mathrm{pCi} / \mathrm{g}$ \\
Cobalt-58 & $1.6 \mathrm{E} 03 \mathrm{pCi} / \mathrm{g}$ \\
Cobalt-60 & $3.6 \mathrm{E} 02 \mathrm{pCi} / \mathrm{g}$ \\
Copper-67 & $2.0 \mathrm{E} 03 \mathrm{pCi} / \mathrm{g}$ \\
Curium-242 & $1.0 \mathrm{E} 03 \mathrm{pCi} / \mathrm{g}$ \\
Curium-243 & $1.5 \mathrm{E} 03 \mathrm{pCi} / \mathrm{g}$ \\
Curium-244 & $1.0 \mathrm{E} 03 \mathrm{pCi} / \mathrm{g}$ \\
Europium-152 & $1.7 \mathrm{E} 03 \mathrm{pCi} / \mathrm{g}$ \\
Europium-154 & $1.4 \mathrm{E} 03 \mathrm{pCi} / \mathrm{g}$ \\
Europium-155 & $1.7 \mathrm{E} 03 \mathrm{pCi} / \mathrm{g}$ \\
Gadolinium-153 & $3.0 \mathrm{E} 03 \mathrm{pCi} / \mathrm{g}$ \\
Gold-195 & $2.0 \mathrm{E} 03 \mathrm{pCi} / \mathrm{g}$ \\
Hafnium-181 & $1.0 \mathrm{E} 03 \mathrm{pCi} / \mathrm{g}$ \\
Hydrogen-3 & $2.0 \mathrm{E} 05 \mathrm{pCi} / \mathrm{g}$ \\
Iodine-125 & $1.5 \mathrm{E} 03 \mathrm{pCi} / \mathrm{g}$ \\
Iodine-129 & $3.1 \mathrm{E} 02 \mathrm{pCi} / \mathrm{g}$ \\
Iridium-192 & $2.5 \mathrm{E} 03 \mathrm{pCi} / \mathrm{g}$ \\
Iron-55 & $2.0 \mathrm{E} 04 \mathrm{pCi} / \mathrm{g}$ \\
Lead-210 & $4.0 \mathrm{E} 02 \mathrm{pCi} / \mathrm{g}$ \\
& $2.0 \mathrm{E} 04 \mathrm{pCi} / \mathrm{g}$ \\
& \\
\hline
\end{tabular}


Table A-3. (continued)

\begin{tabular}{|c|c|}
\hline Radioactive Material & Maximum Concentration \\
\hline Manganese-54 & $5.6 \mathrm{E} 03 \mathrm{pCi} / \mathrm{g}$ \\
\hline Mercury-203 & $1.0 \mathrm{E} 04 \mathrm{pCi} / \mathrm{g}$ \\
\hline Neptumium-237 & $2.0 \mathrm{E} 03 \mathrm{pCi} / \mathrm{g}$ \\
\hline Nickel-59 & $7.0 \mathrm{E} 02 \mathrm{pCi} / \mathrm{g}$ \\
\hline Nickel-63 & $1.0 \mathrm{E} 04 \mathrm{pCi} / \mathrm{g}$ \\
\hline Niobium-94 & $1.6 \mathrm{E} 02 \mathrm{pCi} / \mathrm{g}$ \\
\hline Plutonium-238 & $1.0 \mathrm{E} 03 \mathrm{pCi} / \mathrm{g}$ \\
\hline Plutonium-239 & $1.0 \mathrm{E} 03 \mathrm{pCi} / \mathrm{g}$ \\
\hline Plutonium-240 & $1.0 \mathrm{E} 03 \mathrm{pCi} / \mathrm{g}$ \\
\hline Plutonium-241 & $1.0 \mathrm{E} 03 \mathrm{pCi} / \mathrm{g}$ \\
\hline Plutonium-242 & $1.0 \mathrm{E} 03 \mathrm{pCi} / \mathrm{g}$ \\
\hline Polonium-210 & $2.0 \mathrm{E} 04 \mathrm{pCi} / \mathrm{g}$ \\
\hline Potassium- 40 & 1.0E03 pCi/g \\
\hline Promethium-147 & $4.0 \mathrm{E} 03 \mathrm{pCi} / \mathrm{g}$ \\
\hline Radium-226 & $2.0 \mathrm{E} 03 \mathrm{pCi} / \mathrm{g}$ \\
\hline Radium-228 & $1.8 \mathrm{E} 03 \mathrm{pCi} / \mathrm{g}$ \\
\hline Radium-228 (1 year) & $1.2 \mathrm{E} 03 \mathrm{pCi} / \mathrm{g}$ \\
\hline Radium-228 (5 years) & 6.7E02 pCi/g \\
\hline Radium-228 (10 years) & $5.6 \mathrm{E} 02 \mathrm{pCi} / \mathrm{g}$ \\
\hline Rubidium-83 & $1.0 \mathrm{E} 03 \mathrm{pCi} / \mathrm{g}$ \\
\hline Ruthenium-106 & $1.9 \mathrm{E} 04 \mathrm{pCi} / \mathrm{g}$ \\
\hline Scandium-46 & 4.0E02 $\mathrm{pCi} / \mathrm{g}$ \\
\hline Selenium-75 & $1.0 \mathrm{E} 03 \mathrm{pCi} / \mathrm{g}$ \\
\hline Silver-108m & $5.0 \mathrm{E} 02 \mathrm{pCi} / \mathrm{g}$ \\
\hline Silver $-110 \mathrm{~m}$ & $5.6 \mathrm{E} 02 \mathrm{pCi} / \mathrm{g}$ \\
\hline Sodium-22 & 7.8E02 pCi/g \\
\hline Strontium-85 & $5.9 \mathrm{E} 02 \mathrm{pCi} / \mathrm{g}$ \\
\hline Strontium-89 & $2.0 \mathrm{E} 03 \mathrm{pCi} / \mathrm{g}$ \\
\hline Strontium-90 & $2.0 \mathrm{E} 04 \mathrm{pCi} / \mathrm{g}$ \\
\hline Sulfur-35 & 4.0E03 pCi/g \\
\hline Technetium-90 & $1.0 \mathrm{E} 04 \mathrm{pCi} / \mathrm{g}$ \\
\hline Thorium-230 & $1.5 \mathrm{E} 04 \mathrm{pCi} / \mathrm{g}$ \\
\hline Thorium-232 & $6.8 \mathrm{E} 02 \mathrm{pCi} / \mathrm{g}$ \\
\hline Tin-113 & $1.0 \mathrm{E} 04 \mathrm{pCi} / \mathrm{g}$ \\
\hline Uranium-234 & 3.7E04 pCi/g \\
\hline Uranium-235 & 7.7E02 pCi/g \\
\hline Uranium-236 & $3.6 \mathrm{E} 04 \mathrm{pCi} / \mathrm{g}$ \\
\hline
\end{tabular}


Table A-3. (continued)

\begin{tabular}{ll}
\hline Radioactive Material & Maximum Concentration \\
\hline Uranium-238 & $2.8 \mathrm{E} 04 \mathrm{pCi} / \mathrm{g}$ \\
Uranium-natural & $1.8 \mathrm{E} 04 \mathrm{pCi} / \mathrm{g}$ \\
Uranium-depleted & $1.1 \mathrm{E} 05 \mathrm{pCi} / \mathrm{g}$ \\
Yttrium-88 & $3.0 \mathrm{E} 02 \mathrm{pCi} / \mathrm{g}$ \\
Zinc-65 & $1.1 \mathrm{E} 04 \mathrm{pCi} / \mathrm{g}$ \\
Zirconium-95 & $5.0 \mathrm{E} 02 \mathrm{pCi} / \mathrm{g}$ \\
Bismuth-207 & $4.0 \mathrm{E} 02 \mathrm{pCi} / \mathrm{g}$ \\
Samarium-151 & $1.0 \mathrm{E} 03 \mathrm{pCi} / \mathrm{g}$ \\
Tantalum-182 & $5.0 \mathrm{E} 02 \mathrm{pCi} / \mathrm{g}$ \\
Thallium-204 & $1.0 \mathrm{E} 03 \mathrm{pCi} / \mathrm{g}$ \\
\hline
\end{tabular}

GTS Durotech (formerly SEG) - General Acceptance Criteria

All waste should be package in steel or poly outer containers that are authorized for the transportation of radioactive material in accordance with U.S. Department of Transportation regulations. GTS Durotech's licenses specifically prohibit storage of wooden or fiber containers outdoors in excess of 15 days. These containers must be tarped or otherwise covered within this 15-day period. Customers shall have a valid purchase order, contract, or other legal document permitting waste treatment. Generators/shippers shall provide advance notification of shipment. Shippers shall possess a valid license. Each bulk container or individual package shall be individually identified by a unique number that corresponds with the manifest entry and includes, as a minimum, the following information:

- Radionuclides and activities of each

- Detailed waste description such as paper, plastic, cloth, wood, metal, bead resin, sludge, etc.

- Estimated weight and volume

- Grams of fissile and special nuclear material

- Radiation levels and removable contamination.

Receipt of special nuclear material requires prior approval from GTS Durotech. GTS Durotech is limited to a maximum of 350 grams of $U-235,200$ grams of $U-233$, and 200 grams of $P u$, in combination, at any one time. Tables A-4 - A-11 present specific waste acceptance requirements for various treatment processes. 
Table A-4. Acceptance criteria compaction of dry active waste.

Criteria

Packaging

Receipt Criteria

Radiation Levels

Removable External Contamination

Radionuclide Limits

Total of all nuclides with $>5 y$ r half-life

Other mixed fission and activation products $(\mathrm{Z}<84)$

Th-232

$\mathrm{U}-238$ as metal or oxide

Transuranics

Other Special Nuclear Materials

$\mathrm{Ra}-226$
Requirement/Limit

55-gallon steel drum

SEG provided innerpack boxes $(4 \times 3 \times 4)$

Radionuclides and activity of each drum or innerpack box

Detailed waste description

$\leq 200 \mathrm{mrem} / \mathrm{hr}$ contact

$<2,200$ dpm beta-gamm $/ 100 \mathrm{~cm}^{2}$

$<220 \mathrm{dpm}$ alpha/ $100 \mathrm{~cm}^{2}$

$<1.0 \mu \mathrm{Ci} / \mathrm{cc}$

$\leq 25 \mathrm{mCi} / \mathrm{ft}^{3}$

$<5 \mathrm{mCi} / \mathrm{ft}^{3}\left(100 \mathrm{lb} \mathrm{Th} / \mathrm{ft}^{3}\right)$

$<15 \mathrm{mCi} / \mathrm{ft}^{3}\left(100 \mathrm{lb} \mathrm{U} / \mathrm{ft}^{3}\right)$

$<10 \mathrm{nCi} / \mathrm{gm}$

Prior Approval Required

Prior Approval Required 
Table A-5. Acceptance criteria for sorting/incineration of bulk dry active waste.

\begin{tabular}{|c|c|}
\hline Criteria & Requirement/limit \\
\hline Packaged & $\begin{array}{l}\text { Bulk containers (B-25, Sealand containers) will be sorted } \\
\text { before processing }\end{array}$ \\
\hline Acceptable Materials & $\begin{array}{l}100 \% \text { cotton cloth, } 65 \% \text { polyester } / 35 \% \text { cotton cloth, High } \\
\text { Density Polyethylene } \\
\text { Latex } \\
\text { Leather } \\
\text { Nitrile } \\
\text { Nylon } \\
\text { Paper } \\
\text { Polycarbonate } \\
\text { Polyester } \\
\text { Polyethylene } \\
\text { Polypropylene } \\
\text { Polystyrene } \\
\text { Polyurethane } \\
\text { Natural Rubber } \\
\text { Spun Bonded Polyolefin } \\
\text { Transparent Thermoplastic } \\
\text { Ultra Hi Molecular Weight Polyethylene } \\
\text { Urethane } \\
\text { Wood }\end{array}$ \\
\hline Unacceptable Materials & $\begin{array}{l}\text { Sharps } \\
\text { Metal } \\
\text { Glass } \\
\text { PVC } \\
\text { Asbestos } \\
\text { RCRA/TSCA Hazardous Wastes } \\
\text { Explosives } \\
\text { Pyrophorics }\end{array}$ \\
\hline \multicolumn{2}{|l|}{ Radiological Criteria } \\
\hline Radiation Level per Package & $\leq 200 \mathrm{mRem} / \mathrm{hr}$ \\
\hline Radiation Level on Waste & $\leq 400 \mathrm{mRem} / \mathrm{hr}$ \\
\hline Total of all nuclides with $>5$-year half-life & $\leq 0.2 \mathrm{mCi} / \mathrm{ft}^{3}$. \\
\hline Total of all nuclides with $<5$-year half-life & $\leq 25 \mathrm{mCi} / \mathrm{ft}^{3}$. \\
\hline $\mathrm{H}-3$ & $\leq 0.02 \mathrm{mCi} / \mathrm{ft}^{3}$ \\
\hline C-14 & $\leq 0.01 \mathrm{mCi} / \mathrm{ft}^{3}$. \\
\hline $\mathrm{I}-129$ & $\leq 5.0 \mathrm{E}-05 \mathrm{mCi} / \mathrm{ft}^{3}$ \\
\hline Sr-90 & $\leq 1.0 \mathrm{E}-03 \mathrm{mCi} / \mathrm{ft}^{3}$ \\
\hline $\mathrm{Ra}-226$ & Prior Approval Required \\
\hline Transuranics & $\leq 0.1 \mathrm{nCi} / \mathrm{g}$ \\
\hline Other SNM & Prior Approval Required \\
\hline
\end{tabular}


Table A-6. Acceptance criteria for incineration of nonbulk dry active waste.

Criteria

Package

Acceptable Materials

Unacceptable Materials

Ash Volumes

Radiation Level Per Package

Radionuclide Limits

Total of all nuclides with $>5 y$ r half-life

Total of off nuclides with $<5 \mathrm{yr}$ half-life

H-3

C-14

I-129

Sr-90

Sa-226

Transuranics

Other SNM
Requirement/Limit

Small cardboard/fiber boxes or drums shall be 21 in. $\times 21$ in. $\times 21$ in. and shall not exceed $50 \mathrm{lb}$.

$100 \%$ cotton, $65 \%$ polyester $35 \%$ cotton cloths

High Density Polyethylene

Latex

Leather

Nitrile or Nitrile Rubber

Nylon

Paper

Polycarbonate

polyester

Polyethylene

Polypropylene

Polyurethane

Natural Rubber, Spun Bonded Polyolefin

Transparent Thermoplastic

Ultra Hi Molecular Polyethyene, Urethane

wood

Sharps

metals

Glass

PVC

Asbestos

RCRA/TSCA Hazardous Wastes

Explosives

pyrophorics

Ash volumes will be rounded to the nearest $0.1 \mathrm{ft}^{3}$ with a minimum as volume reported to $0.1 \mathrm{ft}^{3}$.

$\leq 200 \mathrm{mRem} / \mathrm{hr}$

$0.2 \mathrm{mCi} / \mathrm{ft}^{3}$

$25 \mathrm{mCi} / \mathrm{ft}^{3}$

$0.02 \mathrm{mCi} / \mathrm{ft}^{3}$

$0.01 \mathrm{mCi} / \mathrm{ft}^{3}$

$5.0 \mathrm{E}-05 \mathrm{mCi} / \mathrm{ft}^{3}$

$1.0 \mathrm{E}-03 \mathrm{mCi} / \mathrm{ft}^{3}$

Prior Approval Required

$0.1 \mathrm{nCi} / \mathrm{gm}$

Prior Approval Required 
Table A-7. Acceptance criteria for incineration of contaminated oil.

\section{Criteria}

Oil Acceptance Criteria

Viscosity

Solids Content

Aqueous Liquid Content

Nonhazardous by RCRA/TSCA

Packaging

Receipt Requirements

Radiological limits

Radiation Level Per Package

Removable External Contamination

Total of all nuclides not listed below

H-3

C-14

I-129

Tc-99

Ra-226

Transuranics

Other SNM

RCRA/TSCA Limits

TCLP

Total Halogens (TOX)

Polychlorinated Biphenyls

Flashpoint
Requirement/Limit

$\leq 40$ weight $(<100 \mathrm{ssu})$

$\leq 10 \%$ by volume

$\leq 10 \%$ by volume

Containers must be packaged in outerpacks to provide double containment-SEG “6-pack" LSA box with six internal 79-gallon overpacks

Letter with each shipment of oil stating that the oil is not considered a hazardous waste in accordance with RCRA regulations.

$<200 \mathrm{mRem} / \mathrm{hr}$ contact

$<2,200$ dpm beta-gamma $100 \mathrm{~cm}^{2}$

$<220 \mathrm{dpm}$ alpha $/ 100 \mathrm{~cm}^{2}$

$\leq 5.0 \mathrm{E}-02 \mu \mathrm{Ci} / \mathrm{mL}$

$\leq 3.0 \mathrm{E}-03 \mu \mathrm{Ci} / \mathrm{mL}$

$\leq 1.0 \mathrm{E}-03 \mu \mathrm{Ci} / \mathrm{mL}$

$\leq 1.0 \mathrm{E}-05 \mu \mathrm{Ci} / \mathrm{mL}$

$\leq 1.0 \mathrm{E}-04 \mu \mathrm{Ci} / \mathrm{mL}$

Prior Approval Required

$\leq 0.1 \mathrm{nCi} / \mathrm{mL}$

Prior Approval Required

$$
\begin{array}{ll}
\text { Arsenic } & <5.0 \mathrm{mg} / \mathrm{L} \\
\text { Barium } & <100 \mathrm{mg} / \mathrm{L} \\
\text { Cadmium } & <1.0 \mathrm{mg} / \mathrm{L} \\
\text { Chromium } & <5.0 \mathrm{mg} / \mathrm{L} \\
\text { Lead } & <5.0 \mathrm{mg} / \mathrm{L} \\
\text { Mercury } & <0.2 \mathrm{mg} / \mathrm{L} \\
\text { Selenium } & <1.0 \mathrm{mg} / \mathrm{L} \\
\text { Silver } & <5.0 \mathrm{mg} / \mathrm{Ll}
\end{array}
$$

$\leq 1,000 \mathrm{ppm}$

$<2.0 \mathrm{ppm}$

$\geq 140^{\circ} \mathrm{F}$ 
Table A-8. Acceptance criteria for incineration of aqueous liquids.

\begin{tabular}{|c|c|}
\hline Criteria & Requirement/Limits \\
\hline pH Range & 5 to 9 \\
\hline Solids Content & $<10 \%$ by volume \\
\hline Oil Content & $<10 \%$ by volume \\
\hline Chelating Agents & $<1 \%$ by volume \\
\hline RCRA/TSCA & $\begin{array}{ll}\text { Nonhazardous } \\
\begin{array}{ll}\text { Arsenic } & <5.0 \mathrm{mg} / \mathrm{L} \\
\text { Barium } & <100 \mathrm{mg} / \mathrm{L} \\
\text { Cadmium } & <1.0 \mathrm{mg} / \mathrm{L} \\
\text { Chromium } & <5.0 \mathrm{mg} / \mathrm{L} \\
\text { Lead } & <5.0 \mathrm{mg} / \mathrm{L} \\
\text { Mercury } & <0.2 \mathrm{mg} / \mathrm{L} \\
\text { Selenium } & <1.0 \mathrm{mg} / \mathrm{L} \\
\text { Silver } & <5.0 \mathrm{mg} / \mathrm{L}\end{array}\end{array}$ \\
\hline Packaging & $\begin{array}{l}\text { Nonleaking steel or polyethylene containers, } \\
\text { SEG "6-pack" }\end{array}$ \\
\hline \multicolumn{2}{|l|}{ Radiological limits } \\
\hline Radiation Level Per Package & $<200 \mathrm{mRem} / \mathrm{hr}$ contact \\
\hline Removable External Contamination & $\begin{array}{l}<2,200 \mathrm{dpm} \text { beta-gamma } / 100 \mathrm{~cm}^{2} \\
<220 \mathrm{dpm} \text { alpha } / 100 \mathrm{~cm}^{2}\end{array}$ \\
\hline Total of all nuclides not listed below & $\leq 5.0 \mathrm{E}-02 \mu \mathrm{Ci} / \mathrm{mL}$ \\
\hline $\mathrm{H}-3$ & $\leq 3.0 \mathrm{E}-03 \mu \mathrm{Ci} / \mathrm{mL}$ \\
\hline C-14 & $\leq 1.0 \mathrm{E}-03 \mu \mathrm{Ci} / \mathrm{mL}$ \\
\hline $\mathrm{I}-129$ & $\leq 1.0 \mathrm{E}-05 \mu \mathrm{Ci} / \mathrm{mL}$ \\
\hline Tc-99 & $\leq 1.0 \mathrm{E}-04 \mu \mathrm{Ci} / \mathrm{mL}$ \\
\hline $\mathrm{Ra}-226$ & Prior Approval Required \\
\hline Transuranics & $\leq 0.1 \mathrm{nCi} / \mathrm{mL}$ \\
\hline Other SNM & Prior Approval Required \\
\hline Polychlorinated Biphenyls & $<2.0 \mathrm{ppm}$ \\
\hline Flashpoint & $\geq 140^{\circ} \mathrm{F}$ \\
\hline
\end{tabular}


Table A-9. Acceptance criteria for incineration of animal/biological waste.

\begin{tabular}{|c|c|}
\hline Criteria & Requirement/Limit \\
\hline Acceptable Materials & $\begin{array}{l}\text { Animal Carcass/Tissue } \\
\text { Bedding Material (sawdust, cedar chips, corn cobs) } \\
100 \% \text { Cotton Cloth } \\
65 \% \text { Polyester/35\% Cotton Cloth } \\
\text { High Density Polyethylene } \\
\text { Latex } \\
\text { Leather } \\
\text { Nitrile or Nitrile Rubber } \\
\text { Nylon } \\
\text { Paper } \\
\text { Polycarbonate } \\
\text { Polyester } \\
\text { Polyethylene } \\
\text { Polypropylene } \\
\text { Polystyrene } \\
\text { Polyurethane } \\
\text { Natural Rubber } \\
\text { Spun Bonded Polyolefin } \\
\text { Transparent Thermoplastic } \\
\text { Ultra Hi Molecular Polyethylene } \\
\text { Urethane } \\
\text { Wood }\end{array}$ \\
\hline Unacceptable Materials & $\begin{array}{l}\text { Sharps } \\
\text { Metal } \\
\text { Glass } \\
\text { PVC } \\
\text { Asbestos } \\
\text { RCRA/TSCA Hazardous Wastes } \\
\text { Explosives } \\
\text { Pyrophorics }\end{array}$ \\
\hline Bio-Hazard Pretreatment & $\begin{array}{l}\text { Waste containing pathogenic or infectious material shall be } \\
\text { treated to reduce the potential hazard associated with handling of } \\
\text { materials. }\end{array}$ \\
\hline Packaging & Cardboard or fiber drums \\
\hline Weight & $<50 \mathrm{lb}$ \\
\hline Decayable materials & Shipped Frozen \\
\hline Radiation Level Per Package & $\leq 200 \mathrm{mRem} / \mathrm{hr}$ \\
\hline \multicolumn{2}{|l|}{ Radionuclide Limits } \\
\hline Total of all nuclides with $>5 y$ half-life & $0.2 \mathrm{mCi} / \mathrm{ft}^{3}$ \\
\hline Total of off nuclides with $<5$ yr half-life & $25 \mathrm{mCi} / \mathrm{ft}^{3}$ \\
\hline $\mathrm{H}-3$ & $0.02 \mathrm{mCi} / \mathrm{ft}^{3}$ \\
\hline C-14 & $0.01 \mathrm{mCi} / \mathrm{ft}^{3}$ \\
\hline $\mathrm{I}-129$ & $5.0 \mathrm{E}-05 \mathrm{mCi} / \mathrm{ft}^{3}$ \\
\hline Sr-90 & $1.0 \mathrm{E}-03 \mathrm{mCi} / \mathrm{ft}^{3}$ \\
\hline Sa-226 & Prior Approval Required \\
\hline Transuranics & $0.1 \mathrm{nCi} / \mathrm{gm}$ \\
\hline Other SNM & Prior Approval Required \\
\hline
\end{tabular}


Table A-10. Acceptance criteria for metal melting.

\begin{tabular}{|c|c|}
\hline Criteria & Requirement/Limit \\
\hline Acceptable Metals & $\begin{array}{l}\text { Stainless Steel } \\
\text { Carbon Steel } \\
\text { Iron } \\
\text { Galvanized metal } \\
\text { Nickel alloys } \\
\text { Chromium alloys } \\
\text { Ferrous alloys } \\
\text { Small quantities of copper, aluminum, brass, } \\
\text { bronze, and stellite are acceptable as long as they do } \\
\text { not exceed } 1 \% \text { by weight. }\end{array}$ \\
\hline Unacceptable Metals & $\begin{array}{l}\text { Lead } \\
\text { Tin } \\
\text { Mercury } \\
\text { Other Heavy Metals } \\
\text { Pyrophorics } \\
\text { Zirconium } \\
\text { Tungsten } \\
\text { Tantalum } \\
\text { Molybdenum }\end{array}$ \\
\hline Weight/Size & $\begin{array}{l}\text { Limited to a } 20 \mathrm{ft} \text {. Sealand container, and not } \\
\text { exceed } 20,000 \mathrm{lb} \text {. }\end{array}$ \\
\hline \multicolumn{2}{|l|}{ Metal Recycle Radiological Limits } \\
\hline Surface-Contaminated Metal & $\leq 50 \mathrm{mRem} / \mathrm{hr}$ \\
\hline Activated Metal & $\leq 0.5 \mathrm{mRem} / \mathrm{hr}$ \\
\hline \multicolumn{2}{|l|}{ Radionuclide Limits } \\
\hline Total of all nuclides not listed below & $\leq 2.0 \mathrm{E}-03 \mu \mathrm{Ci} / \mathrm{g}$ \\
\hline $\mathrm{H}-3$ & $\leq 1.0 \mathrm{E}-05 \mu \mathrm{Ci} / \mathrm{g}$ \\
\hline C-14 & $\leq 3.0 \mathrm{E}-05 \mu \mathrm{Ci} / \mathrm{g}$ \\
\hline $\mathrm{I}-129$ & $\leq 1.0 \mathrm{E}-07 \mu \mathrm{Ci} / \mathrm{g}$ \\
\hline $\mathrm{Ra}-226$ & $\leq 10 \mathrm{nCi} / \mathrm{g}$ \\
\hline Ra-226 (commercial) & Prior Approval Required \\
\hline Transuranics & $\leq 1.0 \mathrm{nCi} / \mathrm{g}$ \\
\hline SNM & Prior Approval Required \\
\hline \multicolumn{2}{|l|}{ Metal Volume Radiological Limits } \\
\hline Surface Contamination & $\leq 200 \mathrm{mRem} / \mathrm{hr}$ \\
\hline \multicolumn{2}{|l|}{ Radionuclide Limits } \\
\hline Total of all nuclides not listed below & $\leq 0.1 \mu \mathrm{Ci} / \mathrm{g}$ \\
\hline Co-60 & $\leq 5.0 \mathrm{E}-02 \_\mu \mathrm{Ci} / \mathrm{g}$ \\
\hline Cs-137 & $\leq 2.0 \mathrm{E}-03 \_\mu \mathrm{Ci} / \mathrm{g}$ \\
\hline $\mathrm{H}-3$ & $\leq 1.0 \mathrm{E}-05 \_\mu \mathrm{Ci} / \mathrm{g}$ \\
\hline C-14 & $\leq 3.0 \mathrm{E}-05 \_\mu \mathrm{Ci} / \mathrm{g}$ \\
\hline I-129 & $\leq 1.0 \mathrm{E}-07 \_\mu \mathrm{Ci} / \mathrm{g}$ \\
\hline $\mathrm{Ra}-226$ & $\leq 10 \mathrm{nCi} / \mathrm{g}$ \\
\hline Transuranics & $\leq 1.0 \mathrm{nCi} / \mathrm{g}$ \\
\hline Other SNM & Prior Approval Required \\
\hline
\end{tabular}


Table A-11. Acceptance criteria for drying/incineration of resins and sludges.

\section{Criteria}

Packaging

Radiological Criteria- Drying

Radiation Level Per Package

Removable External Contamination

Total of all nuclides with $>5$-yr half-life

Other mixed fission and activation products

$(\mathrm{Z}<84)$

Th-232

U-238

Transuranics

Other SNM

Ra-226

Radiological Criteria - Incineration

Total of all nuclides with $>5$-yr half-life

Total of all nuclides with $<5$-yr half-life

H-3

C-14

I-129

Sr-90

Ra-226

Transuranics

Other SNM
Requirement/Limits

Steel or poly drums or boxes (B-25)

$\leq 200 \mathrm{mRem} / \mathrm{hr}$ contact

$<2,200 \mathrm{dpm}$ beta-gamma $/ 100 \mathrm{~cm}^{2}$

$<220 \mathrm{dpm}$ alpha $100 \mathrm{~cm}^{2}$

$<5.7 \mathrm{mCi} / \mathrm{ft}^{3}$

$\leq 25 \mathrm{mCi} / \mathrm{ft}^{3}$

$<5 \mathrm{mCi} / \mathrm{ft}^{3}$

$<15 \mathrm{mCi} / \mathrm{ft}^{3}$

$<10 \mathrm{nCi} / \mathrm{gm}$

Prior Approval Requested

Prior Approval Requested

$\leq 0.2 \mathrm{mCi} / \mathrm{ft}^{3}$

$\leq 25 \mathrm{mCi} / \mathrm{ft}^{3}$

$\leq 0.02 \mathrm{mCi} / \mathrm{ft}^{3}$

$\leq 0.01 \mathrm{mCi} / \mathrm{ft}^{3}$

$\leq 5.0 \mathrm{E}-05 \mathrm{mCi} / \mathrm{ft}^{3}$

$\leq 1.0 \mathrm{E}-03 \mathrm{mCi} / \mathrm{ft}^{3}$

Prior Approval Required

$\leq 0.1 \mathrm{nCi} / \mathrm{g}$

Prior Approval Required 


\section{Appendix B}

Box Waste Distribution By Site 
Table B-1. Distribution of boxes by waste stream (number of boxes).

\begin{tabular}{lccccc}
\hline \multicolumn{1}{c}{ Site } & TRU & MLLW & LLW & HAZ & NON \\
\hline INEEL* & 6,602 & 4,420 & - & - & - \\
LLNL & 34 & - & - & - & 222 \\
OR-Y12 & 3 & 525 & 2,488 & - & 43 \\
OR-ETTC & - & 1,105 & 4,066 & 52 & - \\
OR-ORNL & 150 & 11 & 4,640 & 11 & - \\
RL & 122 & - & - & - & 75 \\
RF & 120 & 5,796 & 2,099 & - & 4 \\
SRS & 1,136 & 289 & 536 & 365 &
\end{tabular}

* Data based on Reference 3. More recent data indicate total box inventory of 12,530.

Table B-2. Distribution of Boxes By Waste Stream (Volume $\mathrm{m}^{3}$ of Boxes)

\begin{tabular}{lccccc}
\hline \multicolumn{1}{c}{ Site } & TRU & MLLW & LLW & HAZ & NON \\
\hline INEEL* & 21,052 & 14,062 & - & - & - \\
LLNL & 160.4 & - & 4.5 & - & - \\
OR-Y12 & 8.2 & 1,180 & $5,689.4$ & - & 807 \\
OR-ETTC & - & $1,544.6$ & $11,060.1$ & 141.4 & 94.7 \\
OR-ORNL & 389.9 & 29.9 & $23,250.7$ & 29.9 & - \\
RL & $1,186.8$ & - & - & - & - \\
RF & 296.6 & $16,805.7$ & 5,700 & - & 197.9 \\
SRS & $4,863.5$ & 582.9 & 659.3 & 450 & 10.2 \\
\hline *Data based on Reference 3. More recent data indicates total box inventory volume of & \\
36,770.8 ${ }^{3}$. & & &
\end{tabular}


Table B-3. Description of boxes by site.

\begin{tabular}{|c|c|c|c|}
\hline Site & Description & Size & Volume $\left(\mathrm{m}^{3}\right)$ \\
\hline \multirow[t]{33}{*}{ Idaho } & Box & $84 \times 48 \times 24$ & 1.58 \\
\hline & $\begin{array}{l}\text { Fiberglass Reinforced } \\
\text { Plywood (FRP) }\end{array}$ & $36 \times 24 \times 24$ & 0.34 \\
\hline & FRP & & 1.95 \\
\hline & Retrieval & & 2.21 \\
\hline & Rectangular & $68 \times 54 \times 38.5$ & 2.29 \\
\hline & 6-drum Overpack & $74.75 \times 50.5 \times 38.5$ & 2.30 \\
\hline & Plywood Box RFP & & 2.32 \\
\hline & Standard Waste Box & $71 \times 55 \times 37$ & 2.34 \\
\hline & Mexican AM & $72 \times 48 \times 48$ & 2.72 \\
\hline & TX-4 Steel Type 1 & $78.5 \times 54.5 \times 41.25$ & 2.89 \\
\hline & Retrieval & & 2.94 \\
\hline & Retrieval & & 3.06 \\
\hline & Plywood box RFP & & 3.14 \\
\hline & SAND Type 1 & $88 \times 48 \times 48$ & 3.17 \\
\hline & FRP & $84 \times 48 \times 48$ & 3.17 \\
\hline & Retrieval & & 2.23 \\
\hline & Retrieval & $81.5 \times 57.6 \times 43.2$ & 3.33 \\
\hline & Plywood Box RFP & $84 \times 52 \times 48$ & 3.41 \\
\hline & FRP (MRC,FRP) & $84 \times 48 \times 52$ & 3.44 \\
\hline & M-III, M-IV & $50.4 \times 58.4 \times 72.4$ & 3.49 \\
\hline & FRP (ICPP) & $96 \times 48 \times 48$ & 3.62 \\
\hline & Plywood Box (RFP) & $112 \times 62 \times 35$ & 3.97 \\
\hline & FRP Overpack & $88 \times 54 \times 54$ & 4.21 \\
\hline & SAND Type-2 & $88 \times 54 \times 54$ & 4.21 \\
\hline & TX-4 Steel Type-2 & $88.25 \times 54.5 \times 54.5$ & 4.30 \\
\hline & TX-4 Steel Type-3 & $92 \times 56 \times 56.75$ & 4.79 \\
\hline & FRP (ICPP) & $96 \times 48 \times 66$ & 4.98 \\
\hline & TX-4 Steel Type- 4 & $92 \times 58.25 \times 59$ & 5.18 \\
\hline & FRP (MRC) & $103.5 \times 60.5 \times 62.5$ & 6.38 \\
\hline & FRP (MRC) & & 7.70 \\
\hline & Rectangular & $112 \times 68 \times 77$ & 9.61 \\
\hline & Metal (Mound) & $108 \times 104 \times 60$ & 11.04 \\
\hline & FRP (MRC) & $108.5 \times 60.5 \times 104.25$ & 11.24 \\
\hline
\end{tabular}


Table B-3. (continued)

\begin{tabular}{|c|c|c|c|}
\hline Site & Description & Size & Volume $\left(\mathrm{m}^{3}\right)$ \\
\hline & FRP (MRC) & $136.5 \times 71.5 \times 108$ & 17.27 \\
\hline & FRP (MRC) & $137 \times 108 \times 72$ & 17.43 \\
\hline & Cargo Container & $240 \times 96 \times 96$ & 36.24 \\
\hline \multirow[t]{10}{*}{ Livermore } & Cap. Industries & $54 \times 52 \times 87$ & 4.47 \\
\hline & & $55 \times 77 \times 108$ & 7.46 \\
\hline & Rogar Chem. \& Nuc & $52 \times 89 \times 56$ & 4.25 \\
\hline & & $54 \times 52 \times 87$ & 4.36 \\
\hline & & $60 \times 66 \times 87$ & 5.56 \\
\hline & & $138 \times 48 \times 53$ & 5.75 \\
\hline & & $55 \times 77 \times 92$ & 6.41 \\
\hline & & $67 \times 85 \times 89$ & 7.19 \\
\hline & & $55 \times 77 \times 108$ & 7.46 \\
\hline & SWB & & 1.90 \\
\hline \multirow[t]{14}{*}{ Oak Ridge } & .5 & & .283 \\
\hline & 1 & & .028 \\
\hline & 10 & & .283 \\
\hline & 2 & & .06 \\
\hline & 3 & & .08 \\
\hline & 4 & & .206 \\
\hline & B-25 & & 1.718 \\
\hline & $\mathrm{F}$ & & .0283 \\
\hline & $\mathbf{M}$ & & 2.718 \\
\hline & M1280 & & 36.25 \\
\hline & M64 & & 1.79 \\
\hline & M96 & & 2.718 \\
\hline & W & & 5.09 \\
\hline & BOX & & 2.718 \\
\hline \multirow[t]{6}{*}{ Richland } & BOX & $1.5 \times 5$ & .81 \\
\hline & . & $7.3 \times 4.5 \times 4.5$ & 4.21 \\
\hline & & $7 \times 4 \times 4$ & 3.17 \\
\hline & & $9.3 \times 6.5 \times 5.6$ & 9.61 \\
\hline & & $7 \times 6 \times 6$ & 7.14 \\
\hline & & $5.7 \times 4.5 \times 3.2$ & 2.3 \\
\hline
\end{tabular}


Table B-3. (continued)

\begin{tabular}{|c|c|c|c|}
\hline Site & Description & Size & Volume $\left(\mathrm{m}^{3}\right)$ \\
\hline & & $6 \times 4.4 \times 3$ & 1.9 \\
\hline & & $5.9 \times 4.5 \times 3.1$ & 2.04 \\
\hline & & $5.7 \times 2.3 \times 2.3$ & .84 \\
\hline & & $6 \times 4 \times 3$ & 2.04 \\
\hline & & $11 \times 6 \times 5$ & 9.75 \\
\hline & & $9.3 \times 9.7 \times 4.2$ & 9.6 \\
\hline & & $12 \times 7 \times 6$ & 14.1 \\
\hline & & $9.3 \times 5.7 \times 6.4$ & 9.61 \\
\hline & & $4 \times 4$ & 1.45 \\
\hline & & $4 \times 5$ & 2.22 \\
\hline & & $1.5 \times 5$ & .234 \\
\hline & & $5.73 \times 4.32 \times 3.06$ & 1.94 \\
\hline & & $5.3 \times 5.6$ & .79 \\
\hline \multirow[t]{7}{*}{ Rocky Flats } & $\mathrm{BFM}$ & $4.3 \times 4 \times 7$ & 3.41 \\
\hline & BFW & $4 \times 4 \times 7$ & 3.17 \\
\hline & BHO & $2 \times 4 \times 7$ & 1.59 \\
\hline & BHR & $2 \times 4 \times 7$ & 1.59 \\
\hline & BHW & $2 \times 4 \times 7$ & 1.58 \\
\hline & BMV & $88 \times 47 \times 39.75$ & 2.69 \\
\hline & BST & & 1.9 \\
\hline \multirow[t]{6}{*}{ Savannah River } & B-6 & & .62 \\
\hline & B-12 & & 1.23 \\
\hline & B-25 & & 2.55 \\
\hline & Poly & $16 \times 29 \times 7$ & .249 \\
\hline & Black Box & $12 \times 18 \times 7$ & 42.5 \\
\hline & Casks & $27 \times 27 \times 42$ & .5 \\
\hline
\end{tabular}


Table B-4. Distribution of boxes by type for Idaho National Engineering and Environmental Laboratory (based on Reference 4).

\begin{tabular}{ccccccc}
\hline Wood Box & $\begin{array}{c}\text { FRP } \\
\text { Boxes }\end{array}$ & $\begin{array}{c}\text { Oversize } \\
\text { FRP }\end{array}$ & $\begin{array}{c}\text { Odd Size } \\
\text { FRP }\end{array}$ & Metal Bins & $\begin{array}{c}\text { SAND } \\
\text { Type- }\end{array}$ & $\begin{array}{c}\text { Odd Sized } \\
\text { Metal }\end{array}$ \\
\hline $48 \times 48 \times 84$ & $84 \times 84 \times 48$ & $84 \times 48 \times 52$ & & $48 \times 60 \times 72$ & $48 \times 48 \times 84$ & \\
956 & 7,607 & 29 & 258 & 1,011 & 2,366 & 303 \\
\hline
\end{tabular}

Table B-5. Distribution of boxes by type for LLNL box volume $\left(\mathrm{ft}^{3}\right)$.

\begin{tabular}{cccccccccccc}
\hline MPC & 150 & 154 & 158 & 197 & 203 & 226 & 254 & 268 & 264 & 304 & SBW \\
\hline S5110 & 1 & 9 & 1 & 1 & $?$ & & 1 & 1 & 1 & 1 \\
S5420 & & 4 & & & $?$ & 1 & & & & \\
S5440 & 1 & & 7 & & & $?$ & & & & & 1 \\
S5490 & & 2 & & & $?$ & & & & & \\
\hline
\end{tabular}

Table B-6. Distribution of boxes by type for Oak Ridge.

\begin{tabular}{cccc}
\hline TYPE & Y-12 & ETTP & ORNL \\
\hline .5 & 31 & & 11 \\
1 & 4 & & \\
2 & 12 & 1 & \\
3 & 4 & & 564 \\
4 & 2 & & \\
B-25 & 5 & 33 & 2,951 \\
F & 2,044 & 545 & 334 \\
M & 1 & 3 & \\
M1280 & 20 & 1 & 945 \\
M64 & 32 & & 7 \\
M96 & 30 & 4,629 & \\
W & 960 & 4 & \\
BOX & 13 & 41 & \\
\hline
\end{tabular}


Table B-7. Distribution of boxes by type for Hanford Site.

\begin{tabular}{ccccc}
$\begin{array}{c}\text { Small } \\
\left(<2 \mathrm{~m}^{3}\right)\end{array}$ & $\begin{array}{c}\text { Medium } \\
\left(2<<7 \mathrm{~m}^{3}\right)\end{array}$ & $\begin{array}{c}\text { Large } \\
\left(>7 \mathrm{~m}^{3}\right)\end{array}$ & Casks & Total \\
\hline 15 & 41 & 47 & 19 & 122 \\
\hline
\end{tabular}

Table B-8. Distribution of boxes by type for Rocky Flats Site.

\begin{tabular}{|c|c|}
\hline BOX TYPE & NUMBER \\
\hline Half wood & 766 \\
\hline Half wood reject & 158 \\
\hline Half wood overpack & 189 \\
\hline Full metal & 2,171 \\
\hline Full wood & 2,031 \\
\hline Misc. box & 17 \\
\hline Metal & 2,720 \\
\hline Standard waste & 38 \\
\hline Total & 8,090 \\
\hline
\end{tabular}

Table B-9. Distribution of boxes by type for Savannah River Site.

\begin{tabular}{lccc}
\hline \multicolumn{1}{c}{ Type } & B-6 & B-12 & B-25 \\
\hline Number & 60 & 930 & 204 \\
Type & Poly & Black & Misc \\
Number & 822 & 97 & 217 \\
\hline
\end{tabular}



Appendix C

Waste Distribution by MPC

C-1 


\section{Matrix Parameter Categories}

This section examines the overall, composite physical/chemical form of waste stored in boxes or crates. The primary purpose of this discussion is to better understand what types of waste form configurations are to be nondestructively assayed, the chemical and physical properties of these common or majority wastes types, and identification of potential assay limitations.

The approach used to classify the various types of waste forms in this analysis is based on the Matrix Parameter Categories (MPCs) as defined in the DOE Waste Treatability Group Guidance. This approach divides the waste into broad categories based on a generalized matrix description, specifically liquids, solids, specific waste forms, final waste forms, and unknown/other matrices. Within these broad categories, subcategories are defined to further detail specific waste forms.

An assessment of the existing inventories of box/crate waste at the major DOE sites shows that waste described as liquids, solids, specific waste forms, final waste forms, and unknown/other matrices can be found. Although selected examples can be identified representing almost all of the possible MPCs, the majority of the DOE box/crate waste is represented by possibly five to seven definitive MPCs. The following presents a general discussion of the major MPCs identified.

\section{Liquids (L)}

The liquids summary category addresses wastes that are liquids, including slurries. Slurries are defined as liquids with total suspended/settled solids content of $\geq 1 \%$ and $\leq 30 \%$. Only liquids and slurries packaged in bulk, free form are included in this category.

The only examples of box/crate waste in the liquids category fall within the Unknown/Other Wastewaters (L1190) and are characterized as collected runoff or discharge water.

\section{Solids}

The solids summary category addresses wastes that are physically solid matrices, including sludges. Sludges are defined as having a total suspended/settled solids content of greater than $30 \%$. The largest portion of box/crate waste can be described as solids. Significant inventories of waste are found to be characterized as sludge, soil/gravel, and debris.

\section{Homogeneous solids (S3000)}

Homogeneous solids are defined as solid waste materials, excluding soil/gravel, that do not meet the EPA Land Disposal Requirement (LDR) criteria for classification as debris. Homogeneous solids may include waste or other residual liquids. Both inorganic and organic solid materials are found in the box/crate waste inventory.

Inorganic homogeneous solids (S3100) - Materials containing sufficient inorganic solids such that a minimum of approximately $20 \%$ by weight would remain as residual following incineration are defined as inorganic. A significant number of boxes are identified as containing inorganic particulates (S3110). Typical examples of this waste include incinerator ash, dust, sandblasting residue, vermiculite, and ionexchange media. Examples of inorganic sludge (S3120) are found and include wastewater treatment, pond, and reprocessing sludge. Other examples of homogeneous solids include solidified homogeneous solids (S3150) and represent materials the have been immobilized, but require further treatment to meet LDR standards. 
Organic homogeneous solids (S3200) - Waste solids with a base structure that is primarily organic such that a maximum of approximately $20 \%$ by weight would remain following incineration. The box/crate waste inventory has containers of organic particulates (S3210) and organic sludge (S3220). Specific examples of organic particulate containing boxes have materials such as wastewater treatment resins and particulate organic absorbent. Specific boxes were identified to contain tars, greases or biological (sewer) sludge.

\section{Soils/Gravel (S4000)}

Because of environmental restoration activities and the storage volume advantage of boxes/crates, a large number of items are identifiable as soils and gravel. Major matrix types are soil (S4100) and soil with debris (S4200). Waste estimated to be greater than $95 \%$ by volume soil including sand, silt, and rock and gravel falls into the S4100 MPC. Remediation activities associated with pits and trenches generate soil and debris. This waste falls within the $\$ 4200 \mathrm{MPC}$ and is estimated to be at least $50 \%$, but no greater than $95 \%$, by volume soil with the balance of the matrix being debris.

\section{Debris Waste (S5000)}

Debris means solid material having physical dimensions that exceeds a $60 \mathrm{~mm}$ particle size that is intended for disposal. Specific examples of materials that are classified as debris include manufactured objects, plant or animal matter, and/or geologic material. A large number of box/crates contain inorganic, organic, and heterogeneous debris.

Inorganic debris ( $\mathrm{S} 5100$ ) - Waste that is estimated to be $80 \%$ by volume either metal or inorganic debris falls within this category. Metal debris (S5110) contained in the box/crate inventory includes metal with or without lead and cadmium. Boxes and crates are found to also contain inorganic debris (S5120) and concrete, glass, ceramic/brick, rock, asbestos, and graphite.

Organic debris ( $\mathrm{S} 5300$ ) - Waste that is estimated to be $80 \%$ by volume plastic, rubber, wood, paper, cloth, and/or biological matter. Most of these matrices are identified in the box/crate inventory. Plastic/rubber debris (S5310) boxes contain leaded gloves and aprons, halogenated plastic, and nonhalogenated plastic. Wood debris (S5320) containers have wood products such as timber, building materials, doors, pallets, etc. Boxes classified as paper/cloth (S5330) contain material such as protective clothing, rags, and wipes. ORNL has some boxes containing biological matter (S5340), such as biological samples and animal carcasses and may also contain lime and formaldehyde chemical agents.

\section{Heterogeneous Debris (5400)}

Another major category of debris waste identified in the box/crate inventory is heterogeneous debris (5400). This waste category includes filter (S5410), predominantly inorganic (S5120), predominantly organic (S5140), and asphalt (5450). The principal component representing constituents of filter debris is HEPA filters and frames. Paving, roofing materials, bituminous cement, and materials containing tar and gravel make up the main constituents in asphalt debris.

\section{Special Waste (X7000)}

This category of waste includes materials that (a) is inherently hazardous, often with specific LDR treatment requirements, or (b) presents a unique treatment concern. Examples of box/crates waste categorized as special waste include elemental lead and mercury (X7200) and Beryllium dust (X7300). 
Element Lead (X7210) - Waste that is at least $50 \%$ by volume bulk elemental lead. Examples of box waste matrices include lead bricks, shielding, sheets, and pipe material. The lead can be either activated or nonactivated.

Other elemental hazardous metals ( 7290 ) - Waste that is at least $50 \%$ by volume bulk hazardous metal, other than lead and cadmium. Specific examples of box/crate waste material within this category include elemental mercury waste.

\section{Other Final Forms (Z)}

This category addresses waste that is in final form and meets applicable disposal criteria. The primary representatives found in the box/crate inventory are cemented forms.

Cemented forms (Z1110)-The waste in this category has been immobilized with grout or other cement type binders. Examples found in the box/crate inventory include pondcrete and cemented filter elements.

The final category identified as being represented by a portion of the box/crate waste inventory is the unknown/other matrix (U9999) description. This category includes waste for which insufficient characterization exists or does not satisfy specific criteria for assignment to a specific category. 
Table C-1. Distribution of boxes by MPC for Idaho National Engineering and Environmental Laboratory (based on Reference 3).

\begin{tabular}{lc}
\hline MPC & Number of Boxes \\
\hline S5110 & 4,694 \\
S5300 5410 & 3,760 \\
S5100 & 1,320 \\
S5440 & 372 \\
U9999 & 359 \\
S3110 & 183 \\
U0000 & 77 \\
$S 5120$ & 72 \\
S3120 & 72 \\
$S 4100$ & 40 \\
$S 5400$ & 39 \\
$S 3140$ & 6 \\
\hline
\end{tabular}

Table C-2. Box waste distribution by MPC for Lawrence Livermore National Laboratory.

\begin{tabular}{ccc}
\hline MPC & Number & Volume $\left(\mathrm{m}^{3}\right)$ \\
\hline $\mathrm{S} 5110$ & 16 & 89.69 \\
$\mathrm{~S} 5420$ & 5 & 17.64 \\
$\mathrm{~S} 5440$ & 8 & 35.56 \\
$\mathrm{~S} 5490$ & 2 & 8.95 \\
\hline
\end{tabular}


Table C-3. Box waste distribution by MPC for Oak Ridge Site.

\begin{tabular}{|c|c|c|}
\hline MPC & Number & Volume $\left(\mathrm{m}^{3}\right)$ \\
\hline L1190 & 2 & 5.4 \\
\hline L1210 & 2 & 5.4 \\
\hline L2190 & 1 & 2.7 \\
\hline L2290 & 1 & 2.7 \\
\hline L9000 & 0 & 0 \\
\hline S3110 & 203 & 539.7 \\
\hline S3120 & 815 & 747.7 \\
\hline S3140 & 22 & 57.1 \\
\hline S3150 & 9 & 23.5 \\
\hline S3160 & 21 & 57.1 \\
\hline S3190 & 2 & 5.4 \\
\hline S3210 & 1 & 2.7 \\
\hline S3220 & 1 & 2.7 \\
\hline S3230 & 14 & 35.6 \\
\hline S3290 & 9 & 24.5 \\
\hline S3900 & 1 & 1.7 \\
\hline$S 4100$ & 385 & 953.7 \\
\hline$\$ 4200$ & 355 & 908.9 \\
\hline$S 4300$ & 55 & 120.5 \\
\hline S5110 & 3,207 & $12,001.3$ \\
\hline S5120 & 1,148 & $2,905.1$ \\
\hline S5190 & 11 & 24.9 \\
\hline S5310 & 225 & 585.6 \\
\hline S5320 & 426 & 977.1 \\
\hline S5330 & 190 & 450.4 \\
\hline S5340 & 21 & 27.5 \\
\hline S5390 & 2,233 & 577.4 \\
\hline S5410 & 132 & 313.1 \\
\hline S5420 & 262 & 466.1 \\
\hline S5440 & 901 & $2,345.9$ \\
\hline S5450 & 453 & 961.3 \\
\hline
\end{tabular}

C-6 
Table C-3. (continued)

\begin{tabular}{ccc}
\hline MPC & Number & Volume $\left(\mathrm{m}^{3}\right)$ \\
\hline $\mathrm{S} 5460$ & 133 & 471.1 \\
$\mathrm{~S} 5490$ & 1,954 & $13,312.8$ \\
$\mathrm{~S} 5900$ & 12 & 24 \\
$\mathrm{~S} 9000$ & 46 & 148.3 \\
$\mathrm{U} 9000$ & 2 & 4.4 \\
$\mathrm{X} 6200$ & 2 & 5.4 \\
$\mathrm{X} 6300$ & 3 & 8.2 \\
X6900 & 15 & 5.5 \\
X7100 & 3 & 15.3 \\
X7200 & 8 & 21.7 \\
X7410 & 7 & 19 \\
X7490 & 3 & 5.5 \\
X7700 & 2 & 5.4 \\
X7900 & 17 & 46.2 \\
TOTALS & 13,315 & $44,225.7$ \\
\hline
\end{tabular}


Table C-4. Box waste distribution by MPC for Hanford Site.

\begin{tabular}{ccc}
\hline MPC & Number & Volume $\left(\mathrm{m}^{3}\right)$ \\
\hline S3110 & 2 & 17.7 \\
S5110 & 19 & 135.9 \\
S5120 & 18 & 25.8 \\
S5130 & 1 & 3.2 \\
S5390 & 5 & 25.5 \\
S5410 & 9 & 18.9 \\
S5420 & 25 & 162.7 \\
S5440 & 26 & 140.5 \\
S5900 & 8 & 49.9 \\
U9999 & 1 & 4.2 \\
X6200 & 1 & 9.6 \\
X7219 & 5 & 1.4 \\
X7290 & 8 & 1 \\
TOTALS & 122 & 593.4 \\
\hline
\end{tabular}


Table C-5. Box waste distribution by MPC for Rocky Flats Site.

\begin{tabular}{ccc}
\hline MPC & Number & Volume $\left(\mathrm{m}^{3}\right)$ \\
\hline S1190 3110 & 4 & 13.6 \\
S3120 & 26 & 80.3 \\
S3220 & 23 & 47.2 \\
S5110 & 197 & 313.2 \\
S5120 & 825 & 264.6 \\
S5300 & 58 & 166.5 \\
S5410 & 771 & $2,353.9$ \\
S5420 & 195 & 541.3 \\
S5430 & 638 & 1,260 \\
S5440 & 0 & 0 \\
U0000 & 145 & 413.2 \\
U9999 & 10 & 26.6 \\
X7219 & 299 & 884.6 \\
X7300 & 8 & 20 \\
Z1110 & 3 & 4.8 \\
TOTALS & 4,888 & $14,610.2$ \\
& 8,090 & $23,000.1$ \\
\hline
\end{tabular}


Table C-6. Box waste distribution by MPC for Savannah River Site (excludes TRU Waste Containers).

\begin{tabular}{ccc}
\hline MPC & Number & Volume $\left(\mathrm{m}^{3}\right)$ \\
\hline L2290 & 1 & 2.6 \\
S4100 & 533 & 659.6 \\
S5110 & 390 & 466.3 \\
S5330 & 24 & 59.3 \\
S5400 & 100 & 255 \\
S5410 & 3 & 3.7 \\
X7100 & 48 & 122.4 \\
X7219 & 1 & 0.6 \\
TOTALS & 36 & 131.9 \\
\hline
\end{tabular}


Appendix D

Matrix Properties

D-1 
Table D-1. Reference table of material densities.

\begin{tabular}{|c|c|c|c|}
\hline Material & Density & Material & Density \\
\hline Metals \& Alloys & & Other Materials & \\
\hline Aluminum & $2.55-2.80$ & Asbestos & $2.0-2.8$ \\
\hline Brass & $8.4-8.7$ & Asphalt & $1.0-1.5$ \\
\hline Copper & $8.8-8.9$ & Brick & $1.4-1.5$ \\
\hline Iron & $7.03-7.2$ & Cardboard & 0.69 \\
\hline Lead & 11.34 & Clay (Dry) & 1.0 \\
\hline Mercury & 13.6 & Clay (Damp) & 1.28 \\
\hline Nickel & 8.9 & Concrete & $2.2-2.4$ \\
\hline \multirow[t]{2}{*}{ Steel } & $7.7-7.8$ & Cinder Block & $1.5-1.7$ \\
\hline & & Mortar & $1.4-1.9$ \\
\hline Various Solids & & Portland Cement & $2.08-2.25$ \\
\hline Cotton & $1.47-1.5$ & & \\
\hline Glass & $2.4-2.8$ & Earth (Excavated) & \\
\hline Hay & 0.32 & Ashes & $0.64-0.72$ \\
\hline Paper & $.7-1.15$ & Earth (Dry) & 1.2 \\
\hline Rubber & $0.92-0.96$ & Earth (Dry Packed) & 1.5 \\
\hline Salt & $0.77-1.2$ & Earth (Moist) & 1.3 \\
\hline Wood & $0.35-0.8$ & Mud & 1.7 \\
\hline \multirow[t]{2}{*}{ Wool } & 1.32 & Rock & $1.3-1.7$ \\
\hline & & Sand \& Gravel & $1.4-1.7$ \\
\hline Various Liquids & & Soil & 1.12 \\
\hline Alcohol & 0.79 & Crushed rock & 1.0 \\
\hline Acid - $\mathrm{HCl}$ & 1.20 & & \\
\hline Acid - Nitric & 1.50 & Various & \\
\hline Acid - Sulfuric & 1.80 & Bituminous Solids & 0.87 \\
\hline Chloroform & 1.5 & Coal & $1.1-1.5$ \\
\hline Ether & 0.74 & Dolomite & 2.84 \\
\hline Oils & $0.88-0.94$ & Granite & $1.6-1.7$ \\
\hline \multirow[t]{2}{*}{ Water } & 1.0 & Gypsum & $2.31-2.33$ \\
\hline & & Wax & $0.87-0.91$ \\
\hline Plastics & & Pitch & $1.07-1.15$ \\
\hline Abs & $1.02-1.06$ & Tar & 1.2 \\
\hline Acrylic & $1.18-1.2$ & Benzene & 0.73 \\
\hline Polycarbonate & 1.2 & Gasoline & $0.7-0.75$ \\
\hline Polypropylene & $0.9-0.91$ & & \\
\hline Polyurethane & $1.03-1.06$ & & \\
\hline PVC & 1.38 & & \\
\hline
\end{tabular}


Table D-2. Composition and density of various Matrix Parameter Categories.

L1190 Wastewater (less than 1.0\% suspended or settled solids)

Material packaged in drums or tanks

Density Estimate (Assume 55-gallon drum weighs $30 \mathrm{lb}$ )

$\begin{array}{lcccc}\text { Material } & \text { Weight } & \text { Fraction } & \text { Density } & \text { Partial Density } \\ \text { Steel Drum } & 66 & 0.24 & 7.8 & 1.87 \\ \text { Waster } & \underline{208} & \underline{0.76} & \underline{1.0} & \underline{0.76}\end{array}$

Estimated Density Range $=2.3$ to 2.8 (included lighter drums and partially filled drums)

Material packaged in poly drums

$\begin{array}{lcccc}\text { Material } & \text { Weight } & \text { Fraction } & \text { Density } & \text { Partial Density } \\ \text { Poly Drum } & 22 & 0.1 & 0.9 & 0.09 \\ \text { Water } & \underline{208} & \underline{0.9} & \underline{1.0} & \underline{0.90}\end{array}$

Estimated Density Range $=0.99$ to 1.0

L1210 Wastewater ( $>1 \%$ but $<30 \%$ suspended or settled solids)

Material packaged in drums or tanks or poly containers

Density Estimate (Assume 15\% solids)

$\begin{array}{lcccc}\text { Material } & \text { Weight } & \text { Fraction } & \text { Density } & \text { Partial Density } \\ \text { Steel Drum } & 66 & 0.24 & 7.8 & 1.87 \\ \text { Solids } & 31 & 0.12 & 1.1 & 0.13 \\ \text { Water } & \underline{176} & \underline{0.64} & \underline{1.0} & \underline{0.64}\end{array}$

Estimated Density Range $=2.3$ to 2.7

$\begin{array}{lcccc}\text { Material } & \text { Weight } & \text { Fraction } & \text { Density } & \text { Partial Density } \\ \text { Poly Drum } & 22 & 0.1 & 0.9 & 0.09 \\ \text { Solids } & 31 & 0.13 & 1.1 & 0.15 \\ \text { Water } & 176 & 0.77 & 1.0 & \underline{0.77}\end{array}$

Estimated Density Range $=0.9$ to 1.02

L2210 Pure Organic Liquids

Material packaged in drums or tanks.

Using above process for two cases: hydrocarbon and chloro-hydrocarbon

Estimated hydrocarbon density for steel drums $=2.2$ to 2.8 
Table D-2. (continued).

L9000 Unknown pure liquids

Material packaged in drums or tanks

Estimated density range $=2.0$ to 2.8

S3110 Inorganic Particulates (fraction $>50 \%$ by volume)

Applicable densities:

Dust

0.64 to 0.72

Sand

0.5 to 1.1

Other

0.8 to 1.8

1.8 to 2.8

Material can have debris such as rags and paper

S3120 Inorganic Sludges (total suspended or settled solids $>30 \%$ )

Applicable densities:

Mud flowing

Mud packed

Clay wet 1.76

1.7

1.8

Portland cement 2.08 to 2.25

S3140 Salts (total $>50 \%$ by volume)

Applicable densities:

$\begin{array}{ll}\mathrm{NaCl} & 2.1 \\ \mathrm{NaNO}_{3} & 2.2 \\ \mathrm{NaSO}_{4} \cdot \mathrm{H}_{2} \mathrm{O} & 1.4 \\ \mathrm{NaOH} & 2.1\end{array}$

S3150 Solidified Homogeneous Solids (solids immobilized by cement) Portland cement 2.08 to 2.25

Estimated density range $=2.0$ to 2.3

S3190 Other Inorganic Homogeneous Solids

Estimated density range $=1.6$ to 3.0

S3210 Organic Homogeneous Solids (solids $>50 \%$ by volume)

Applicable densities:

$\begin{array}{ll}\text { Gelatin } & 1.27 \\ \text { Resin } & 1.07 \\ \text { Paraffin } & 0.9 \\ \text { Tar } & 1.02 \\ \text { Chlorinated greases } & 1.5 \\ \text { Ion Exchange Resin } & 1.1\end{array}$

D-4 
Table D-2. (continued).

Saw Dust

0.35

Estimated density range $=0.35$ to 1.5

S3220 Organic Sludge (solids $>50 \%$ by volume)

Applicable densities:

Chlorinated solvent + grease

0.9 to 1.3

S3230 Organic Chemicals ( $>50 \%$ )

Organic compounds

0.8 to 1.3

Glass

2.4

Vermiculite

0.35 (estimated)

S3290 Other Homogeneous Organic Solids ( $>50 \%$ by volume) Material can contained halogenated materials

Estimated density range $=0.9$ to 1.7

S3900 Other Heterogeneous Solids

Estimated density range $=0.5$ to 5.0 (depends on amount of metals)

S4100 Soil $(>50 \%)$

Estimated density range $=$ approximately 1.2 to 1.6 (depends on moisture)

S4200 Soil + Debris

Estimated density range $=1.1$ to 4.0 (depends on amount of metal)

1.2 to 1.5 (concrete)

S4300 Rock and Gravel

Applicable densities:

Sand/gravel/rock

Asphalt
1.4 to 1.7

1.1 to 1.5 
Table D-2. (continued).

S5110 Inorganic Debris (80\% inorganic debris material) (Metals)

Applicable densities:

$\begin{array}{ll}\text { Aluminum } & 2.7 \text { to } 2.8 \\ \text { Copper } & 8.8 \text { to } 8.9 \\ \text { Brass } & 8.4 \text { to } 8.7 \\ \text { Steel } & 7.8\end{array}$

Estimated density range $=2.5$ to 7.0 (depends on amount of aluminum)

S5120 Concrete Debris ( $80 \%$ by volume)

Applicable densities:
Concrete
2.7 to 3.0
Cinderblock
1.5 to 1.7

Estimated density $=1.8$ to 2.7

S5122 Glass ( $80 \%$ by volume)

Applicable densities:

Flint glass $\quad 2.4$ to 2.8

Fiberglass $\quad 0.3$ to 0.8 (depends on backing material)

S5126 Graphite Debris

Applicable density:

Graphite

1.7

S5190 Other Inorganic Debris

Estimated range $=1.2$ to 5.5

S5210 Plastic/Rubber Debris ( $80 \%$ by volume)

Applicable densities:

$\begin{array}{ll}\text { Abs plastic } & 1.02 \text { to } 1.06 \\ \text { Acrylic } & 1.18 \text { to } 1.2 \\ \text { Polycarbonate } & 1.2 \\ \text { Polypropylene } & 0.9 \text { to } 0.91 \text { (not high density) } \\ \text { Polystyrene } & 1.02 \text { to } 1.06 \\ \text { Polyurethane } & 1.03 \text { to } 1.06 \text { (solid) } \\ \text { PVC } & 1.38 \\ \text { Rubber } & 0.9 \text { to } 0.96 \\ \text { Teflon } & 2.1 \text { to } 2.3\end{array}$

Estimated density range $=0.9$ to 2.3 
Table D-2. (continued).

\$5320 Wood Debris ( $80 \%$ by volume)

Applicable densities:

Wood $\quad 0.4$ to 0.8

Plywood $\quad 0.6$ to 0.8

S5330 Paper/Cloth (80\% by volume)

Applicable densities:

Paper $\quad 0.7$ to 1.15

Cardboard $\quad 0.69$

Cotton $\quad 1.47$ to 1.5

Estimated density range $=0.7$ to 1.3

\$5340 Biological Debris

Estimated density range $=0.9$ to 1.0

S5390 Other Organic Debris

Estimated density range $=0.8$ to 1.2

S5410 Composite Filters (>50\%)

Applicable densities:

$\begin{array}{ll}\text { Wool } & 1.32 \\ \text { Paper } & 0.7 \text { to } 1.15 \\ \text { Wood } & 0.4 \text { to } 0.7 \\ \text { Metal } & 2.2 \text { to } 7.8\end{array}$

Estimated density range $=0.5$ to 1.4

S5420 Predominantly Inorganic Debris

Estimated density range $=1.0$ to 4.0

\$5440 Predominantly Organic Debris

Estimated density range $=0.9$ to 2.2 
Table D-2. (continued).

S5450 Asphalt Debris

Applicable densities:

$\begin{array}{ll}\text { Asphalt } & 1.1 \text { to } 1.5 \\ \text { Tar } & 1.02 \\ \text { Gravel } & 1.0 \\ \text { Sand \& Gravel } & 1.4 \text { to } 1.7 \\ \text { Wood } & 0.4 \text { to } 0.8 \\ \text { Cement } & 1.7 \text { to } 3.0\end{array}$

Estimated density range $=1.1$ to 2.2

S5460 Electrical Equipment

Applicable densities:

$\begin{array}{ll}\text { Metal } & 2 \text { to } 8 \\ \text { Plastic } & 1.0 \text { to } 1.5 \\ \text { Fiberglass } & 1.0 \text { to } 1.4 \text { (estimated) } \\ \text { Copper } & 8.0\end{array}$

Estimated density range $=2$ to 7 (depends on amount and type metal)

S5490 Heterogeneous Debris

Estimated density range $=0.6$ to 6.0 (could be anything)

S5900 Other Debris

Estimated density range $=$ (could be anything)

S9000 Unknown/Other Solids

Estimated density range $=$ (could be anything)

X6200 Aqueous Lab Packs

X6300 Solid Lab Packs

X6900 Other Lab Packs

X7100 Elemental Mercury

Mercury 13.6

X7219 Elemental Lead

Applicable density:

Lead

X7410 Lead Acid Batteries 
Table D-2. (continued).

Estimated density range $=11$

X7490 Other Batteries

Estimated density range $=? ? ?$

X7700 Compressed Gas

Estimated density range $=7$ (steel cylinders)

X7900 Other Special Waste 
Table D-3. Box material density by MPC for Idaho and Rocky Flats.

\begin{tabular}{cccc}
\hline MPC & Average Density & Minimum Density & Maximum Density \\
\hline S3110 & .46 & .27 & .88 \\
S3120 & 1 & & \\
S3220 & 1.58 & 1.08 & 2.05 \\
S5110 & .55 & .3 & 2.92 \\
S5120 & .85 & .8 & 1.64 \\
S5300 & .39 & .01 & 1.12 \\
S5410 & .28 & .02 & .78 \\
S5420 & .97 & .09 & 2.04 \\
S5440 & .58 & .19 & 1.62 \\
S9000 & .6 & .13 & 2.7 \\
Z1110 & 1.02 & .19 & 1.48 \\
\hline
\end{tabular}

Table D-4. Box material density by MPC for LLNL.

\begin{tabular}{cccc}
\hline MPC & Average Density & Minimum Density & Maximum Density \\
\hline S5110 & .13 & .03 & .38 \\
S5410 & .11 & & \\
S5420 & .12 & .11 & .18 \\
S5440 & .12 & .03 & .19 \\
S5490 & .21 & .08 & .34 \\
\hline
\end{tabular}


Table D-5. Box material density by MPC for Oak Ridge Site ETTP.

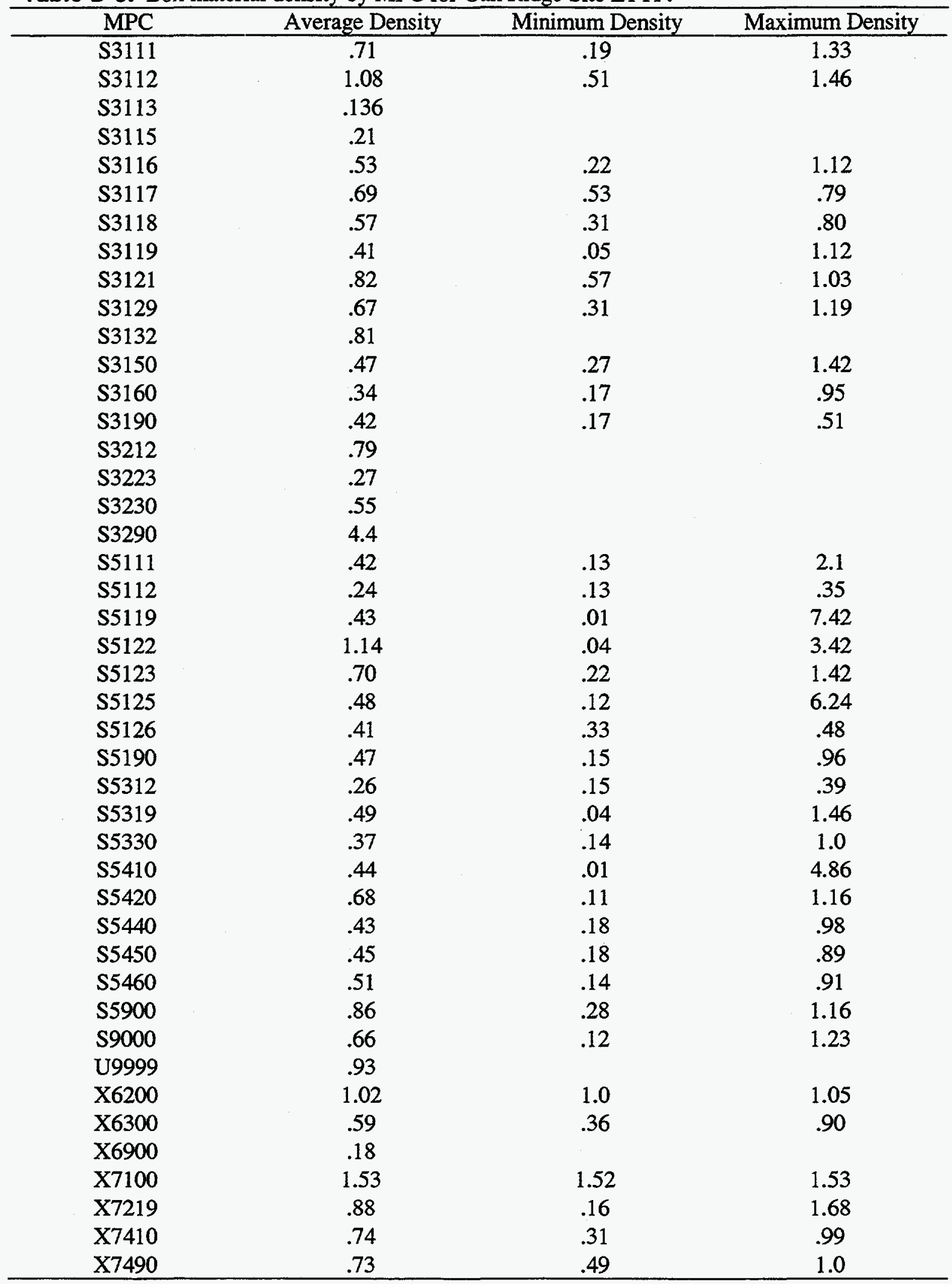


Table D-6. Box material density by MPC for Oak Ridge Site ORNL.

\begin{tabular}{|c|c|c|c|}
\hline MPC & Average Density & Minimum Density & Maximum Density \\
\hline L1190 & 1.08 & .80 & 1.33 \\
\hline S3111 & 1.29 & .99 & 1.47 \\
\hline S3114 & .94 & & \\
\hline S3115 & .73 & .28 & 1.05 \\
\hline S3119 & .87 & .66 & 1.05 \\
\hline S3121 & .84 & .71 & 1.01 \\
\hline S3129 & .79 & .57 & .89 \\
\hline S3144 & .84 & .80 & .87 \\
\hline S3150 & .88 & & \\
\hline S3230 & .97 & & \\
\hline S4100 & 1.43 & .34 & 1.99 \\
\hline$S 4200$ & 1.56 & .33 & 2.13 \\
\hline$S 4300$ & 1.25 & 1.13 & 1.5 \\
\hline Ș5112 & .34 & & \\
\hline S5119 & .46 & .02 & 2.8 \\
\hline S5125 & .34 & .02 & 2.06 \\
\hline S5312 & .33 & & \\
\hline S5319 & .28 & .05 & 2.99 \\
\hline S5230 & .27 & .03 & 1.49 \\
\hline S5330 & .13 & & \\
\hline S5340 & .33 & .32 & .33 \\
\hline S5410 & .10 & .02 & .24 \\
\hline S5440 & .12 & .01 & .81 \\
\hline$S 5450$ & 1.0 & .99 & 1.01 \\
\hline S5460 & .30 & .02 & .93 \\
\hline$\$ 9000$ & .88 & .07 & 4.66 \\
\hline X7219 & .62 & .42 & .82 \\
\hline X7900 & 1.71 & .21 & 6.32 \\
\hline
\end{tabular}


Table D-7. Box material density by MPC for Oak Ridge Site Y-12.

\begin{tabular}{|c|c|c|c|}
\hline MPC & Average Density & Minimum Density & Maximum Density \\
\hline L1210 & 1.68 & & \\
\hline L2190 & 1.20 & & \\
\hline L2210 & .01 & & \\
\hline L2290 & 1.19 & & \\
\hline S3111 & .20 & & \\
\hline S3114 & .52 & & \\
\hline S3116 & .26 & .20 & .40 \\
\hline S3118 & .71 & .50 & 1.0 \\
\hline S3121 & .94 & & \\
\hline S3129 & 10 & & \\
\hline S3142 & 1.2 & & \\
\hline S3144 & .75 & & \\
\hline S3149 & .24 & .05 & .50 \\
\hline S3290 & .08 & & \\
\hline S3900 & .29 & & \\
\hline$S 4100$ & 1.46 & .83 & 5.48 \\
\hline$S 4200$ & .85 & .33 & 1.56 \\
\hline$S 4300$ & 1.08 & .33 & 2.17 \\
\hline S5111 & .50 & .03 & 3.73 \\
\hline S5121 & .85 & .08 & 2.00 \\
\hline S5122 & .28 & .08 & .67 \\
\hline S5123 & 1.0 & .44 & 2.40 \\
\hline S5124 & .44 & .27 & .62 \\
\hline S5125 & .32 & .07 & 1.66 \\
\hline S5126 & .58 & .47 & .81 \\
\hline S5129 & .36 & .17 & .60 \\
\hline S5312 & .27 & .22 & .32 \\
\hline S5320 & .31 & .03 & 1.0 \\
\hline S5410 & .33 & .02 & 2.34 \\
\hline S5440 & .28 & .10 & 2.17 \\
\hline S5460 & .44 & .16 & .99 \\
\hline S5900 & .06 & .02 & .08 \\
\hline S9000 & .5 & .04 & 1.06 \\
\hline U9999 & .2 & & \\
\hline X7219 & .67 & & \\
\hline X7700 & .66 & & \\
\hline
\end{tabular}


Table D-8. Box material density by MPC for Hanford Site.

\begin{tabular}{cccc}
\hline MPC & Average Density & Minimum Density & Maximum Density \\
\hline S3113 & 1.03 & 1.01 & 1.04 \\
S5119 & .17 & .06 & .27 \\
S5121 & 2.37 & 2.38 & 2.35 \\
S5122 & 1.47 & 1.40 & 1.51 \\
S5390 & .12 & .05 & .26 \\
S5410 & .71 & .05 & .10 \\
S5420 & .13 & .06 & .39 \\
S5440 & .15 & .05 & .43 \\
S5900 & .15 & .07 & .42 \\
U9999 & .35 & & .81 \\
X6200 & .69 & .57 & 8.5 \\
X7290 & 8.08 & 7.95 &
\end{tabular}

Table D-9. Box material density by MPC for Savannah River Site.

\begin{tabular}{cccc}
\hline PC & Average Density & Minimum Density & Maximum Density \\
\hline L2290 & .04 & & \\
S4100 & 1.04 & .78 & 1.53 \\
S4200 & 1.1 & .71 & 1.84 \\
S5110 & .16 & .07 & .26 \\
S5113 & .08 & .04 & .10 \\
S5330 & .14 & .07 & .20 \\
S5410 & .07 & .04 & .07 \\
S5440 & .18 & & \\
X7100 & .11 & & 2.6 \\
X7219 & .82 & .04 & \\
\hline
\end{tabular}


Table D-10. INEEL Alpha Low-Level Mixed Waste content information.

\begin{tabular}{|c|c|c|c|c|}
\hline ID & IDC & MPC & Component & $\% \mathrm{WT}$ \\
\hline \multirow[t]{9}{*}{ ID-MDO-824 } & 824 & S5111 & Carbon Steel & 64.6 \\
\hline & & S5310 & Plexiglass & 17.9 \\
\hline & & X7211 & Bulk Lead & 5.5 \\
\hline & & S5410 & Filters & 5 \\
\hline & & S5330 & Cardboard & 2.5 \\
\hline & & S5320 & Wood & 2.5 \\
\hline & & $\mathrm{S} 5330$ & Paper & 1.4 \\
\hline & & S5310 & Plastic & 0.4 \\
\hline & & S5110 & Other Metals & 0.1 \\
\hline \multirow[t]{8}{*}{ ID-AEO-100 } & 100 & S5110 & Carbon Steel & 34.2 \\
\hline & & S5330 & Paper & 28.1 \\
\hline & & $\$ 5310$ & Plastic & 24.7 \\
\hline & & S5330 & Cloth & 5 \\
\hline & & S5122 & Glass & 5 \\
\hline & & S3113 & Sludge & 1 \\
\hline & & S3211 & Resins & 1 \\
\hline & & S5100 & Inorganics & 1 \\
\hline \multirow[t]{12}{*}{ ID-RFO-1 16} & 116 & S5310 & Plastics & 39.6 \\
\hline & & S5330 & Paper & 28.2 \\
\hline & & S5310 & Gloves & 7.7 \\
\hline & & S5320 & Wood & 4.8 \\
\hline & & S5330 & Cardboard & 4.8 \\
\hline & & S5330 & Cloth & 4.7 \\
\hline & & S5110 & Other Metal & 3.7 \\
\hline & & S5311 & Leaded Rubber & 2.4 \\
\hline & & S3113 & Oil-dri & 1.7 \\
\hline & & S5310 & Rubber & 1.3 \\
\hline & & S3113 & Vermiculite & 1.1 \\
\hline & & S5111 & Carbon Steel & 0.1 \\
\hline
\end{tabular}


Table D-10. (continued)

\begin{tabular}{|c|c|c|c|c|}
\hline ID & IDC & MPC & Component & $\% \mathrm{WT}$ \\
\hline \multirow[t]{11}{*}{ ID-RFO-330 } & 330 & S5310 & Plastics & 39.6 \\
\hline & & S5330 & Paper & 28.2 \\
\hline & & S5310 & Gloves & 7.7 \\
\hline & & S5330 & Cardboard & 4.8 \\
\hline & & S5320 & Wood & 4.8 \\
\hline & & $\mathbf{S 5 3 3 0}$ & Cloth & 4.7 \\
\hline & & S5110 & Other Metal & 3.7 \\
\hline & & S5311 & Oil-dri & 1.7 \\
\hline & & S5310 & Rubber & 1.3 \\
\hline & & S3113 & Vermiculite & 1.1 \\
\hline & & S5110 & Carbon Steel & 0.1 \\
\hline \multirow[t]{18}{*}{ ID-RFO-480 } & 480 & S5111 & Carbon Steel & 58.1 \\
\hline & & S5110 & Other Metal & 19.4 \\
\hline & & S5111 & Stainless Steel & 8.0 \\
\hline & & $\mathrm{X} 7219$ & Lead & 3.8 \\
\hline & & S5300 & Plastics & 3.8 \\
\hline & & S5330 & Paper & 3.4 \\
\hline & & $\$ 3113$ & Oil-dri & 2.0 \\
\hline & & S5122 & Other Glass & 0.9 \\
\hline & & S5122 & $\begin{array}{l}\text { Glass Filter } \\
\text { Material }\end{array}$ & 0.6 \\
\hline & & S5123 & Ceramic Molds & 0.6 \\
\hline & & S5125 & $\begin{array}{l}\text { Asbestos Filters } \\
\text { and Insulation }\end{array}$ & 0.6 \\
\hline & & $\mathrm{S} 4100$ & Soil & 0.6 \\
\hline & & S5111 & Tantalum (10W) & 0.6 \\
\hline & & S3113 & Vermiculite & 0.3 \\
\hline & & S3117 & $\begin{array}{l}\text { Glass Rashig } \\
\text { Rings }\end{array}$ & 0.2 \\
\hline & & S5320 & Wood & 0.1 \\
\hline & & S5121 & Concrete & 0.1 \\
\hline & & S5311 & Leaded Rubber & 0.1 \\
\hline
\end{tabular}


Table D-10. (continued)

\begin{tabular}{|c|c|c|c|c|}
\hline ID & $\mathrm{IDC}$ & MPC & Component & $\% \mathrm{WT}$ \\
\hline \multirow[t]{11}{*}{ ID-RFO-490 } & 490 & S5410 & Stainless Steel & 36 \\
\hline & & S5410 & Wood & 25 \\
\hline & & S5410 & $\begin{array}{l}\text { Glass Filter } \\
\text { Medium }\end{array}$ & 11 \\
\hline & & S5419 & $\begin{array}{l}\text { Asbestos filters } \\
\text { and Insulation }\end{array}$ & 11 \\
\hline & & S5310 & Plastics & 7 \\
\hline & & S5410 & Filter Dust & 2 \\
\hline & & S3133 & Vermiculite & 2 \\
\hline & & S5410 & Rubber & 2 \\
\hline & & S5410 & Cardboard & 2 \\
\hline & & S3113 & Oil-dri & 1 \\
\hline & & $\$ 3113$ & Portland Cement & 1 \\
\hline \multirow[t]{8}{*}{ ID-RFO-950 } & 950 & S5111 & Carbon Steel & 43.1 \\
\hline & & S5120 & Sheet Rock & 26.5 \\
\hline & & S5122 & Other Glass & 17.9 \\
\hline & & X7219 & Lead & 5.5 \\
\hline & & S5320 & Wood & 5.0 \\
\hline & & $\$ 5330$ & Paper & 1.4 \\
\hline & & S5310 & Plastics & 0.4 \\
\hline & & S5111 & Other Metal & 0.1 \\
\hline \multirow[t]{5}{*}{ ID-RFO-338 } & 338 & S5410 & $\begin{array}{l}\text { Glass Filter } \\
\text { Media }\end{array}$ & 42.1 \\
\hline & & S5410 & $\begin{array}{l}\text { Asbestos Filters } \\
\text { and Insulation }\end{array}$ & 42.1 \\
\hline & & $\mathrm{S} 5310$ & Plastics & 7.4 \\
\hline & & S3113 & Oil-dri & 4.4 \\
\hline & & S5410 & Filter Dust & 4.0 \\
\hline
\end{tabular}


Appendix E

Radionuclide Inventories 
Table E-1. Idaho Alpha Low-Level Mixed radiological activity.

\begin{tabular}{ccccc}
\hline Nuclide & Avg. Ci/g & Median Ci/g & Min. Ci/g & Max. Ci/g \\
\hline Pu-52 & $1.78 E-8$ & $1.73 E-8$ & $1.24 \mathrm{E}-8$ & $2.49 \mathrm{E}-8$ \\
Pu-239 & $3.4 \mathrm{E}-8$ & - & $6.5 \mathrm{E}-8$ & $2.97 \mathrm{E}-9$ \\
Pu-242 & $9.9 \mathrm{E}-10$ & & & \\
Th-232 & $2.95 \mathrm{E}-12$ & & & \\
$\mathrm{U}-233$ & $5.07 \mathrm{E}-7$ & $4.41 \mathrm{E}-7$ & $1.08 \mathrm{E}-6$ & $5.77 \mathrm{E}-10$ \\
$\mathrm{U}-235$ & $2.82 \mathrm{E}-11$ & $1.42 \mathrm{E}-11$ & $7.62 \mathrm{E}-11$ & $8.21 \mathrm{E}-12$ \\
$\mathrm{U}-238$ & $7.45 \mathrm{E}-9$ & - & $8.13 \mathrm{E}-12$ & $1.49 \mathrm{E}-8$ \\
\hline
\end{tabular}

Idaho Transuranic Radiological Activities of Nine Major Matrix Types

\begin{tabular}{ccccc}
\hline Nuclide & Avg. nCi/g & Median nCi/g & Max nCi/g & Min.nCi/g \\
\hline Am-241 & $5.15 \mathrm{E}+5$ & $2.56 \mathrm{E}+5$ & $2.6 \mathrm{E}+6$ & $1.58 \mathrm{E}+2$ \\
$\mathrm{~Np}-237$ & $1.32 \mathrm{E}+2$ & $1.32 \mathrm{E}+2$ & $2.34 \mathrm{E}+2$ & $3.07 \mathrm{E}+1$ \\
$\mathrm{Cf}-241$ & $3.70 \mathrm{E}+5$ & $1.07 \mathrm{E}+5$ & $1.25 \mathrm{E}+6$ & $1.38 \mathrm{E}+4$ \\
$\mathrm{Pu}-238$ & $5.47 \mathrm{E}+6$ & $1.95 \mathrm{E}+5$ & $1.25 \mathrm{E}+6$ & $1.38 \mathrm{E}+4$ \\
$\mathrm{Pu}-239$ & $1.84 \mathrm{E}+5$ & & & \\
$\mathrm{Pu}-240$ & & & & \\
$\mathrm{Pu}-241$ & $6.01 \mathrm{E}+2$ & & $1.2 \mathrm{E}+3$ & 1.73 \\
$\mathrm{Pu}-52$ & $1.15 \mathrm{E}+5$ & & $2.80 \mathrm{E}+5$ & $8.79 \mathrm{E}+3$ \\
$\mathrm{Pu}-83$ & $3.50 \mathrm{E}+6$ & & $6.52 \mathrm{E}+6$ & $4.78 \mathrm{E}+5$ \\
\hline
\end{tabular}


Table E-2. Rocky Flats radiological activity by waste type.

\begin{tabular}{|c|c|c|c|c|}
\hline Waste Type & Isotope & Avg. Mass & $g / g$ (waste) & $\mathrm{g} / \mathrm{g}(\mathrm{kg})$ \\
\hline \multirow[t]{11}{*}{ LLM } & Am-241 & $7.3 \mathrm{E}-4$ & $2.67 \mathrm{E}-7$ & $5.87 \mathrm{E}-7$ \\
\hline & $\mathrm{K}-40$ & 1.94 & $7.08 \mathrm{E}-4$ & $1.55 \mathrm{E}-3$ \\
\hline & $\mathrm{Pu}-000$ & 0.21 & $1.65 \mathrm{E}-4$ & $3.6 \mathrm{E}-4$ \\
\hline & $\mathrm{Pu}-238$ & $5.11 \mathrm{E}-6$ & $1.86 \mathrm{E}-9$ & 4.1E-9 \\
\hline & $\mathrm{Pu}-239$ & $4.06 \mathrm{E}-2$ & $1.48 \mathrm{E}-5$ & $3.26 \mathrm{E}-5$ \\
\hline & $\mathrm{Pu}-240$ & $2.57 \mathrm{E}-2$ & $9.36 \mathrm{E}-7$ & $2.06 \mathrm{E}-6$ \\
\hline & $\mathrm{Pu}-241$ & $6.59 \mathrm{E}-6$ & $2.40 E-9$ & $5.29 \mathrm{E}-9$ \\
\hline & Th-230 & $3.55 \mathrm{E}-3$ & $1.30 \mathrm{E}-6$ & $2.85 \mathrm{E}-6$ \\
\hline & $\mathrm{U}-235$ & $5 E-3$ & $1.1 \mathrm{E}-6$ & $2.42 \mathrm{E}-6$ \\
\hline & U238 & $7.6 \mathrm{E}-1$ & $1.68 \mathrm{E}-4$ & $3.69 \mathrm{E}-4$ \\
\hline & Unat & $8.75 \mathrm{E} 2$ & $3.19 \mathrm{E}-1$ & $7.02 \mathrm{E}-1$ \\
\hline \multirow[t]{2}{*}{ LLT } & Am-241 & $1.9 \mathrm{E}-3$ & $5.61 \mathrm{E}-7$ & $1.23 \mathrm{E}-6$ \\
\hline & $\mathrm{Pu}-000$ & $4 \mathrm{E}-1$ & $2.6 \mathrm{E}-4$ & $4.53 \mathrm{E}-4$ \\
\hline \multirow[t]{8}{*}{ LLW } & Am-241 & $1 \mathrm{E}-3$ & $6.11 \mathrm{E}-7$ & $1.34 \mathrm{E}-6$ \\
\hline & $\mathrm{Pu}-000$ & $3.74 \mathrm{E}-1$ & $3.1 \mathrm{E}-4$ & $6.8 E-4$ \\
\hline & $\mathrm{Pu}-238$ & $1.05 \mathrm{E}-4$ & $3.9 \mathrm{E}-8$ & $8.58 \mathrm{E}-8$ \\
\hline & $\mathrm{Pu}-240$ & $2 \mathrm{E}-6$ & $7.88 \mathrm{E}-10$ & 8.54E-10 \\
\hline & U-234 & $1.62 \mathrm{E}-3$ & $6.28 \mathrm{E}-7$ & $1.38 \mathrm{E}-6$ \\
\hline & $\mathrm{U}-235$ & $2.45 \mathrm{E} 1$ & $6.23 E-3$ & $1.82 \mathrm{E}-1$ \\
\hline & U-238 & $1.17 \mathrm{E} 1$ & $6.23 E-3$ & $1.37 \mathrm{E}-2$ \\
\hline & $\mathrm{U}($ pond) & $1.82 \mathrm{E} 3$ & 4.16 & 9.16 \\
\hline \multirow[t]{2}{*}{ TRM } & Am-241 & $6.67 \mathrm{E}-1$ & $2.79 \mathrm{E}-4$ & $6.14 \mathrm{E}-4$ \\
\hline & $\mathrm{Pu} 000$ & $1.73 \mathrm{E} 1$ & $9.58 \mathrm{E}-3$ & $2.1 \mathrm{E}-2$ \\
\hline \multirow[t]{2}{*}{ TRU } & $\mathrm{Am}-241$ & $9.02 \mathrm{E}-1$ & $5.62 E-4$ & $1.23 \mathrm{E}-3$ \\
\hline & $\mathrm{Pu} 000$ & $3.47 \mathrm{E} 1$ & $2.08 \mathrm{E}-2$ & $4.58 \mathrm{E}-2$ \\
\hline
\end{tabular}


Table E-3. Radionuclide content for TRU box waste at LLNL.

\begin{tabular}{ccccc}
\hline Isotope & Avg. Ci/g & Median Ci/g & Max & Min \\
\hline Am-241 & $7.14 \mathrm{E}-8$ & $8.52 \mathrm{E}-9$ & $7.47 \mathrm{E}-7$ & $1.09 \mathrm{E}-9$ \\
Pu-238 & $7.58 \mathrm{E}-8$ & $3.29 \mathrm{E}-9$ & $1.52 \mathrm{E}-6$ & $4.33 \mathrm{E}-10$ \\
Pu-239 & $3.24 \mathrm{E}-7$ & $7.16 \mathrm{E}-8$ & $2.12 \mathrm{E}-6$ & $9.19 \mathrm{E}-9$ \\
Pu-240 & $8.12 \mathrm{E}-8$ & $1.54 \mathrm{E}-8$ & $4.89 \mathrm{E}-7$ & $2.12 \mathrm{E}-9$ \\
Pu-241 & $2.4 \mathrm{E}-6$ & $4.51 \mathrm{E}-7$ & $1.42 \mathrm{E}-5$ & $6.18 \mathrm{E}-8$ \\
Pu242 & $1.71 \mathrm{E}-11$ & $1.81 \mathrm{E}-12$ & $1.89 \mathrm{E}-10$ & $2.48 \mathrm{E}-13$ \\
\hline
\end{tabular}


Table E-4. Radionuclide content of boxed waste at Oak Ridge National Laboratory.

\begin{tabular}{|c|c|c|c|c|}
\hline Waste Type & Isotope & Avg. Ci/g & $\operatorname{Max}$ & Min \\
\hline \multirow[t]{31}{*}{ LLW } & Ac-225 & $5.14 \mathrm{E}-9$ & $2.35 \mathrm{E}-8$ & $2.20 \mathrm{E}-11$ \\
\hline & $\mathrm{Ag}-108 \mathrm{~m}$ & $3 E-10$ & & \\
\hline & $\mathrm{Ag}-110 \mathrm{~m}$ & $1.11 \mathrm{E}-8$ & $4.32 \mathrm{E}-7$ & $2.19 \mathrm{E}-13$ \\
\hline & Ag-111 & $3.1 \mathrm{E}-10$ & $7.5 \mathrm{E}-10$ & $2.76 \mathrm{E}-11$ \\
\hline & Am-241 & $1.86 \mathrm{E}-9$ & $6.79 \mathrm{E}-7$ & $3.06 \mathrm{E}-17$ \\
\hline & Am-243 & $5.91 \mathrm{E}-10$ & $1.26 \mathrm{E}-7$ & $5.11 \mathrm{E}-16$ \\
\hline & Am-244 & $8.16 \mathrm{E}-18$ & & \\
\hline & $\mathrm{Ba}-137 \mathrm{~m}$ & $4.47 \mathrm{E}-9$ & $9.61 \mathrm{E}-9$ & $2.41 \mathrm{E}-9$ \\
\hline & C-14 & $9.40 \mathrm{E}-9$ & $2.45 \mathrm{E}-7$ & $6.84 \mathrm{E}-19$ \\
\hline & Cd-109 & $4.83 \mathrm{E}-13$ & & \\
\hline & Ce-141 & $4.31 \mathrm{E}-8$ & $5.8 \mathrm{E}-7$ & $2.31 \mathrm{E}-10$ \\
\hline & $\mathrm{Ce}-144$ & $2.88 \mathrm{E}-7$ & $1.83 \mathrm{E}-5$ & $6.82 \mathrm{E}-18$ \\
\hline & Cf-252 & $2.02 \mathrm{E}-12$ & $2.76 \mathrm{E}-11$ & $3.62 \mathrm{E}-15$ \\
\hline & $\mathrm{Cm}-244$ & $1.11 \mathrm{E}-6$ & $4.66 \mathrm{E}-4$ & $5.51 \mathrm{E}-17$ \\
\hline & $\mathrm{Co}-57$ & $1.96 \mathrm{E}-11$ & $6.99 \mathrm{E}-11$ & $2.94 \mathrm{E}-12$ \\
\hline & $\mathrm{Co}-58$ & $5.43 \mathrm{E}-11$ & & \\
\hline & $\mathrm{Co}-60$ & $3.01 \mathrm{E}-7$ & $6.33 \mathrm{E}-5$ & $6.57 \mathrm{E}-19$ \\
\hline & $\mathrm{Cr}-51$ & $8.4 \mathrm{E}-8$ & $4.87 E-6$ & $9.57 \mathrm{E}-17$ \\
\hline & Cs-134 & 1.17E-7 & $4.96 \mathrm{E}-5$ & $1.08 \mathrm{E}-17$ \\
\hline & Cs-137 & $2.41 \mathrm{E}-6$ & $2.76 \mathrm{E}-3$ & $4.41 \mathrm{E}-17$ \\
\hline & Dy-166 & $1.43 \mathrm{E}-8$ & & \\
\hline & $\mathrm{Eu}-152$ & $1.34 \mathrm{E}-7$ & $3.33 \mathrm{E}-5$ & $5.9 \mathrm{E}-71$ \\
\hline & Eu-154 & $9.43 \mathrm{E}-8$ & $1.39 \mathrm{E}-5$ & $1.62 \mathrm{E}-19$ \\
\hline & Eu-155 & $1.45 \mathrm{E}-8$ & $4.51 E-6$ & $4.11 \mathrm{E}-19$ \\
\hline & Eu-156 & $2.82 \mathrm{E}-10$ & & \\
\hline & $\mathrm{Fe}-55$ & $8.46 \mathrm{E}-8$ & $2.72 \mathrm{E}-7$ & $4.41 \mathrm{E}-10$ \\
\hline & $\mathrm{Fe}-59$ & $2.08 \mathrm{E}-10$ & $8.26 \mathrm{E}-9$ & $6.63 \mathrm{E}-15$ \\
\hline & Gd-153 & $4.11 \mathrm{E}-10$ & $1.23 \mathrm{E}-9$ & $5.64 \mathrm{E}-12$ \\
\hline & $\mathrm{H}-3$ & $4.17 \mathrm{E}-4$ & $2.53 \mathrm{E}-2$ & $2.49 \mathrm{E}-19$ \\
\hline & Hf-181 & $2.2 \mathrm{E}-10$ & $1.01 \mathrm{E}-9$ & $2.44 \mathrm{E}-13$ \\
\hline & $\mathrm{Hg}-203$ & 2.13E-11 & 2.75E-11 & $1.52 \mathrm{E}-11$ \\
\hline
\end{tabular}


Table E-4. (continued)

\begin{tabular}{|c|c|c|c|c|}
\hline Waste Type & Isotope & Avg. Ci/g & $\operatorname{Max}$ & Min \\
\hline & Ho-166m & $5.18 \mathrm{E}-10$ & & \\
\hline & $1-125$ & $1.15 \mathrm{E}-9$ & $1.80 \mathrm{E}-8$ & $8.82 \mathrm{E}-12$ \\
\hline & $\mathrm{I}-131$ & $8.39 \mathrm{E}-10$ & $5.13 \mathrm{E}-9$ & $4.41 \mathrm{E}-13$ \\
\hline & In-114m & 1.E-11 & & \\
\hline & $\mathrm{Ir}-192$ & 2.E-7 & $1.9 \mathrm{E}-5$ & $1.05 \mathrm{E}-15$ \\
\hline & $\mathrm{K}-40$ & $2.20 \mathrm{E}-9$ & $5.67 \mathrm{E}-9$ & $2.17 \mathrm{E}-13$ \\
\hline & $\mathrm{Kr}-85$ & $2.92 \mathrm{E}-13$ & $3.22 \mathrm{E}-13$ & $2.61 \mathrm{E}-13$ \\
\hline \multirow[t]{25}{*}{. } & $M n-54$ & $1.45 \mathrm{E}-8$ & $7.88 \mathrm{E}-8$ & $1.26 \mathrm{E}-12$ \\
\hline & Mo-99 & $5.92 \mathrm{E}-9$ & $7.72 \mathrm{E}-9$ & 4.13E-9 \\
\hline & $\mathrm{Na}-22$ & $8.87 \mathrm{E}-13$ & $1.06 \mathrm{E}-12$ & $7.85 \mathrm{E}-13$ \\
\hline & $\mathrm{Na}-24$ & $8.78 \mathrm{E}-10$ & & \\
\hline & $\mathrm{Ni}-63$ & $5.75 \mathrm{E}-5$ & $1.03 \mathrm{E}-3$ & $9.08 E-9$ \\
\hline & $\mathrm{Np}-237$ & $6.30 \mathrm{E}-12$ & & \\
\hline & Os-191 & $6.06 \mathrm{E}-9$ & $6.21 \mathrm{E}-8$ & $1.46 \mathrm{E}-12$ \\
\hline & $\mathrm{Pa}-231$ & $1.76 \mathrm{E}-11$ & & \\
\hline & $\mathrm{Pb}-210$ & $1.54 \mathrm{E}-10$ & $4.45 \mathrm{E}-10$ & $7.48 \mathrm{E}-12$ \\
\hline & $\mathrm{Pm}-147$ & $3.75 \mathrm{E}-7$ & & \\
\hline & $\mathrm{Pu}-238$ & $3.18 \mathrm{E}-10$ & $1.98 \mathrm{E}-8$ & 8.07E-17 \\
\hline & $\mathrm{Pu}-239$ & $1.14 \mathrm{E}-9$ & $1.29 \mathrm{E}-7$ & $8.78 \mathrm{E}-18$ \\
\hline & $\mathrm{Pu}-240$ & $7.67 \mathrm{E}-10$ & $4.41 \mathrm{E}-8$ & $8.78 \mathrm{E}-18$ \\
\hline & $\mathrm{Pu}-241$ & $3.43 \mathrm{E}-11$ & $1.22 \mathrm{E}-10$ & $9.13 \mathrm{E}-12$ \\
\hline & $\mathrm{Pu}-242$ & $3.43 \mathrm{E}-9$ & $2.94 \mathrm{E}-8$ & $9.04 \mathrm{E}-11$ \\
\hline & $\mathrm{Ra}-226$ & $1.69 \mathrm{E}-8$ & $9.24 \mathrm{E}-8$ & $5.99 \mathrm{E}-13$ \\
\hline & $\operatorname{Re}-186$ & $5.46 \mathrm{E}-8$ & $4.1 \mathrm{E}-7$ & $7.56 \mathrm{E}-12$ \\
\hline & $\operatorname{Re}-188$ & $1.36 \mathrm{E}-7$ & $5.07 \mathrm{E}-7$ & $2.65 \mathrm{E}-11$ \\
\hline & Ru-106 & $7.41 \mathrm{E}-10$ & $2.67 \mathrm{E}-9$ & $1.42 \mathrm{E}-10$ \\
\hline & Sb-124 & 3.7E-9 & $5.51 \mathrm{E}-8$ & $3.36 \mathrm{E}-13$ \\
\hline & Sb-125 & 2.E-10 & $5.69 \mathrm{E}-10$ & $5.88 \mathrm{E}-12$ \\
\hline & $\mathrm{Sc}-46$ & $4.98 \mathrm{E}-10$ & $4.49 E-9$ & $4.23 E-13$ \\
\hline & $\mathrm{Se}-75$ & 8.33E-11 & & \\
\hline & Sm-151 & $2.24 \mathrm{E}-11$ & $7.95 \mathrm{E}-11$ & $5.96 \mathrm{E}-12$ \\
\hline & Sn-117m & $1.76 \mathrm{E}-10$ & $5.88 \mathrm{E}-10$ & $294 \mathrm{E}-12$ \\
\hline
\end{tabular}


Table E-4. (continued)

\begin{tabular}{|c|c|c|c|c|}
\hline Waste Type & Isotope & Avg. $\mathrm{Ci} / \mathrm{g}$ & $\operatorname{Max}$ & Min \\
\hline & Sr-85 & $2.87 \mathrm{E}-10$ & $7.27 \mathrm{E}-10$ & $1.01 \mathrm{E}-12$ \\
\hline & Sr-89 & $2.87 \mathrm{E}-7$ & $5.24 \mathrm{E}-7$ & $1.66 \mathrm{E}-8$ \\
\hline & Sr-90 & $6.95 \mathrm{E}-7$ & $3.33 E-4$ & $7.69 E-33$ \\
\hline & Ta-182 & $2.11 \mathrm{E}-10$ & $2.35 E-9$ & $1.87 \mathrm{E}-12$ \\
\hline & $\mathrm{Tb}-160$ & $1.6 \mathrm{E}-12$ & & \\
\hline & Tc-99 & $2.48 \mathrm{E}-10$ & $2.94 \mathrm{E}-8$ & $7.70 \mathrm{E}-14$ \\
\hline & Th-228 & $2.22 \mathrm{E}-12$ & $1.67 \mathrm{E}-11$ & $4.74 \mathrm{E}-13$ \\
\hline & Th-230 & $1.23 \mathrm{E}-12$ & $1.01 \mathrm{E}-11$ & $9.44 \mathrm{E}-14$ \\
\hline & Th-232 & $2.55 \mathrm{E}-10$ & $2.72 \mathrm{E}-8$ & $2.64 \mathrm{E}-24$ \\
\hline & Th-234 & $8.03 E-12$ & & \\
\hline & U-232 & $5.88 \mathrm{E}-9$ & $1.15 \mathrm{E}-7$ & $1.08 \mathrm{E}-79$ \\
\hline & $U-233$ & $4.76 E-9$ & $4.12 \mathrm{E}-7$ & $5.69 \mathrm{E}-17$ \\
\hline & U-234 & $4.60 \mathrm{E}-10$ & $2.54 \mathrm{E}-8$ & $2.36 \mathrm{E}-14$ \\
\hline & U-235 & $1.71 \mathrm{E}-10$ & $8.05 \mathrm{E}-8$ & $2.38 \mathrm{E}-18$ \\
\hline & $\mathrm{U}-236$ & $2.93 \mathrm{E}-12$ & $1.21 \mathrm{E}-10$ & $5.03 \mathrm{E}-16$ \\
\hline & U-238 & $4.26 \mathrm{E}-9$ & $4.23 \mathrm{E}-7$ & $1.68 \mathrm{E}-23$ \\
\hline & U-239 & $7.94 \mathrm{E}-12$ & & \\
\hline & W-188 & $1.24 \mathrm{E}-7$ & $4.89 \mathrm{E}-6$ & $3.21 \mathrm{E}-13$ \\
\hline & $Y-90$ & $3.17 \mathrm{E}-7$ & $4.27 \mathrm{E}-5$ & $6.12 \mathrm{E}-12$ \\
\hline & $\mathrm{Zn}-65$ & $1.06 \mathrm{E}-6$ & $7.05 \mathrm{E}-5$ & $7.28 \mathrm{E}-17$ \\
\hline \multirow[t]{11}{*}{ TRU } & $\mathrm{Ag}-110 \mathrm{~m}$ & $2.68 \mathrm{E}-7$ & $8.64 \mathrm{E}-7$ & $4.08 \mathrm{E}-8$ \\
\hline & Am-241 & $3.07 \mathrm{E}-7$ & $8.82 E-6$ & $3.46 \mathrm{E}-12$ \\
\hline & Am-243 & $2.74 \mathrm{E}-8$ & $4.89 \mathrm{E}-8$ & $3.66 \mathrm{E}-9$ \\
\hline & Cd-109 & $4.28 \mathrm{E}-11$ & & \\
\hline & Cf-252 & $7.72 \mathrm{E}-7$ & & \\
\hline & $\mathrm{Cm}-244$ & $4.75 \mathrm{E}-7$ & $4.69 \mathrm{E}-6$ & $4.41 E-15$ \\
\hline & Cs-134 & $3.64 \mathrm{E}-8$ & $1.18 \mathrm{E}-8$ & $5.54 E-9$ \\
\hline & Cs-137 & $6.82 \mathrm{E}-7$ & $2.78 \mathrm{E}-6$ & $1.57 \mathrm{E}-10$ \\
\hline & Eu-154 & $4.57 \mathrm{E}-8$ & $1.47 \mathrm{E}-7$ & $6.93 \mathrm{E}-9$ \\
\hline & Eu-155 & $2.76 \mathrm{E}-8$ & $8.91 \mathrm{E}-8$ & $4.2 \mathrm{E}-9$ \\
\hline & Np-237 & $2.78 \mathrm{E}-7$ & $5.51 \mathrm{E}-7$ & $3.94 \mathrm{E}-9$ \\
\hline
\end{tabular}


Table E-4. (continued)

\begin{tabular}{ccccc}
\hline Waste Type & Isotope & Avg. Ci/g & Max & Min \\
\hline Pu-238 & $2.2 \mathrm{E}-8$ & $7.01 \mathrm{E}-8$ & $1.63 \mathrm{E}-12$ \\
Pu-239 & $5.98 \mathrm{E}-7$ & $4.41 \mathrm{E}-6$ & $3.67 \mathrm{E}-13$ \\
Pu-240 & $1.37 \mathrm{E}-7$ & $8.42 \mathrm{E}-7$ & $3.53 \mathrm{E}-9$ \\
Pu-241 & $5.45 \mathrm{E}-4$ & & \\
Pu-242 & $1.85 \mathrm{E}-7$ & $3.69 \mathrm{E}-7$ & $1.36 \mathrm{E}-11$ \\
Sr-90 & $3.42 \mathrm{E}-7$ & $1.16 \mathrm{E}-6$ & $1.57 \mathrm{E}-10$ \\
$\mathrm{U}-233$ & $1.20 \mathrm{E}-6$ & $1.5 \mathrm{E}-5$ & $3.67 \mathrm{E}-13$ \\
$\mathrm{U}-234$ & $3.66 \mathrm{E}-10$ & & \\
$\mathrm{U}-235$ & $5.95 \mathrm{E}-12$ & & \\
$\mathrm{U}-236$ & $1.02 \mathrm{E}-10$ & & \\
$\mathrm{U}-238$ & $7.35 \mathrm{E}-10$ & & \\
\hline
\end{tabular}


Table E-5. Radionuclide content for boxed waste by MPC at the Hanford Site (Ci/g).

\begin{tabular}{|c|c|c|c|c|c|c|c|}
\hline MPC & $\mathrm{Mn}-54$ & $\mathrm{C} 0-60$ & Sr-90 & $Y-90$ & Tc-99 & Cs-137 & $\mathrm{Ba} 137$ \\
\hline S3113 & & $1.5 \mathrm{E}-8$ & $1.3 \mathrm{E}-6$ & $1.27 \mathrm{E}-6$ & $1.23 \mathrm{E}-7$ & $1.23 \mathrm{E}-6$ & $1.16 \mathrm{E}-6$ \\
\hline S5119 & & & $1.1 \mathrm{E}-6$ & $1.15 \mathrm{E}-6$ & $8.7 \mathrm{E}-11$ & $1.28 \mathrm{E}-6$ & $1.21 \mathrm{E}-6$ \\
\hline S5121 & & $3.1 \mathrm{E}-12$ & 0.21 & .21 & $4.25 \mathrm{E}-12$ & .254 & .241 \\
\hline \multicolumn{8}{|l|}{ S5319 } \\
\hline S5390 & $4.0 \mathrm{E}-10$ & $6 \mathrm{E}-9$ & & & & $1.1 \mathrm{E}-6$ & $1.04 \mathrm{E}-6$ \\
\hline S5410 & & $8.2 \mathrm{E}-7$ & 3.7E-5 & $3.69 \mathrm{E}-5$ & & $9.55 \mathrm{E}-5$ & $3.0 \mathrm{E}-7$ \\
\hline S5420 & & & & & & $3.99 \mathrm{E}-6$ & $3.78 \mathrm{E}-6$ \\
\hline \multicolumn{8}{|l|}{ S5440 } \\
\hline \multicolumn{8}{|l|}{ S5900 } \\
\hline \multicolumn{8}{|l|}{ U0000 } \\
\hline \multicolumn{8}{|l|}{$X 6200$} \\
\hline$X 7219$ & . & & & & & & \\
\hline \multicolumn{8}{|l|}{$X 7290$} \\
\hline MPC & Pu-238 & \multicolumn{2}{|c|}{ Pu-239 } & $\mathrm{Pu}-240$ & \multicolumn{2}{|c|}{$\mathrm{Pu}-241$} & Am-241 \\
\hline$\$ 3113$ & $5.56 \mathrm{E}-8$ & \multicolumn{2}{|c|}{$1.14 \mathrm{E}-7$} & $5.56 \mathrm{E}-8$ & \multicolumn{2}{|c|}{$3.44 \mathrm{E}-6$} & $1.58 \mathrm{E}-7$ \\
\hline S5119 & $1.34 \mathrm{E}-7$ & \multicolumn{2}{|c|}{$4.19 \mathrm{E}-7$} & $1.66 \mathrm{E}-7$ & \multicolumn{2}{|c|}{$9.01 \mathrm{E}-6$} & $3.89 \mathrm{E}-7$ \\
\hline S5121 & $1.2 \mathrm{E}-7$ & \multicolumn{2}{|c|}{$1.51 \mathrm{E}-6$} & $3.48 \mathrm{E}-7$ & \multicolumn{2}{|c|}{$1.24 \mathrm{E}-5$} & $5.44 \mathrm{E}-7$ \\
\hline S5319 & 4.47E-9 & \multicolumn{2}{|c|}{$2.2 \mathrm{E}-8$} & 3.28E-9 & \multicolumn{2}{|c|}{$2.41 \mathrm{E}-7$} & $3.82 \mathrm{E}-7$ \\
\hline S5390 & $2.58 \mathrm{E}-8$ & \multicolumn{2}{|c|}{$2.77 \mathrm{E}-7$} & $6.34 \mathrm{E}-8$ & \multicolumn{2}{|c|}{$2.12 \mathrm{E}-6$} & $4.94 \mathrm{E}-7$ \\
\hline S5410 & $1.04 \mathrm{E}-6$ & \multicolumn{2}{|c|}{$2.38 \mathrm{E}-6$} & $1.02 \mathrm{E}-6$ & \multicolumn{2}{|c|}{$1.18 \mathrm{E}-4$} & 4.27E-8 \\
\hline S5420 & $3.71 \mathrm{E}-7$ & \multicolumn{2}{|c|}{$3.45 \mathrm{E}-6$} & $8.79 \mathrm{E}-7$ & \multicolumn{2}{|c|}{$4.08 \mathrm{E}-5$} & $2.91 \mathrm{E}-7$ \\
\hline S5440 & $5.71 \mathrm{E}-7$ & \multicolumn{2}{|c|}{$6.73 E-6$} & $1.50 \mathrm{E}-6$ & \multicolumn{2}{|c|}{$5.36 \mathrm{E}-5$} & $5.01 \mathrm{E}-7$ \\
\hline$\$ 5900$ & $6.44 \mathrm{E}-8$ & \multicolumn{2}{|c|}{$7.52 \mathrm{E}-7$} & $1.67 \mathrm{E}-7$ & \multicolumn{2}{|c|}{$5.91 \mathrm{E}-6$} & $5.96 \mathrm{E}-8$ \\
\hline \multicolumn{8}{|l|}{ U0000 } \\
\hline $\mathrm{X} 6200$ & $2.97 \mathrm{E}-8$ & \multicolumn{2}{|c|}{$3.66 \mathrm{E}-7$} & $7.71 \mathrm{E}-8$ & \multicolumn{2}{|c|}{$2.72 \mathrm{E}-6$} & $2.74 \mathrm{E}-8$ \\
\hline$X 7219$ & $6.29 \mathrm{E}-7$ & \multicolumn{2}{|c|}{$8.16 \mathrm{E}-6$} & $1.82 \mathrm{E}-6$ & \multicolumn{2}{|c|}{$6.69 \mathrm{E}-5$} & $5.06 \mathrm{E}-7$ \\
\hline$X 7290$ & $7.49 \mathrm{E}-7$ & 8.9 & & $2.01 \mathrm{E}-6$ & 7.3 & & 5.7E-7 \\
\hline
\end{tabular}


Table E-6. Radionuclide content for boxed waste at the Savannah River Site.

\begin{tabular}{|c|c|c|c|c|}
\hline Isotope & $\begin{array}{c}\text { Average Activity } \\
\text { (Ci/g) }\end{array}$ & $\begin{array}{l}\text { Median Activity } \\
(\mathrm{Ci} / \mathrm{g})\end{array}$ & Maximum & Minimum \\
\hline A-1 & $2.51 \mathrm{E}-13$ & $1.0 \mathrm{E}-13$ & $7.22 \mathrm{E}-13$ & $6.77 \mathrm{E}-18$ \\
\hline Am-241 & $3.49 \mathrm{E}-11$ & $1.23 \mathrm{E}-11$ & $2.72 \mathrm{E}-10$ & $2.22 \mathrm{E}-16$ \\
\hline B-1 & $3.23 E-10$ & $2.29 \mathrm{E}-12$ & $4.33 \mathrm{E}-9$ & $4.11 \mathrm{E}-20$ \\
\hline$C-14$ & $6.71 \mathrm{E}-12$ & 2.22E-14 & $2.87 \mathrm{E}-11$ & $5.17 \mathrm{E}-20$ \\
\hline Ce-144 & $8.70 \mathrm{E}-14$ & $1.1 \mathrm{E}-13$ & $2.87 \mathrm{E}-11$ & $2.26 \mathrm{E}-17$ \\
\hline Cf-249 & $2.63 \mathrm{E}-18$ & 2.63E-18 & $2.64 \mathrm{E}-18$ & $2.62 \mathrm{E}-18$ \\
\hline Cf -250 & $4.10 \mathrm{E}-12$ & 4.27E-12 & $4.27 \mathrm{E}-12$ & $3.77 \mathrm{E}-12$ \\
\hline Cf-251 & $1.54 \mathrm{E}-17$ & $2.31 \mathrm{E}-17$ & - & $2.3 \mathrm{E}-17$ \\
\hline Cf-252 & $6.58 \mathrm{E}-12$ & $6.85 \mathrm{E}-12$ & $6.86 \mathrm{E}-12$ & $6.04 \mathrm{E}-12$ \\
\hline $\mathrm{Cm}-243$ & $7.87 \mathrm{E}-9$ & $1.18 \mathrm{E}-8$ & $1.18 \mathrm{E}-8$ & $4.81 \mathrm{E}-15$ \\
\hline $\mathrm{Cm}-244$ & $3.07 \mathrm{E}-9$ & $6.52 \mathrm{E}-10$ & $1.01 \mathrm{E}-8$ & $3.46 \mathrm{E}-16$ \\
\hline Co-60 & $3.81 \mathrm{E}-11$ & $7.02 \mathrm{E}-17$ & $2.19 \mathrm{E}-10$ & $4.05 \mathrm{E}-17$ \\
\hline Cs-137 & $6.92 \mathrm{E}-11$ & $3.76 \mathrm{E}-11$ & $4.53 \mathrm{E}-10$ & $1.21 \mathrm{E}-18$ \\
\hline Eu-152 & $3.05 \mathrm{E}-13$ & $3.21 \mathrm{E}-13$ & $3.22 \mathrm{E}-13$ & $2.73 E-13$ \\
\hline Eu-154 & $7.39 \mathrm{E}-14$ & $6.35 \mathrm{E}-14$ & $9.49 \mathrm{E}-14$ & $6.34 \mathrm{E}-14$ \\
\hline Eu-155 & $5.25 \mathrm{E}-13$ & - & - & - \\
\hline H-3 & $4.91 \mathrm{E}-5$ & $2.85 \mathrm{E}-11$ & $8.83 \mathrm{E}-4$ & $1.32 \mathrm{E}-17$ \\
\hline I-129 & $6.44 \mathrm{E}-14$ & $1.11 \mathrm{E}-17$ & $3.83 \mathrm{E}-13$ & $4.46 \mathrm{E}-25$ \\
\hline $\mathrm{Ni}-59$ & $3.72 \mathrm{E}-12$ & $9.74 \mathrm{E}-14$ & $2.44 \mathrm{E}-11$ & 4.54E-18 \\
\hline $\mathrm{Np}-237$ & $2.99 \mathrm{E}-13$ & $3.13 \mathrm{E}-16$ & $2.86 \mathrm{E}-12$ & $7.71 \mathrm{E}-25$ \\
\hline Pm-147 & $2.39 \mathrm{E}-11$ & $3.53 \mathrm{E}-13$ & $6.61 \mathrm{E}-11$ & $1.81 \mathrm{E}-16$ \\
\hline Pu-238 & $3.83 \mathrm{E}-9$ & $2.71 \mathrm{E}-11$ & $3.43 \mathrm{E}-8$ & $1.81 \mathrm{E}-15$ \\
\hline Pu-239 & $4.85 \mathrm{E}-10$ & $3.70 \mathrm{E}-12$ & $2.37 \mathrm{E}-9$ & $6.72 E-16$ \\
\hline Pu-240 & $3.78 \mathrm{E}-10$ & $7.34 \mathrm{E}-13$ & $2.43 \mathrm{E}-9$ & $3.84 \mathrm{E}-16$ \\
\hline Pu-241 & $3.78 \mathrm{E}-10$ & $3.9 \mathrm{E}-11$ & $2.33 \mathrm{E}-8$ & $1.12 \mathrm{E}-14$ \\
\hline Pu-242 & $6.5 \mathrm{E}-12$ & $2.54 \mathrm{E}-16$ & $8.19 \mathrm{E}-11$ & $3.83 \mathrm{E}-20$ \\
\hline $\mathrm{Ra}-226$ & $9.45 \mathrm{E}-13$ & - & - & - \\
\hline $\mathrm{Ra}-228$ & $1.28 \mathrm{E}-9$ & $1.92 \mathrm{E}-9$ & $1.92 \mathrm{E}-9$ & $8.72 \mathrm{E}-12$ \\
\hline Pu-106 & $6.76 \mathrm{E}-15$ & $7.28 \mathrm{E}-15$ & $1.83 \mathrm{E}-14$ & $1.22 \mathrm{E}-17$ \\
\hline
\end{tabular}


Table E-6. (continued)

\begin{tabular}{ccccc}
\hline Isotope & $\begin{array}{c}\text { Average Activity } \\
\text { (Ci/g) }\end{array}$ & $\begin{array}{c}\text { Median Activity } \\
\text { (Ci/g) }\end{array}$ & Maximum & Minimum \\
\hline Sb-125 & $6.17 \mathrm{E}-14$ & $5.99 \mathrm{E}-14$ & $6.62 \mathrm{E}-14$ & $5.90 \mathrm{E}-14$ \\
Se-79 & $4.57 \mathrm{E}-10$ & $1 \mathrm{E}-15$ & $2.55 \mathrm{E}-9$ & $5.27 \mathrm{E}-24$ \\
Sn-126 & $3.70 \mathrm{E}-11$ & $4.52 \mathrm{E}-17$ & $5.56 \mathrm{E}-12$ & $8.87 \mathrm{E}-25$ \\
Sr-90 & $3.29 \mathrm{E}-11$ & $1.17 \mathrm{E}-11$ & $1.46 \mathrm{E}-10$ & $8.43 \mathrm{E}-19$ \\
Tc-99 & $1.53 \mathrm{E}-10$ & $1.46 \mathrm{E}-13$ & $1 \mathrm{E}-9$ & $1.97 \mathrm{E}-22$ \\
Th-228 & $3.52 \mathrm{E}-12$ & - & - & - \\
Th-230 & $1.53 \mathrm{E}-12$ & - & - & - \\
Th-232 & $6.66 \mathrm{E}-12$ & - & - & - \\
Th-234 & $1.57 \mathrm{E}-10$ & - & - & - \\
U-233 & $5.76 \mathrm{E}-12$ & $1.06 \mathrm{E}-15$ & $2.96 \mathrm{E}-11$ & $2.59 \mathrm{E}-25$ \\
U-234 & $6.46 \mathrm{E}-10$ & $8.92 \mathrm{E}-14$ & $9.61 \mathrm{E}-9$ & $2.59 \mathrm{E}-25$ \\
U-235 & $5.25 \mathrm{E}-11$ & $7.82 \mathrm{E}-15$ & $5.31 \mathrm{E}-10$ & $4.21 \mathrm{E}-24$ \\
U-236 & $8.16 \mathrm{E}-12$ & $2.44 \mathrm{E}-15$ & $3.64 \mathrm{E}-11$ & $4.29 \mathrm{E}-24$ \\
U-238 & $9.64 \mathrm{E}-10$ & $5.98 \mathrm{E}-13$ & $1.30 \mathrm{E}-8$ & $3.84 \mathrm{E}-23$ \\
Y-90 & $3 \mathrm{E}-6$ & - & - & $1.36 \mathrm{E}-12$ \\
Zr-95 & $8.83 \mathrm{E}-18$ & - & - & - \\
\hline
\end{tabular}


Appendix F

Future Waste Generation

F-1 
Table F-1. Summary of as-generated waste-form volumes $\left(\mathrm{m}^{3}\right)$ of Contact-Handled TRU waste Mixed CH TRU Nonmixed CH TRU.

\begin{tabular}{|c|c|c|c|c|c|c|c|}
\hline Site & $\begin{array}{l}\text { Stored at } \\
\text { end of } \\
\text { FY-1996 }\end{array}$ & $\begin{array}{c}\text { Projected } \\
\text { waste } \\
\text { during FY } \\
1997- \\
2033\end{array}$ & $\begin{array}{c}\begin{array}{c}\text { Total at } \\
\text { end of }\end{array} \\
\text { FY } \\
2033\end{array}$ & $\begin{array}{c}\text { Stored at } \\
\text { end of FY- } \\
1996\end{array}$ & $\begin{array}{c}\text { Projected } \\
\text { waste during } \\
\text { FY } 1997 \text { to } \\
2033\end{array}$ & $\begin{array}{l}\text { Total at end } \\
\text { of FY } 2033\end{array}$ & $\begin{array}{l}\text { Grand total } \\
\text { at end of } \\
\text { FY } 2033\end{array}$ \\
\hline ANL-E & 1 & 2 & 3 & 80 & 165 & 245 & 247 \\
\hline Hanford & 216 & 2,065 & 2,281 & 10,792 & 4,205 & 14,997 & 17,278 \\
\hline INEEL & 63,291 & 550 & 63,841 & 1,469 & 0 & 1,469 & 65,310 \\
\hline LANL & 8,179 & 3,296 & 11,474 & 461 & 2,923 & 3,354 & 14,829 \\
\hline LLNL & 9 & 66.7 & 76 & 230 & 578 & 809 & 885 \\
\hline Mound & 2 & 0 & 2 & 234 & 18 & 251 & 254 \\
\hline NTS & 609 & 8 & 617 & 9 & 0 & 9 & 626 \\
\hline ORNL & 603 & 296 & 899 & 318 & 74 & 392 & 1291 \\
\hline RFETS & 932 & 188 & 1,120 & 957 & 3,030 & 3,986 & 5,107 \\
\hline SRS & 3,442 & 1,151 & 4,593 & 2,592 & 7,198 & 9,790 & 14,382 \\
\hline SQS & 10 & 3 & 7 & 168 & 183 & 196 & - \\
\hline Other & 6 & 0 & 11 & 144 & 176 & 181 & - \\
\hline Total & $77,299.8$ & $7,624.7$ & 84,924 & 17,159 & 18,503 & 35,662 & 120,587 \\
\hline
\end{tabular}

Table F-2. Volume $\left(\mathrm{m}^{3}\right)$ inventory and generation of DOE RCRA and RCRA-PCB MLLW by Sites.

\begin{tabular}{cccccc}
\hline Site & Inventory & $\begin{array}{c}\text { Actual } \\
1996\end{array}$ & 1997 & $1998-2006$ & $2007-2030$ \\
\hline Idaho & 846 & & - & - & - \\
LANL & 765 & 54 & 83 & 2,420 & 474 \\
LLNL & 493 & 116 & 189 & 1,745 & 3,797 \\
Oak Ridge Site & 33,342 & 880 & 1,054 & 9,505 & 24,458 \\
Hanford Site & 8,018 & 318 & 616 & 12,771 & 47,684 \\
RFETS & 19,730 & - & 179 & 47,050 & 13,874 \\
Savannah River & 7,712 & 61 & 336 & 4,386 & - \\
\hline
\end{tabular}


Table F-3. Actual and projected volumes $\left(\mathrm{m}^{3}\right)$ of LLW by site projected.

\begin{tabular}{ccccc}
\hline Site & Actual & & & \\
& FY 1996 & 1997 & $1998-2006$ & $2007-2030$ \\
\hline INEEL & 6,791 & 3,783 & 18,638 & 44,289 \\
LANL & 4,022 & 4,296 & 66,882 & 120,000 \\
LLNL & 279 & 205 & 1,611 & 3,412 \\
Oak Ridge & 3,159 & 2,477 & 22,293 & 58,449 \\
Hanford & 3,922 & 6,711 & 40,272 & 201,234 \\
Rocky Flats & 0 & 1,170 & 57,548 & 2,558 \\
Savannah River & 8,195 & 13,534 & 57,757 & 130,258 \\
\hline
\end{tabular}


Table F-4. Total volume $\left(\mathrm{m}^{3}\right)$ inventory and generation of DOE RCRA and RCRA-PCB MLLW by MPC.

\begin{tabular}{|c|c|c|c|c|c|}
\hline MPC & $\begin{array}{c}\text { Current } \\
\text { Inventory }\end{array}$ & 1996 & 1997 & $1998-2006$ & $\begin{array}{c}2007- \\
2030 \\
\end{array}$ \\
\hline 10000 & 148 & 12 & 19 & 546 & 107 \\
\hline L1000 & 4,903 & 5 & 255 & 6,706 & 1,232 \\
\hline L2000 & 1,311 & 69 & 140 & 1,441 & 2,935 \\
\hline S0000 & 490 & 41 & 63 & 1,843 & 361 \\
\hline S3000 & 22 & 1 & 10 & 55 & 60 \\
\hline$\$ 3100$ & 49,991 & 90 & 149 & 11,279 & 8,000 \\
\hline S3200 & 502 & 0 & 2 & 13 & 25 \\
\hline$S 4000$ & 1,459 & 21 & 63 & 7,738 & 2,638 \\
\hline S5000 & 784 & 24 & 0 & 2 & 6 \\
\hline S5100 & 1,353 & 106 & 219 & 16,671 & 36,147 \\
\hline S5300 & 2,258 & 67 & 97 & 3,239 & 2,834 \\
\hline S5400 & 6,146 & 111 & 325 & 13,672 & 8,703 \\
\hline U9999 & 331 & 1 & 1 & 35 & 7 \\
\hline $\mathrm{X} 6000$ & 527 & 14 & 40 & 2,559 & 924 \\
\hline X7000 & 6 & 2 & - & - & - \\
\hline$X 7100$ & 8 & 1 & 0 & 1 & 1 \\
\hline $\mathrm{X} 7200$ & 870 & 34 & 57 & 2,714 & 1,126 \\
\hline $\mathrm{X} 7300$ & 5 & - & - & - & - \\
\hline$X 7400$ & 26 & 0 & 1 & 4 & 27 \\
\hline X7500 & 395 & 0 & 0 & 2 & 1 \\
\hline$X 7600$ & 16 & 9 & 7 & 31 & 40 \\
\hline$X 7700$ & 10 & 0 & - & 0 & 0 \\
\hline $\mathrm{Z} 1000$ & 146 & 0 & 14 & 98 & 1068 \\
\hline $\mathrm{Z} 2000$ & 0 & - & - & 294 & 135 \\
\hline
\end{tabular}

